Université de Montréal

\title{
Cost-Utility Analysis of Imaging for Surveillance and Diagnosis of Hepatocellular Carcinoma
}

\author{
par \\ Paulo Henrique Moura Costa Lima, MD \\ Programme de Sciences biomédicales \\ Faculté de médecine
}

Mémoire présenté à la Faculté de médecine en vue de l'obtention du grade de Maîtrise en sciences (M. Sc.) en Sciences biomédicales option Recherche clinique

Juin, 2019

(C) Paulo Henrique Moura Costa Lima, 2019 



\section{Résumé}

Le carcinome hépatocellulaire $(\mathrm{CHC})$ est une complication sérieuse associée aux maladies hépatiques chroniques. Les lignes directrices actuelles recommandent la surveillance du CHC par échographie tous les six mois. Cependant, la surveillance par échographie peut être difficile chez certains patients, notamment ceux atteints de cirrhose ou d'obésité. Autrement, la tomodensitométrie (TDM), l'imagerie par résonance magnétique (IRM) et l'IRM abrégée ont été explorées comme techniques d'imagerie alternatives et peuvent être utilisées chez les patients qui sont susceptibles d'avoir une échographie techniquement inadéquate. L'objectif de ce mémoire est d'évaluer l'impact économique de différentes stratégies de dépistage et de diagnostic basées sur l'imagerie chez des patients à risque de $\mathrm{CHC}$, tout en tenant compte d'examens techniquement inadéquats et du taux de compliance des patients au programme de dépistage.

Nous avons comparé sept stratégies de dépistage et diagnostic: stratégie A, échographie pour le dépistage et TDM pour le diagnostic; stratégie $B$, échographie pour le dépistage et IRM pour le diagnostic; stratégie $C$, échographie pour le dépistage et TDM pour une surveillance inadéquate ou positive; stratégie $D$, échographie pour le dépistage et IRM pour un dépistage inadéquat ou positif; stratégie $E$, dépistage et diagnostic par TDM suivis par une IRM en cas de dépistage inadéquat; stratégie F, dépistage et diagnostic avec IRM suivis par TDM pour un dépistage inadéquat; et 
stratégie G, dépistage avec IRM abrégée suivi par TDM pour un dépistage inadéquat ou IRM pour un dépistage positif. Deux scénarios de compliance au programme de surveillance ont été évalués: optimal et conservateur. Pour chaque scénario, la stratégie la plus coût-efficace reposait sur un seuil de propension à payer de Can\$50,000 (dollars Canadiens) par année de vie ajustée en fonction de la qualité (AVAQ). Nous avons également effectué des analyses de sensibilité.

Nos résultats ont démontré que la stratégie E était la stratégie la plus coûtefficace dans le scénario de compliance optimal (Can\$13,631/AVAQ). Cependant, dans le scénario conservateur, la stratégie G constituait l'alternative la plus coûtefficace pour remplacer la pratique actuelle de surveillance par échographie (Can\$39,681/AVAQ). Les analyses de sensibilité ont confirmé l'analyse de base dans le scénario de compliance optimal. Par contre, plusieurs paramètres ont modifié le rapport de coût-efficacité dans le scénario d'observance conservateur.

En effectuant cette analyse économique, nous avons conclu qu'une approche individuelle, tenant compte des particularités cliniques des patients, est plus coûtefficace que la stratégie actuelle uniforme. Cependant, avant de mettre en place un programme de surveillance incorporant des modalités d'imagerie autres que l'échographie, les futures études devraient se concentrer sur le fardeau économique associé aux diagnostics faux positifs $\mathrm{du} \mathrm{CHC}$ et sur la performance diagnostique d'examens d'IRM abrégés dans le scénario de surveillance. 
Mots-clés : coût-efficacité, détection précoce, cancer du foie, imagerie du foie, modèle de Markov. 


\section{Abstract}

Hepatocellular carcinoma (HCC) is a serious complication associated with chronic liver disease. Current guidelines recommended HCC surveillance using ultrasound (US) every six months. However, US surveillance can be challenging for some patients, particularly those with cirrhosis or obesity. Alternately, computed tomography $(\mathrm{CT})$, magnetic resonance imaging (MRI), and abbreviated MRI have been explored as alternative imaging modalities and may be used in selected patients who are likely to have experienced inadequate US examinations. In this thesis, we aimed to assess the cost-effectiveness of imaging-based surveillance and diagnostic strategies in patients at risk of $\mathrm{HCC}$ while taking into account technically inadequate examinations and patients' compliance.

We compared seven surveillance and diagnostic strategies: strategy A, US for surveillance and CT for diagnosis; strategy B, US for surveillance and MRI for diagnosis; strategy C, US for surveillance and CT for inadequate or positive surveillance; strategy $\mathrm{D}$, US for surveillance and $\mathrm{MRI}$ for inadequate or positive surveillance; strategy E, surveillance and diagnosis with CT followed by MRI for inadequate surveillance; strategy $F$, surveillance and diagnosis with MRI followed by CT for inadequate surveillance; and strategy G, surveillance with abbreviated MRI followed by $\mathrm{CT}$ for inadequate surveillance or MRI for positive surveillance. Two compliance scenarios were evaluated: optimal and conservative. For each scenario, the most cost-effective strategy was based on a willingness-to-pay threshold of 
Can\$50,000 (Canadian dollars) per quality-adjusted life year (QALY). We also performed sensitivity analyses.

Our results demonstrated that strategy $E$ was the most cost-effective strategy in scenarios with optimal patient compliance (Can\$13,631/QALY). However, in scenarios with low patient compliance, strategy $G$ was the most cost-effective alternative to the current US-surveillance practice (Can $\$ 39,681 / \mathrm{QALY}$ ). Sensitivity analyses supported the base-case analysis in the optimal compliance scenario; however, several parameters altered the cost-effectiveness relationship in the conservative compliance scenario.

By performing this economic analysis, we concluded that an individual approach, considering the clinical particularities of the patients, is more cost-effective than the current "one-size-fits-all" strategy. However, before implementing a surveillance program incorporating imaging modalities other than US, future studies should address the economic burden associated with false-positive HCC diagnoses and the accuracy of abbreviated MRI examinations in a surveillance setting.

Keywords: cost-effectiveness, early detection, liver cancer, liver imaging, Markov model. 


\section{Table of Contents}

Résumé.

Abstract iv

Table of Contents vi

List of Tables xi

List of Figures xii

List of Appendix XV

List of Abbreviations. xvi

Acknowledgements xix

1 Introduction 1

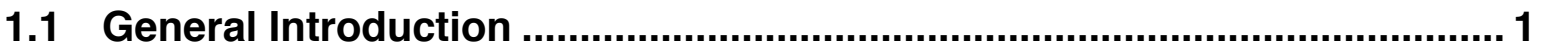

1.2 Reasons to Perform the Economic Analysis .......................................... 3

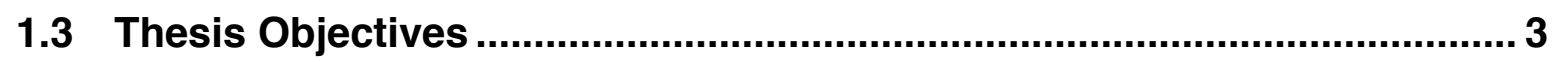

1.3.1 General Objective .................................................................... 3

1.3.2 Specific Objectives ................................................................... 4

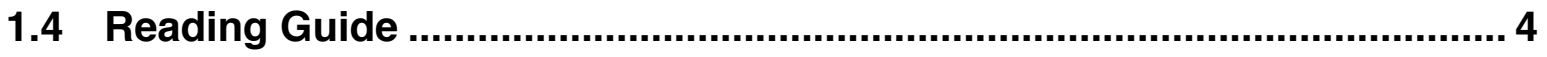




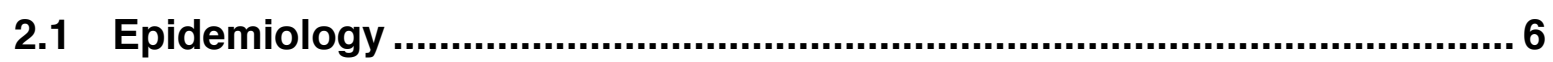

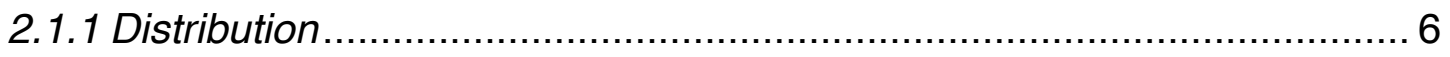

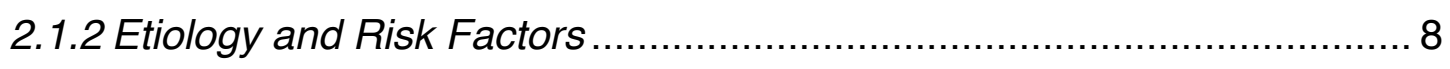

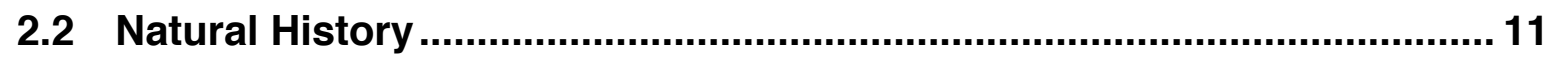

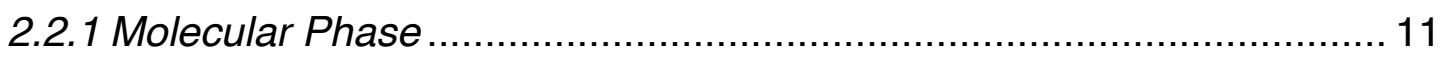

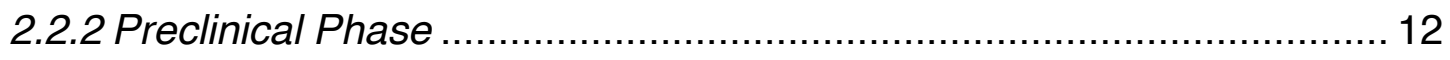

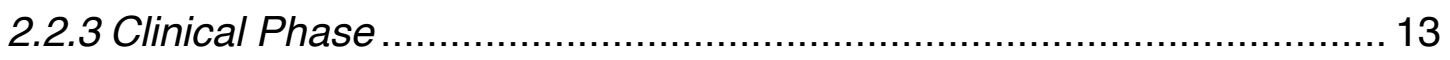

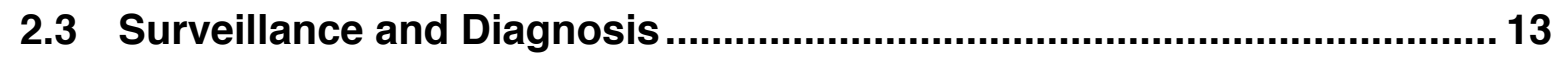

2.3.1 Principles and Importance of Surveillance....................................... 13

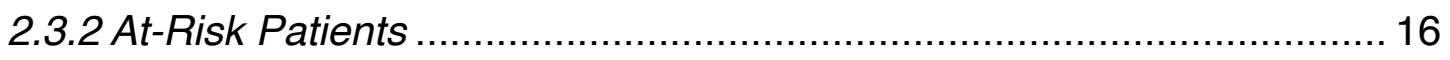

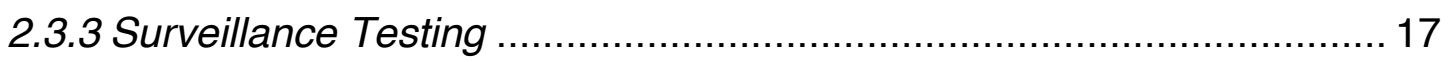

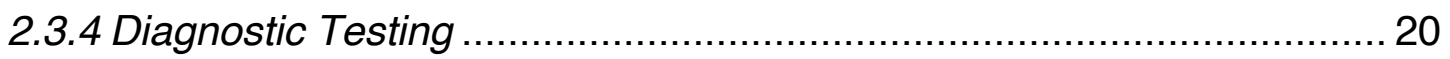

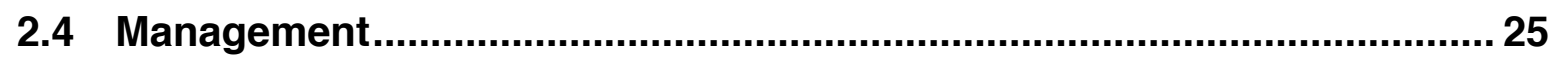

2.4.1 Barcelona Clinic Liver Cancer Staging (BCLC) ................................ 26

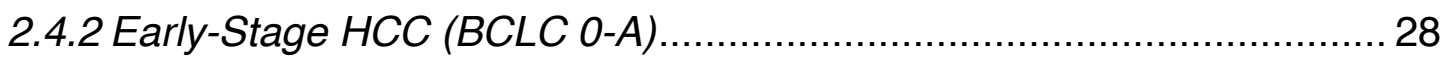

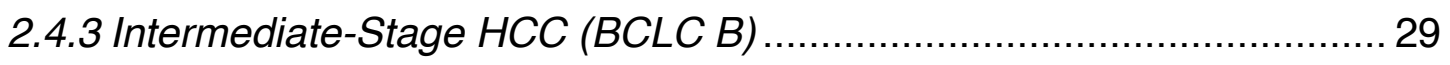

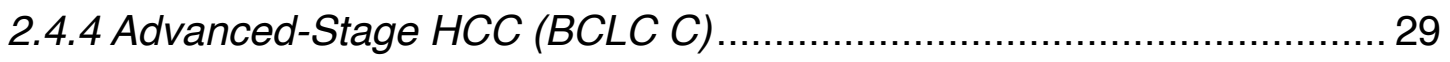

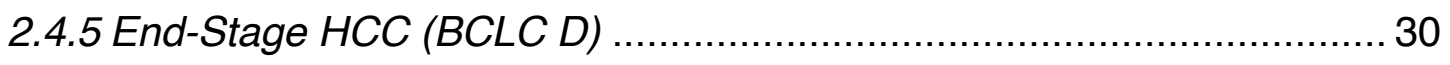

3 Economic Analysis in Health Care .................................31

3.1 Introduction to Economic Analysis ..................................................... 31 


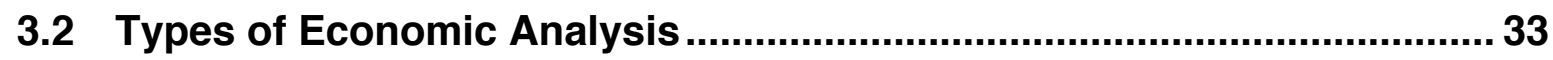

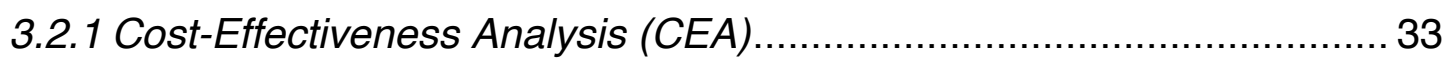

3.2.2 Cost-Utility Analysis (CUA) .......................................................... 34

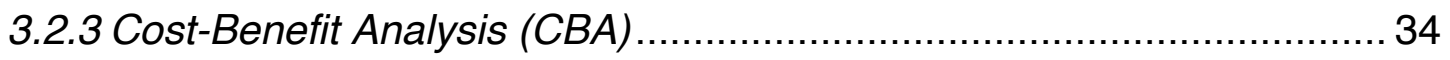

3.2.4 Cost-Minimization Analysis (CMA) …………............................... 34

3.3 Choosing the Population and Comparators …...................................... 35

3.4 Perspective

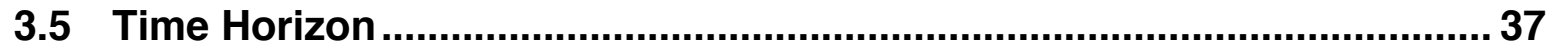

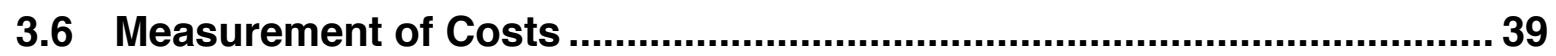

3.6.1 Costs versus Time (Adjusting and Discounting) ............................... 39

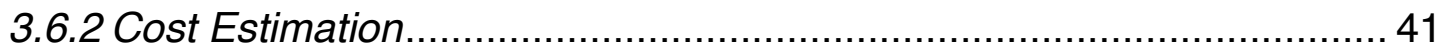

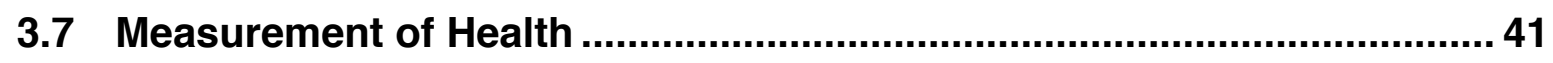

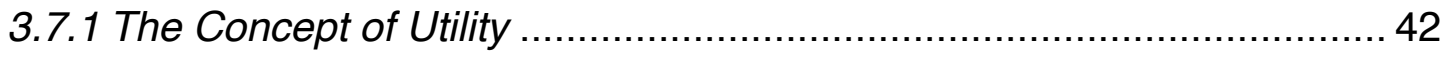

3.7.2 The Concept of Health-Related Quality of Life (HRQoL).................... 45

3.7.3 The Concept of Quality-Adjusted Life Year (QALY) .......................... 46

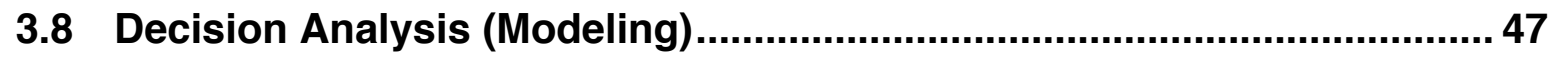

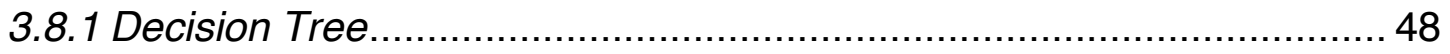

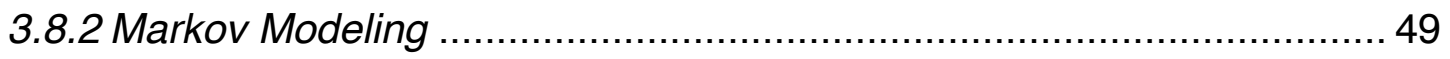

3.8.3 Discrete Event Simulation (DES) .................................................... 50

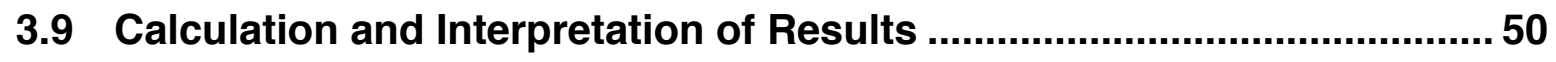

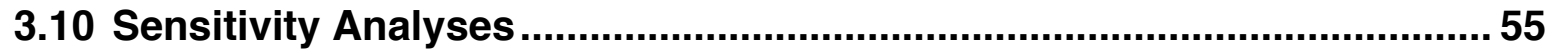

3.10.1 Deterministic Sensitivity Analysis ................................................. 55 


\section{Cost-Utility Analysis of Imaging for Surveillance and}

Diagnosis of Hepatocellular Carcinoma.

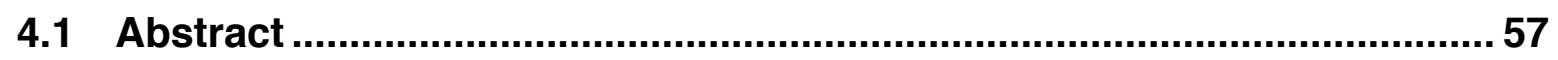

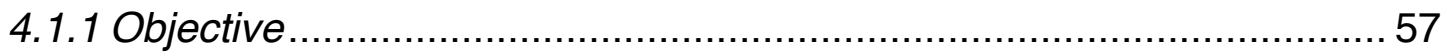

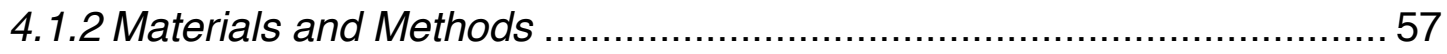

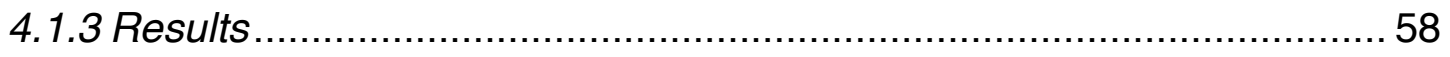

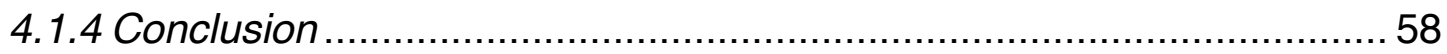

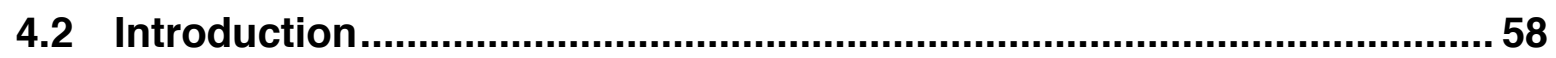

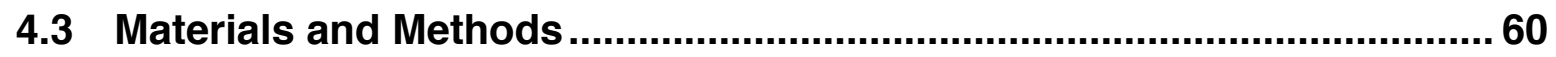

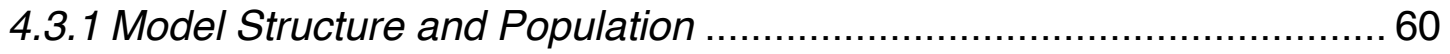

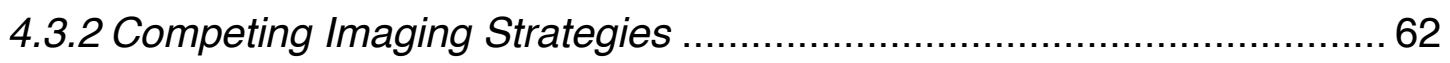

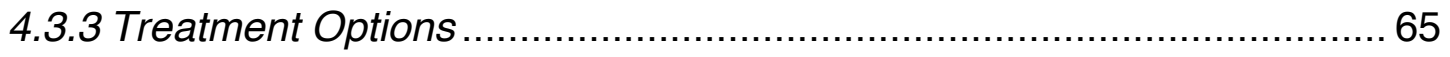

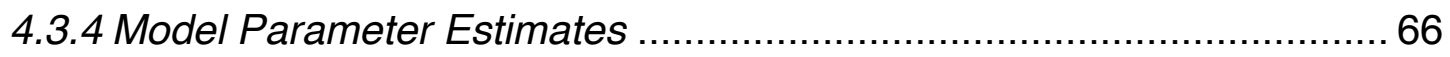

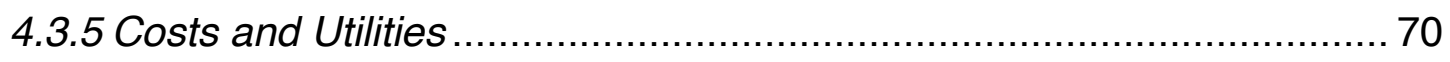

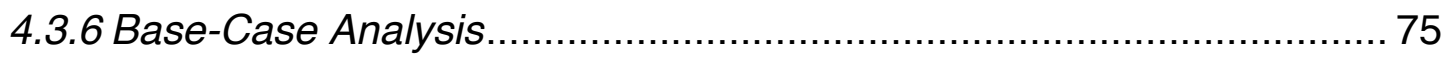

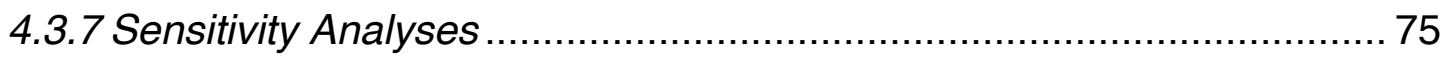

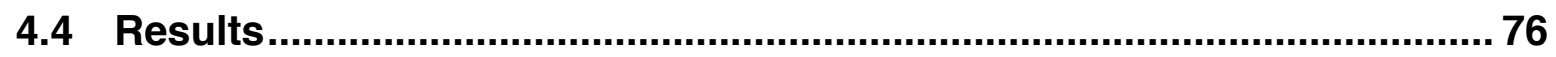

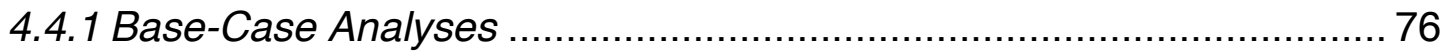

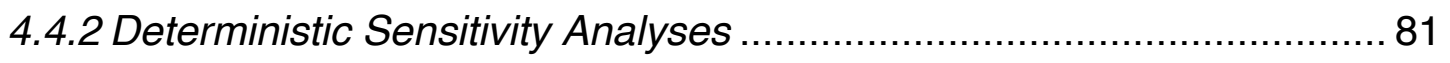

4.4.3 Probabilistic Sensitivity Analyses...................................................... 83 


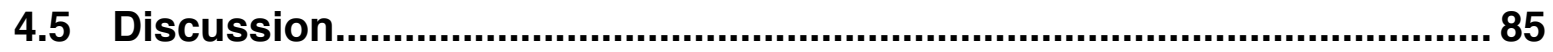

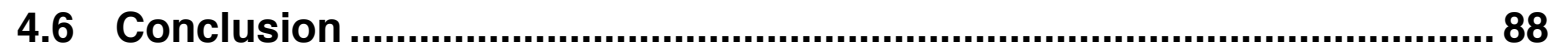

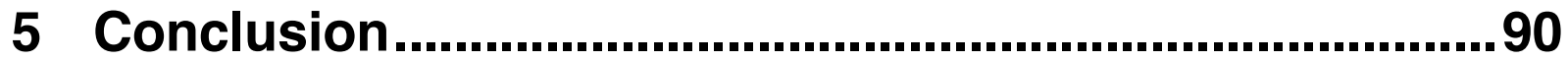

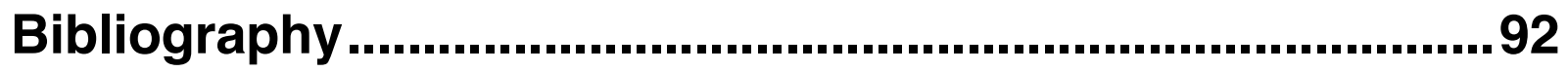

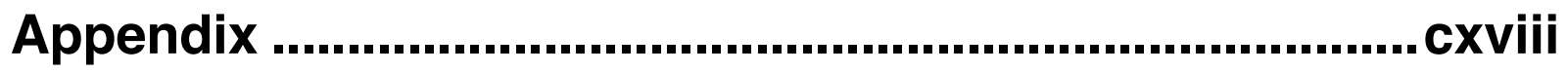




\section{List of Tables}

Table 2.1 Surveillance Recommendations According to Different Associations........ 15

Table 2.2 Hepatocellular Carcinoma Staging Systems........................................ 25

Table 3.1 Relevant Costs According to Different Perspectives ............................... 37

Table 3.2 Probabilities and Costs Used to Explain the Calculations ....................... 52

Table 3.3 Calculation for the Example of Antibiotics........................................... 53

Table 4.1 Initial Parameters and Transition Probabilities...................................... 67

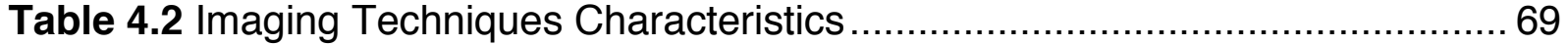

Table 4.3 Health-Care Costs and Utilities ........................................................ 70

Table 4.4 Micro-Costing of Ultrasound, Computed Tomography, and Magnetic

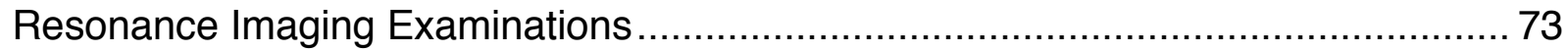

Table 4.5 Micro-Costing of Abbreviated Magnetic Resonance Imaging According to

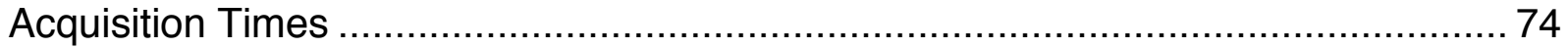

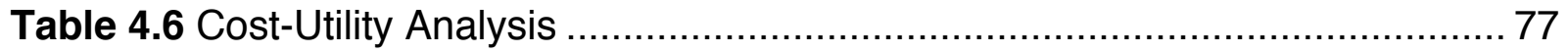

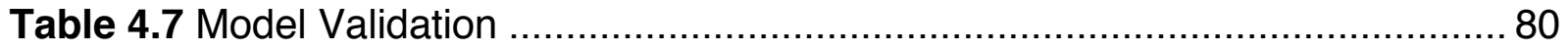




\section{List of Figures}

Figure 1.1 HCV prevalence and HCV-related HCC incidence curves in Canada. ...... 2

Figure 2.1 Worldwide HCC age-standardized incidence rates in 2018. ................... 7

Figure 2.2 Worldwide HCC incidence rates according to age and sex in $2018 \ldots \ldots \ldots . . .8$

Figure 2.3 Distribution of HCC-related deaths by risk factor in selected regions. ....... 9

Figure 2.4 Schematic representation of HCC's natural history.............................. 12

Figure 2.5 Receiver Operating Characteristic $(\mathrm{ROC})$ curve. For the same test (blue curve), the higher the sensitivity (point y) the lower the specificity and the lower the sensitivity (point $x$ ) the higher the specificity. 18

Figure 2.6 Small hypoechoic nodule in a cirrhotic liver corresponding to hepatocellular carcinoma (arrow). 19

Figure 2.7 American Association for the Study of Liver Diseases (AASLD) surveillance and diagnostic algorithm. 22

Figure 2.8 Schematic representation of LI-RADS major criteria for hepatocellular carcinoma diagnosis 23

Figure 2.9 Summary of CT and MRI diagnostic Liver Imaging Reporting and Data System major features. 24

Figure 2.10 Barcelona Clinic Liver Cancer Staging (BCLC) classification and treatment schedule. 
Figure 3.1 Health care cost in selected countries as a percentage of gross domestic product. 32

Figure 3.2 Influence of time horizon in economic analysis. .................................... 38

Figure 3.3 Schematic representation of loss of purchasing power in Canada. ......... 40

Figure 3.4 Schematic representation of the time trade-off method. ........................ 43

Figure 3.5 Schematic representation of the standard gamble method................... 44

Figure 3.6 Schematic representation of visual analogue scale method. ................. 45

Figure 3.7 Schematic representation of quality-adjusted life year for a patient with decompensated cirrhosis (patient A) and decompensated cirrhosis submitted to a LT (patient B) 47

Figure 3.8 Schematic representation of a decision tree. 48

Figure 3.9 Schematic representation of a Markov model. 50

Figure 3.10 Decision tree used as an example to explain the calculations. 51

Figure 4.1 Simplified Markov model illustrating surveillance (gray box) and diagnostic imaging techniques (blue box) interposed on health states (green boxes) and temporary states (beige and pink boxes). Gray arrows indicate health state transitions, and black arrows indicate temporary state transitions (management of positive imaging results). 61

Figure 4.2 Chart of hepatocellular carcinoma (HCC) surveillance and diagnostic strategies $A-G$. 64

Figure 4.3 Schematic representation of treatment options according to hepatocellular carcinoma $(\mathrm{HCC})$ stage and Child-Pugh class. 65 
Figure 4.4 Cost-utility curves. A and B, Graphs show cost-utility curves for optimal (A) and conservative (B) surveillance scenarios.

Figure 4.5 One-way sensitivity analyses. A and B, Graphs show analyses for optimal (strategy E vs strategy A;A) and conservative (strategy G vs strategy C; B) surveillance scenarios. Black lines represent expected incremental cost-effectiveness ratio (ICER) values. Dotted gray lines represent willingness-to-pay threshold. Costs are shown in Canadian dollar (Can\$). 82

Figure 4.6 Acceptability curves after 10,000 iterations. A and B, Graphs show acceptability curves (A) and conservative (B) surveillance scenarios. Dotted gray lines represent willingness-to-pay threshold. Costs are shown in Canadian dollars (Can\$). 


\section{List of Appendix}

Appendix 1 Manuscript: Cost-Utility Analysis of Imaging for Surveillance and Diagnosis of Hepatocellular Carcinoma ............................................................. 


\section{List of Abbreviations}

AASLD American Association for the Study of Liver Diseases

AFP Alpha-Fetoprotein

APHE Arterial Phase Hyperenhancement

ASR Age-Standardized Rate

BCLC Barcelona Clinic Liver Cancer Staging

CASL Canadian Association for the Study of the Liver

CBA Cost-Benefit Analysis

CEA Cost-Effective Analysis

CEUS Contrast-Enhanced US

Cl Confidence Interval

CLIP Cancer of the Liver Italian Program

CMA Cost-Minimization Analysis

CT Computed Tomography

CUA Cost-Utility Analysis

CUPI Chinese University Prognostic Index

DES Discrete Event Simulation

DWI Diffusion-Weighted Imaging

EASL European Association for the Study of the Liver

ECA Extracellular Contrast Agent 


$\begin{array}{ll}\text { ER } & \text { Estrogen Receptor } \\ \text { GDP } & \text { Gross Domestic Product } \\ \text { HBV } & \text { Hepatitis B Virus } \\ \text { HCC } & \text { Hepatocellular Carcinoma } \\ \text { HCV } & \text { Hepatitis C Virus } \\ \text { HRQoL } & \text { Health-Related Quality of Life } \\ \text { ICER } & \text { Incremental Cost-Effectiveness Ratio } \\ \text { JIS } & \text { Japan Integrated Staging Score } \\ \text { LT } & \text { Liver Transplantation } \\ \text { MRI } & \text { Magnetic Resonance Imaging } \\ \text { NAFLD } & \text { Non-Alcoholic Fatty Liver Disease } \\ \text { OR } & \text { Odds Ratio } \\ \text { PEI } & \text { Percutaneous Ethanol Injection } \\ \text { PST } & \text { Performance Status Test } \\ \text { QALY } & \text { Quality-Adjusted Life Year } \\ \text { RFA } & \text { Radiofrequency Ablation } \\ \text { ROC } & \text { Receiver Operating Characteristic } \\ \text { SDI } & \text { Sociodemographic Index } \\ \text { TACE } & \text { Transarterial Chemoembolization } \\ \text { TNM } & \text { Tumor Node Metastasis } \\ \text { US } & \text { Ultrasound } \\ \text { Willingness-to-Pay }\end{array}$


For my parents and devoted wife, who always believed and supported my dreams 


\section{Acknowledgements}

It is a great honor for me to present this thesis as the result of the last two years of hard work, which would not have been possible without the generosity, dedication, and experience of Dr. An Tang and Dr. Catherine Beauchemin. I will be eternally grateful for the opportunity that $\mathrm{Dr}$. Tang gave me. In spite of his many commitments, he showed me the way by taking time to tutor me through my master's program, from the conception of the study to the revision of the final version of this thesis. Dr. Tang is an inspiring professor and profoundly impacted my professional development. I look forward to working with him again.

I am also profoundly grateful to Dr. Catherine Beauchemin. It was a tremendous honor for me to have Dr. Beauchemin as my research director along with Dr. Tang. Despite her professional agenda, she was always available to support me through the conceptualization and construction of the economic models. Furthermore, she significantly contributed to the revision of this thesis. The high methodological quality of this work can be attributed in a great measure to Dr. Beauchemin's expertise in economic analysis.

I would like to acknowledge the essential contribution of all the other co-authors who participated in the construction of the published manuscript, which was the basis for the development of this thesis: Boyan Fan, Joshua Bérubé, Dr. Milena Cerny, Dr. Damien Olivié, and Dr. Jeanne-Marie Giard. 
I am also grateful to Dr. Luigi Lepanto, Dr. Laurent Létourneau-Guillon, Dr. Michelle Savoie, and Dr. Isabelle Chabot, who accepted to serve as jury members for my master's thesis.

In this acknowledgement, I would like to mention the millions of patients with chronic liver disease all over the world. This work only exists because of them and is a small and humble contribution whose main objective is to help mitigate their suffering.

I would like to thank my dear friends, Diogo, Marina, Caroline, Fábio, Tatiana, César, Daniele, and Mozir, who were my second family in Montreal.

Finally, I would like to thank God, for giving me the strength and knowledge to complete this journey, my parents Francisco Robson and Gisele Moura, for their support and dedication, and my wife Ana Marília, for her love and encouragement. This achievement would not have been possible without them, to whom I dedicate this dissertation. 



\section{Introduction}

\subsection{General Introduction}

Hepatocellular carcinoma ( $\mathrm{HCC}$ ) is the sixth most common cancer and the fourth cause of cancer-related deaths worldwide [1]. In Canada, HCC is the only malignancy for which mortality is rising, and the hepatitis $\mathrm{C}$ virus (HCV) infection is considered one of the most critical risk factors associated with HCC (see Etiology and Risk Factors below) [2, 3]. Although the prevalence of HCV infection reached its peak in 2003, the incidence of HCV-related HCC is expected to rise in the next decades due to the aging of the infected population and progression of liver fibrosis to cirrhosis [4, 5] (Figure 1.1).

In parallel, HCC-associated mortality and costs are estimated to increase, imposing a heavy human and economic burden on patients, their families, and society [4, 6]. Historically, the diagnosis of HCC has been made in advanced stages, when curative treatment options are no longer eligible, and the costs linked to care are higher [7]. The implementation of surveillance programs modified this trend by increasing the rate of early-stage tumor detection [8-10]. 


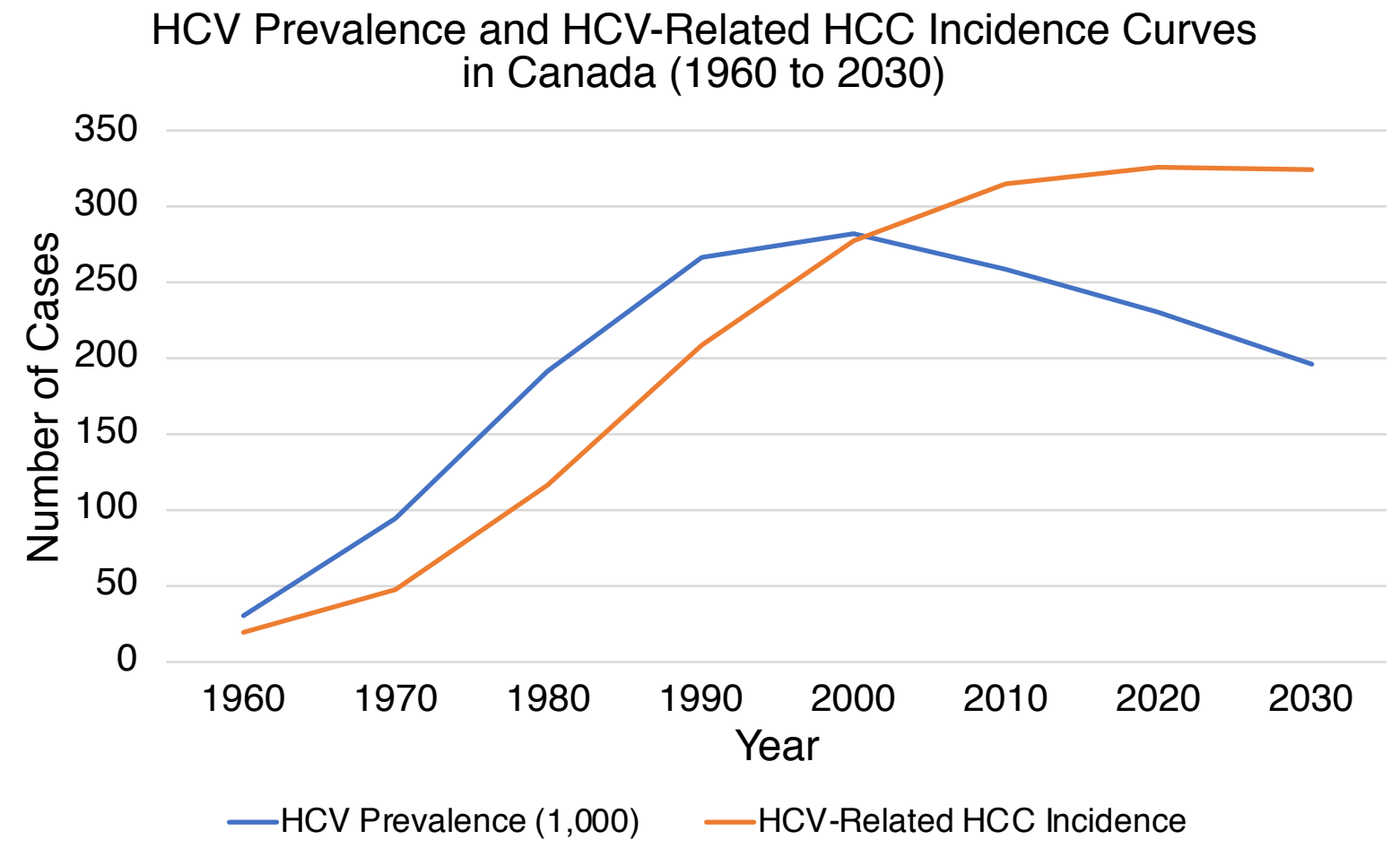

Figure 1.1 HCV prevalence and HCV-related HCC incidence curves in Canada.

Data extracted from Myers et al. [4] and Remis et al. [5]. HCC = hepatocellular carcinoma, $\mathrm{HCV}=$ hepatitis $\mathrm{C}$ virus.

Due to limitations in health care system budgets, large-scale interventions, such as surveillance programs, are evaluated according to their potential cost-effectiveness before being implemented. In this scenario, economic analysis in health care proposes to identify, measure, value, and compare the costs and health outcomes of different health technologies [11]. Economic evaluations are important guides for policymakers, providing them with valuable evidence. 


\subsection{Reasons to Perform the Economic Analysis}

There is a knowledge gap regarding the cost-effectiveness of surveillance for HCC. Current North American guidelines recommend HCC surveillance using ultrasound (US) every six months $[12,13]$. However, US surveillance can be challenging in some patients, particularly those with Child-Pugh class $\mathrm{C}$ cirrhosis (who have advanced liver disease with innumerable nodules which may mask liver cancer) or obesity. In these patients, the US inadequacy rate can be as high as $33 \%$, compromising surveillance effectiveness [14].

Other imaging modalities, like computed tomography (CT), magnetic resonance imaging (MRI), and abbreviated MRI, may be helpful alternatives for patients who are prone to inadequate US. However, previous economic analyses that have assessed this issue did not compare all available imaging modalities or did not take into consideration the effect of inconclusive surveillance imaging and patient compliance in their models [15-18].

\subsection{Thesis Objectives}

\subsubsection{General Objective}

To assess the cost-effectiveness of imaging-based surveillance and diagnostic strategies in patients at risk of HCC, taking into account technically inadequate examinations and patient compliance. 


\subsubsection{Specific Objectives}

- To assess the cost-effectiveness of strategies relying on combinations of four imaging techniques: US, CT, MRI, and abbreviated MRI;

- To identify which is the most cost-effective strategy;

- To identify the parameters that have the greatest impact on the costeffectiveness ratios.

\subsection{Reading Guide}

This master's thesis was structured so as to be accessible to different audiences, including medical students, hepatologists, general radiologists, and health economists. Medical students should read this document sequentially. Hepatologists and general radiologists, who may already be familiar with the medical aspects of HCC, may skip the Chapter 2 and begin their reading with the review of economic analysis in health care provided in Chapter 3. Health economists interested in this subject, but without a previous background in $\mathrm{HCC}$, may begin their reading with the brief medical review provided in Chapter 2 and skip Chapter 3.

Chapters Description:

- Chapter 2: introduces HCC and reviews its epidemiology, natural history, surveillance, diagnosis, and management.

- Chapter 3: presents a short description of economic analysis in health care. 


\section{Chapter 1. Introduction}

- Chapter 4: presents the cost-utility study performed to address the thesis objectives. The published article is presented in Appendix 1.

- Chapter 5: discusses the lessons learned, implications for patient care, and future directions. 


\section{Hepatocellular Carcinoma}

HCC represents approximately $85 \%$ of all primary liver cancer [19]. HCC has a particular epidemiology, natural history, surveillance, diagnosis, and management. This chapter aims to review these key concepts.

\subsection{Epidemiology}

$\mathrm{HCC}$ is a major health problem worldwide, ranked as the sixth most common cancer and the fourth most common cause of cancer-related mortality [1]. In Canada, $\mathrm{HCC}$ has one of the fastest rising cancer incidences, with an increase of $2.6 \%$ to $3.6 \%$ per year [20]. Despite advances in diagnosis and management, the 5-year net survival of $\mathrm{HCC}$ in Canada is only about $19 \%$, highlighting the aggressive nature of this cancer by the time of its diagnosis [21].

\subsubsection{Distribution}

The incidence of HCC differs widely according to geographic regions. While Northern Europe, Australia, New Zealand, and North and South America are the regions with the lowest rates, more than $80 \%$ of $\mathrm{HCC}$ cases occur in developing countries [1, 22] (Figure 2.1). However, in the last few decades, some regions traditionally classified as high-incidence areas are experiencing a decrease in the incidence rates, while several developed countries, such as the United States and 
Canada, are facing an increase $[2,23]$. These variations across geographic regions are explained, at least in part, due to regional differences of important risk factors (see Etiology and Risk Factors below).

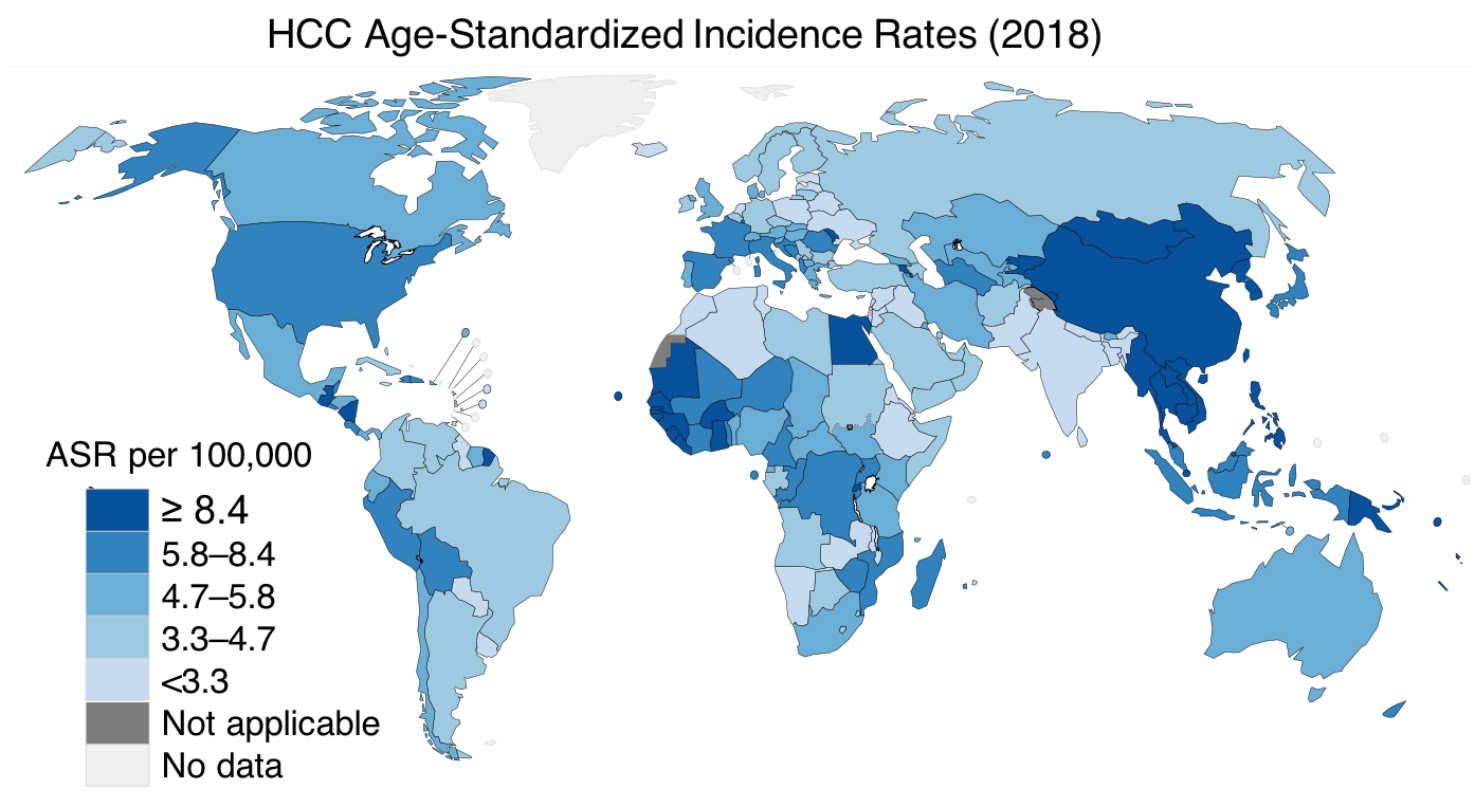

Figure 2.1 Worldwide HCC age-standardized incidence rates in 2018. Reproduced with permission from the Global Cancer Observatory [1]. ASR = age-standardized rate, $\mathrm{HCC}=$ hepatocellular carcinoma.

Furthermore, there is a significant incidence difference according to gender. Men are at a higher risk to develop HCC than women [1, 24]. This discrepancy is more evident in high-incidence regions, where men are affected 3.7 times more frequently than women [25]. Age also influences the HCC incidence. Since the pathogenesis of 
HCC requires several decades, starting from the exposure to an etiologic agent until the diagnosis (see Natural History below), older patients are more prone to develop HCC [1, 24] (Figure 2.2).

HCC Incidence Rates According to Age and Sex (2018)

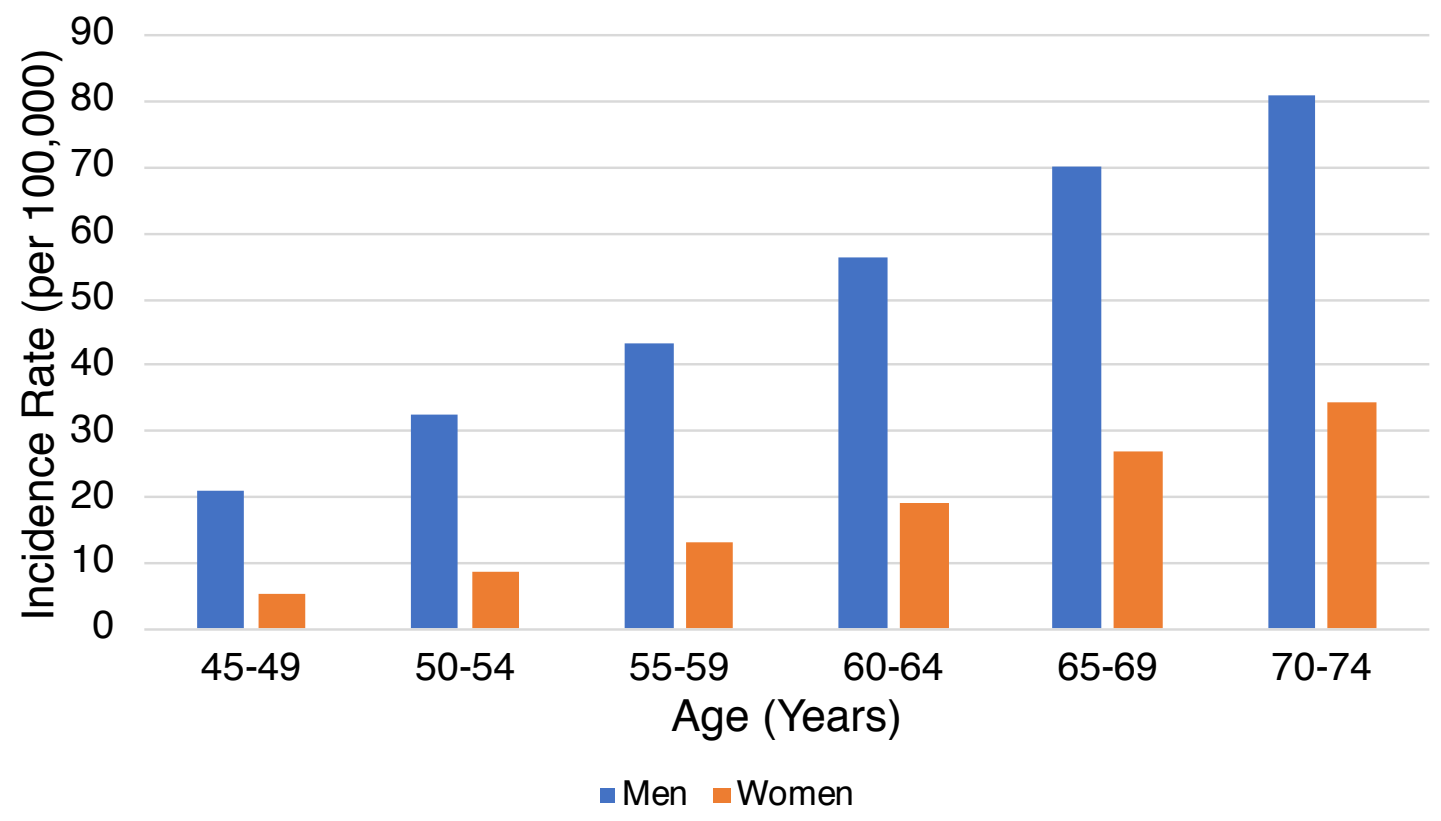

Figure 2.2 Worldwide HCC incidence rates according to age and sex in 2018. Data extracted from the Global Cancer Observatory [1]. HCC = hepatocellular carcinoma.

\subsubsection{Etiology and Risk Factors}

A variety of risk factors associated with HCC development have already been identified. This knowledge has enabled the recognition of etiological agents and risk groups, which are the basis for the development of prevention and surveillance strategies. The most common risk factors are hepatitis B virus (HBV) and HCV 
infections, alcohol abuse, and non-alcoholic fatty liver disease (NAFLD) [26]. The importance of one risk factor over another varies according to the region studied (Figure 2.3). About $80 \%$ to $90 \%$ of patients who develop HCC have cirrhosis, which is the final common pathway of chronic liver aggression, regardless of the underlying etiology [27].

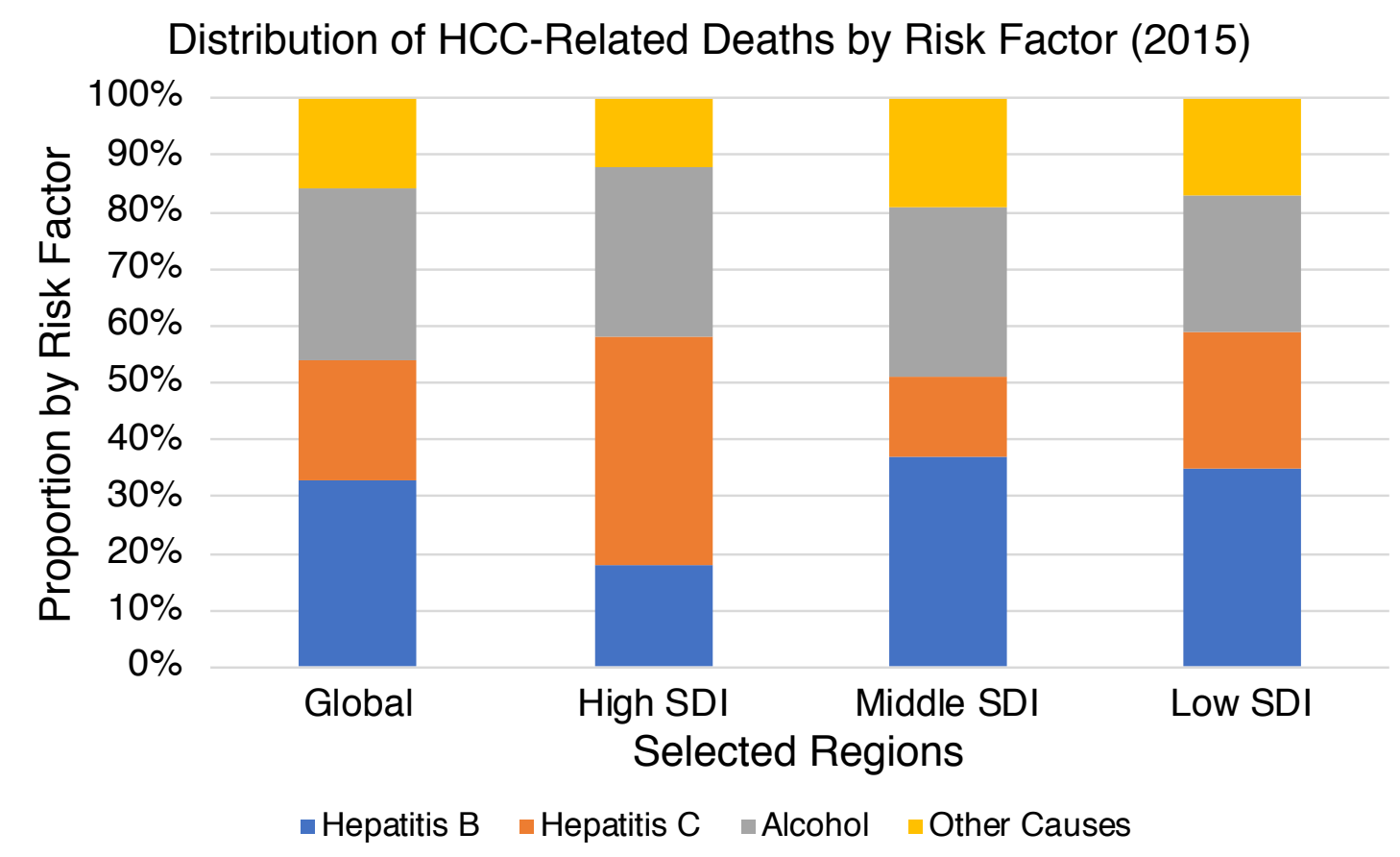

Figure 2.3 Distribution of HCC-related deaths by risk factor in selected regions. Data extracted from the Global Burden of Disease Liver Cancer Collaboration [28]. HCC = hepatocellular carcinoma, $\mathrm{SDI}=$ sociodemographic index. 


\section{Chapter 2. Hepatocellular Carcinoma}

$\mathrm{HBV}$ is the leading cause of $\mathrm{HCC}$ development worldwide, accounting for up to $50 \%$ of all cases [22]. This risk factor is even more important in developing countries, regions where HBV infection is considered endemic and transmission generally occurs during childhood, by vertical or perinatal exposure [29, 30]. In contrast, the horizontal transmission (sexual or parenteral routes), is the most common in developed countries [29]. HBV is linked to HCC even in the absence of cirrhosis; however, patients with cirrhosis are at a higher risk [19]. The implementation of vaccination programs and the advent of successful treatment regimens have led to a decline of $\mathrm{HBV}$-associated $\mathrm{HCC}$ incidence worldwide [31-33].

$\mathrm{HCV}$ is the most common risk factor for $\mathrm{HCC}$ in developed countries [24, 34]. In Canada, modeling data suggest that by 2035, cases of HCV-related HCC will have increased by 205\%, when compared to 2013 levels; although more effective and better tolerated antivirals may change this trend [4]. Differently from chronic HBV infection, virtually all HCCs associated with chronic HCV occur in patients with advanced liver fibrosis or cirrhosis $[35,36]$. The majority of $\mathrm{HCV}$ infections is acquired in adulthood, generally as a result of exposure to contaminated blood products or intravenous drug abuse [37]. HCV treatment is associated with a decrease in risk of developing HCC, though it is not completely eliminated [38, 39].

Alcohol abuse is the third most common cause of $\mathrm{HCC}$, especially in Western countries [37, 40]. Heavy alcohol intake can lead to cirrhosis and, consequently, to HCC. However, the exact pathogenesis is not entirely understood [37]. NAFLD is an emerging cause of HCC and a well-established cause of chronic liver disease [41]. It 
seems that the increased HCC risk associated with NAFLD is limited to patients with cirrhosis [42]. Other risks factors are diabetes mellitus, obesity, aflatoxin, iron overload, alpha-1-antitrypsin deficiency, acute intermittent porphyria, and gallstones [37, 43].

\subsection{Natural History}

Historically, HCC was diagnosed, almost invariably, in its late stages, when curative treatment options are not suitable and the progression to death occurs rapidly [44]. The implementation of surveillance strategies and advances in diagnostic techniques propitiated the detection of tumors in the early stages, leading to a better understanding of HCC's natural history. Didactically, natural history can be divided into three phases: molecular, preclinical, and clinical [45].

\subsubsection{Molecular Phase}

The molecular phase involves several sequential genomic alterations, leading to malignant transformations of the hepatocytes, biliary epithelial, or stem cells [45, 46] (Figure 2.4). These genomic mutations take place over the years, in a setting of continuous liver injury and regeneration, promoting proliferation and inhibiting apoptosis [45]. As a result, single or multiple dysplastic nodules are formed. Further genetic alterations arise in these nodules, leading to the full development of HCC. 


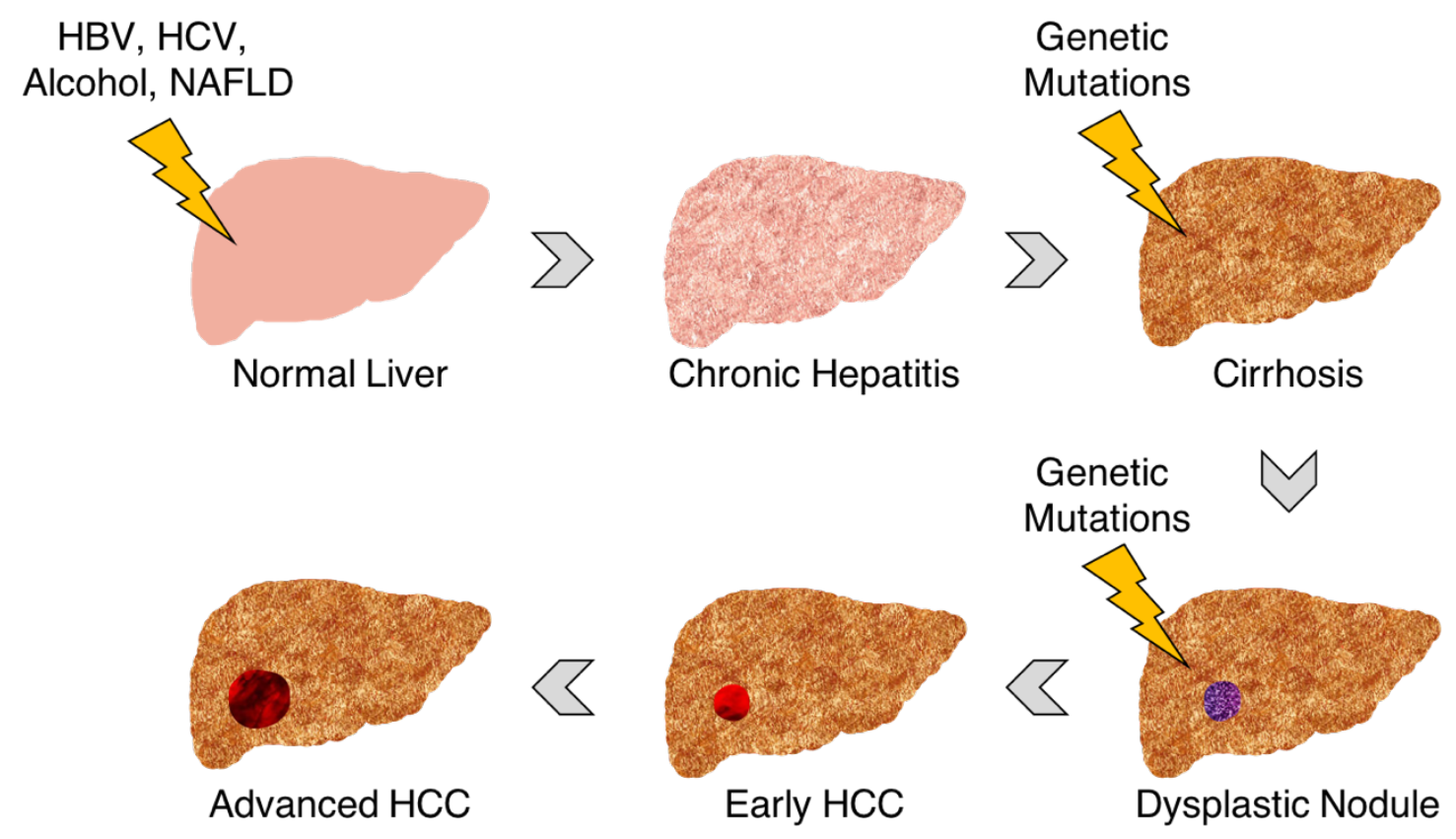

Figure 2.4 Schematic representation of HCC's natural history. HBV = hepatitis B virus, $\mathrm{HCC}=$ hepatocellular carcinoma, $\mathrm{HCV}=$ hepatitis $\mathrm{C}$ virus, NAFLD = nonalcoholic fatty liver disease.

\subsubsection{Preclinical Phase}

The preclinical phase represents two distinct but continuous periods. In the first period (prediagnostic period), the tumor is present but still too small to be diagnosed by imaging techniques. As the tumor grows, it reaches a size threshold for imaging detection, around $1 \mathrm{~cm}$ to $2 \mathrm{~cm}$ (diagnostic period) [45]. In both periods, the tumor remains silent, characterizing the preclinical phase. Surveillance efforts are directed to identify $\mathrm{HCC}$ at this moment, when potentially curative therapies, such as surgical resection, ablation, or liver transplant, are still available. The 5-year survival of patients 
undergoing one of these treatments ranges from $30 \%$ to $80 \%$, versus a 5 -year survival of less than $5 \%$ among those who are not eligible for treatment [15, 24, 47-52].

\subsubsection{Clinical Phase}

The tumor becomes symptomatic only when it reaches $4.5 \mathrm{~cm}$ to $8 \mathrm{~cm}[36,45$, 53]. Before that, patients may experience symptoms associated with their chronic liver disease. HCC is an important differential diagnosis among patients with compensated cirrhotic who progress to decompensation, manifested by ascites, encephalopathy, jaundice, or variceal bleeding [54]. Furthermore, the presence of upper abdominal pain, weight loss, early satiety, or palpable mass may indicate an advanced tumor [55]. The prognosis for patients at this phase is poor, with a median survival of fewer than six months after the onset of symptoms and no benefit from treatment $[52,56]$.

\subsection{Surveillance and Diagnosis}

\subsubsection{Principles and Importance of Surveillance}

Surveillance can be defined as the systematic use of screening tests to identify the occurrence of a given disease, within an at-risk population, while it is still subclinical [57]. The World Health Organization has created a list of criteria to determine if it is worth it or not to perform surveillance [58]; HCC surveillance meets all of these criteria: $\mathrm{HCC}$ has a significant impact on public health, the detection of $\mathrm{HCC}$ at an early stage improves outcomes, there are known groups at high risk of developing $\mathrm{HCC}$, tests are 


\section{Chapter 2. Hepatocellular Carcinoma}

available for surveillance, these tests can detect $\mathrm{HCC}$ at an early stage, the tests are cost-effective and acceptable to physicians and patients, an algorithmic approach to recall and diagnosis after the detection of findings is available, and there are effective treatments for confirmed cases of HCC [57].

The reasoning behind $\mathrm{HCC}$ surveillance is that patients undergoing this program are associated with early tumor detection (odds ratio [OR] 2.08, 95\% confidence interval $[\mathrm{Cl}]$ 1.80-2.37), curative treatment (OR 2.24, 95\% Cl 1.99-2.52), and improved survival (OR 1.90, 95\% Cl 1.67-2.17) [27, 59-61]. Several biases may make the interpretation of HCC surveillance outcomes difficult; these include the lead-time bias (apparent improvement in survival), the prognostic selection bias (identification of patients with slow progressive tumors who are more likely to live longer), and the overdiagnosis bias (false-positive cases). However, authors have shown that the benefits of HCC surveillance persist even after adjustment for lead-time bias [62, 63].

Several liver-study associations have published practice guidelines recommending HCC surveillance $[12,13,64,65]$ (Table 2.1). Despite the presence of slight differences, the overall general approach is similar. In the following topics, we will discuss the recommendations proposed by the North American guidelines [12, 13, 65]. 
Table 2.1 Surveillance Recommendations According to Different Associations

\begin{tabular}{|c|c|c|c|}
\hline Organization & Target Population & $\begin{array}{c}\text { Surveillance } \\
\text { Method }\end{array}$ & Reference \\
\hline AASLD & $\begin{array}{c}\text { Cirrhotic patients, non-cirrhotic } \\
\text { HBV carriers (Asian male }>40 \\
\text { years, Asian female }>50 \\
\text { years, African or North } \\
\text { American blacks, family history } \\
\text { of } \mathrm{HCC} \text { ) }\end{array}$ & $\begin{array}{c}\mathrm{US} \pm \text { AFP every } 6 \\
\text { months }\end{array}$ & [12] \\
\hline EASL & $\begin{array}{l}\text { Cirrhotic patients, non-cirrhotic } \\
\text { HBV carriers at intermediate or } \\
\text { high risk of HCCa, patients with } \\
\text { severe liver fibrosis }\end{array}$ & US every 6 months & [64] \\
\hline $\begin{array}{l}\text { Canadian } \\
\text { Consensus } \\
\text { and CASL }\end{array}$ & $\begin{array}{c}\text { Cirrhotic patients, non-cirrhotic } \\
\text { HBV carriers (Asian male }>40 \\
\text { years, Asian female }>50 \\
\text { years, African or North } \\
\text { American blacks, family history } \\
\text { of } \mathrm{HCC} \text { ) }\end{array}$ & US every 6 months & {$[13,65]$} \\
\hline
\end{tabular}

AASLD = American Association for the Study of Liver Diseases, CASL = Canadian Association for the Study of the Liver, EASL = European Association for the Study of the Liver, $\mathrm{HCC}=$ hepatocellular carcinoma. 


\section{Chapter 2. Hepatocellular Carcinoma}

\subsubsection{At-Risk Patients}

To perform surveillance, it is paramount to define subgroups that are at higher risk of developing $\mathrm{HCC}$. The estimated incidence of $\mathrm{HCC}$ can indicate the level of risk. However, due to the lack of experimental data, economic analyses were used to determine whether or not, and at which incidence rate, it is cost-effective to perform HCC surveillance [12].

Cost-effectiveness models suggested that the incidence threshold for surveillance efficacy among cirrhotic patients ranges from $1.5 \%$ to $2 \%$ per year $[17,66$, 67]. Using this value, current guidelines recommend performing surveillance in all cirrhotic patients once the diagnosis is made [12, 13, 65]. Patients with cirrhosis secondary to HBV or HCV who have cleared the infection seem to show a decrease in risk. However, since the magnitude of this decrease is difficult to evaluate, it is recommended that these patients continue surveillance [68].

Chronic HBV carriers may also benefit from surveillance if the annual HCC incidence exceeds $0.2 \%$ per year [69]. The HCC incidence in Asian patients with HBV starts to exceed $0.2 \%$ per year at around 40 years in men and 50 years in women [7072]. Among Africans or African descendants, the incidence is increased earlier in life; as a consequence, surveillance should begin at the time of HBV diagnosis [73]. Furthermore, chronic HBV carriers with a family history of $\mathrm{HCC}$ are also at a higher risk and should undergo surveillance [74]. 


\subsubsection{Surveillance Testing}

An ideal surveillance method would have a positive result only if the patient has the disease and a negative result only if the patient does not have the disease [75]. Unfortunately, there is no such ideal method for HCC.

Since the primary purpose of surveillance is to detect potential disease indicators, physicians choose surveillance tests with relatively high rates of sensitivity (true positives in patients with disease), to not miss a possible disease. However, for the same method, a high sensitivity rate means a low specificity (true negative in patients without disease) rate. This relationship is demonstrated by the Receiver Operating Characteristic (ROC) curve (Figure 2.5). The consequence is a higher likelihood of false-positive exams, resulting in unnecessary follow-up tests and their consequences, such as physical and psychological stress and financial expenditures. 


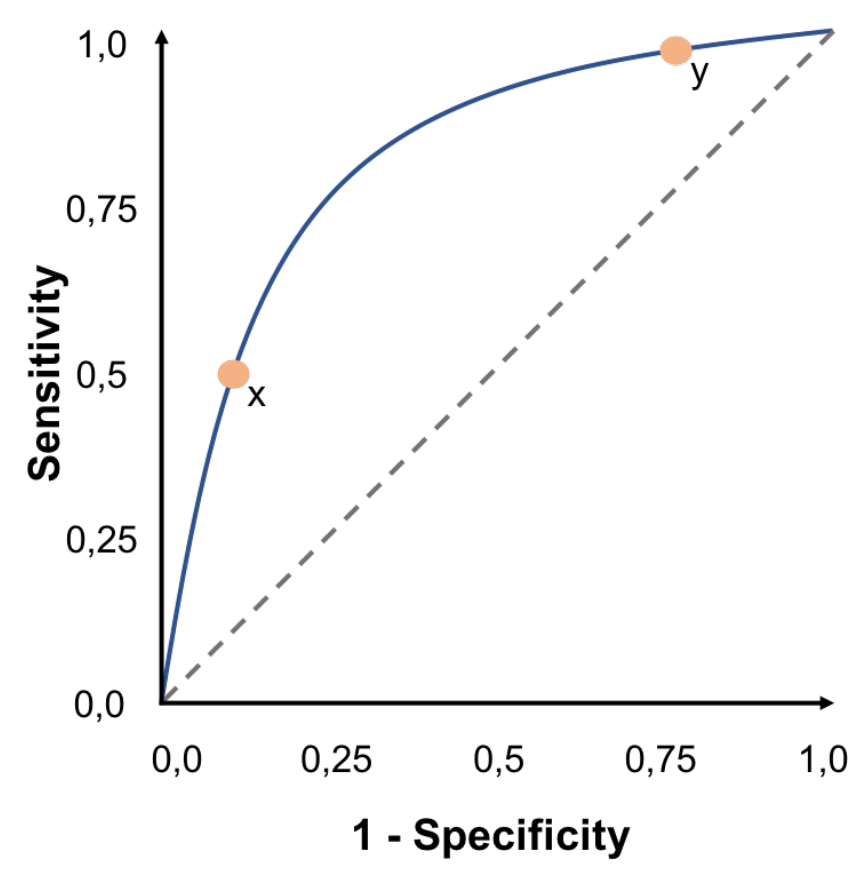

Figure 2.5 Receiver Operating Characteristic $(\mathrm{ROC})$ curve. For the same test (blue curve), the higher the sensitivity (point y) the lower the specificity and the lower the sensitivity (point $\mathrm{x}$ ) the higher the specificity.

In clinical practice, current North American guidelines recommend US every six months as the surveillance method $[12,13,65]$. US appearance of HCC is variable; furthermore, US is extremely operator dependent. In the gray-scale US, HCC typically presents as hypoechoic nodules [76] (Figure 2.6). However, some lesions may show increased echogenicity due to the inclusion of fatty tissue. Large lesions often put pressure on adjacent vessels and infiltrate the portal vein. They may present with hypoechoic halo suggestive of expansive growth or poorly defined margins when infiltrating the surrounding parenchyma [77]. 


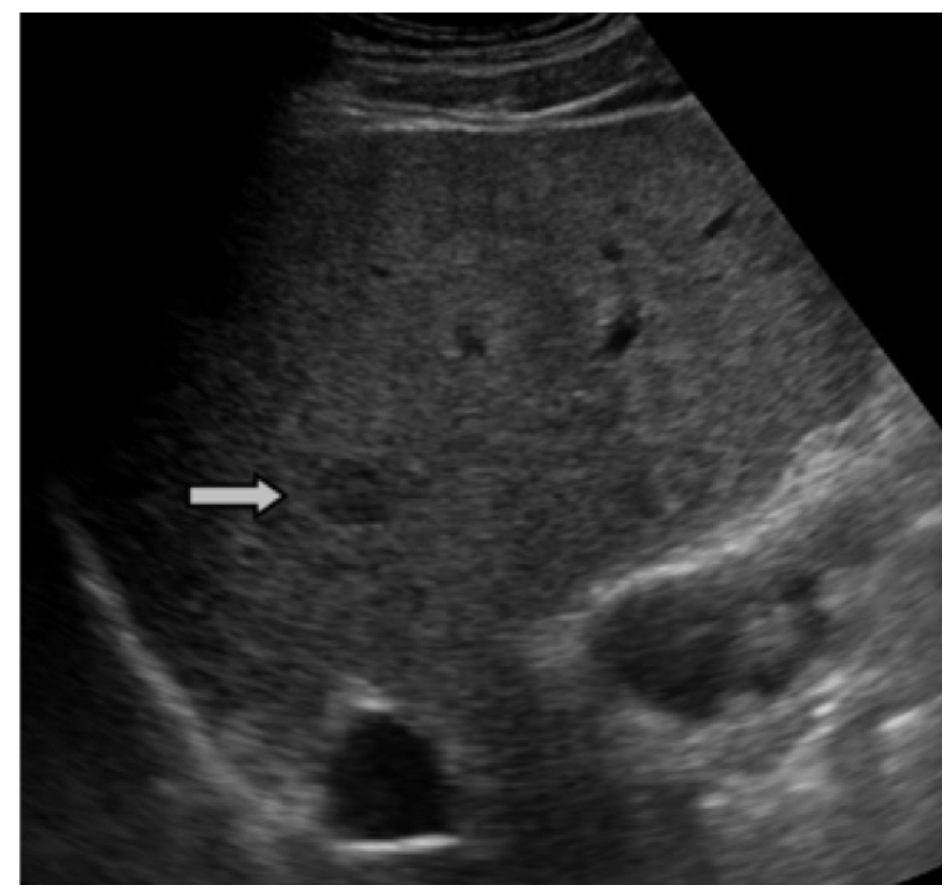

Figure 2.6 Small hypoechoic nodule in a cirrhotic liver corresponding to hepatocellular carcinoma (arrow). Reproduced with permission from Carvalho et al. [76].

A recent meta-analysis estimated an US sensitivity of $0.78(95 \% \mathrm{Cl} 0.60-0.89)$ and specificity of $0.89(95 \% \mathrm{Cl} 0.80-0.94)$ for detecting $\mathrm{HCC}$ in a surveillance setting [78]. However, up to $20 \%$ of US examinations in patients with cirrhosis are characterized as inadequate for HCC exclusion [14]. The most common reasons for inadequacy are rib shadowing and insufficient US beam penetration [14].

It is becoming evident that US limitations affect the efficacy of surveillance. Other imaging modalities, such as CT and MRI, are not recommended for routine use; nonetheless, a recent guideline recognizes these options for selected patients [12]. 
Furthermore, an abbreviated MRI protocol was recently proposed as an acceptable method for HCC surveillance [79-81]. This modality retains the advantages of the MRI, such as high contrast and absence of ionizing radiation, while reducing image acquisition and reading time, resulting in shorter and less expensive exams.

The use of blood biomarkers, such as alpha-fetoprotein (AFP), is considered controversial [65]. The association of AFP with US may improve overall survival [60] and maximize early tumor detection; however, it leads to a higher rate of false positives and an increase in costs [82].

\subsubsection{Diagnostic Testing}

A surveillance method, with few exceptions, does not aim to diagnose the illness. Thus, patients who test positive typically require further evaluation [75]. In the case of $\mathrm{HCC}$, the diagnosis can be established based on noninvasive imaging, either multiphase CT or MRI, without the need for biopsy confirmation [12, 13, 65].

Figure 2.7 represents the surveillance and diagnostic algorithm recently proposed by the American Association for the Study of Liver Diseases (AASLD) [12]. According to this algorithm, patients with a positive surveillance (US demonstrating a lesion $\geq 10 \mathrm{~mm}$ or AFP $\geq 20 \mathrm{ng} / \mathrm{ml}$ ) should undergo a diagnostic imaging modality (multiphase CT or MRI). Multiphase CT and MRI are interpreted and reported through the Liver Imaging Reporting and Data System (LI-RADS) [83]. This system is categorized in codes according to the presence or absence of well-established criteria for the diagnosis of HCC [84]. Patients whose lesion is classified as LI-RADS 1 
(definitely benign) or 2 (probably benign) should return to surveillance imaging in 6 months. Those with lesion classified as LI-RADS 3 (intermediate) should repeat a diagnostic imaging immediately or in 3 to 6 months. Lesions classified as LI-RADS 4 are highly suspect, and a multidisciplinary discussion regarding the best workup is recommended. An image that is classified as LI-RADS 5 confirms the diagnosis of HCC. To be categorized as LI-RADS 5, the image should satisfy one of the following criteria [85] (Figure 2.8 and Figure 2.9):

- Non-rim arterial phase hyperenhancement AND;

- If lesion 10-19 $\mathrm{mm}=$ nonperipheral "washout" OR threshold growth $(\geq 50 \%$ size increase of a mass in $\leq 6$ months) OR nonperipheral "washout" AND enhancing "capsule";

- If lesion $\geq 20 \mathrm{~mm}=$ nonperipheral "washout" OR threshold growth OR enhancing "capsule". 


\section{Chapter 2. Hepatocellular Carcinoma}

SURVEILLANCE

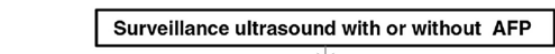

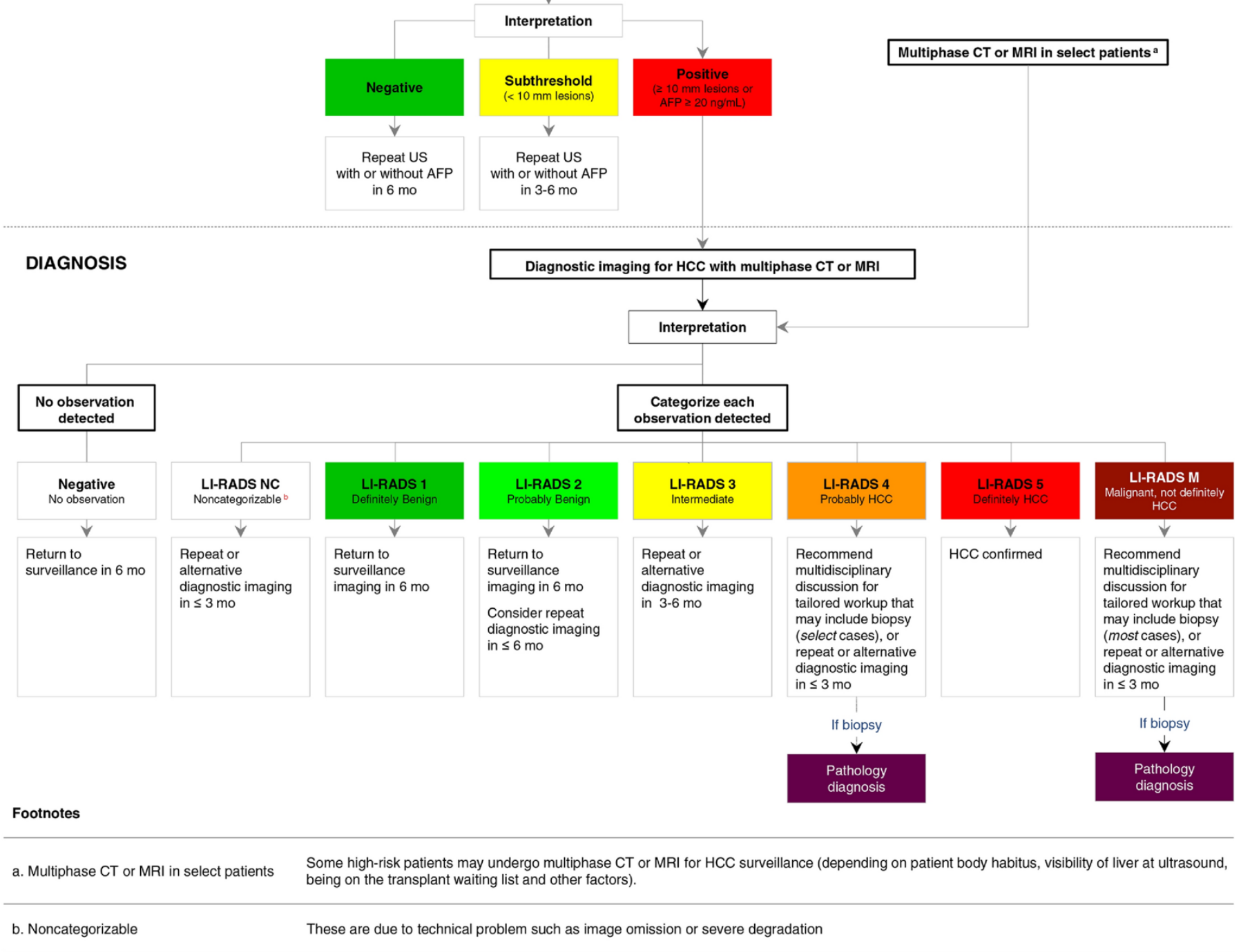

Figure 2.7 American Association for the Study of Liver Diseases (AASLD) surveillance and diagnostic algorithm. Reproduced with permission from Marrero et al. [12]. $\mathrm{AFP}=$ alpha-fetoprotein, $\mathrm{CT}=$ computed tomography, $\mathrm{HCC}=$ hepatocellular carcinoma, $\mathrm{MRI}=$ magnetic resonance imaging, $\mathrm{US}=$ ultrasound . 


\section{Hepatocellular Carcinoma: Major Criteria}

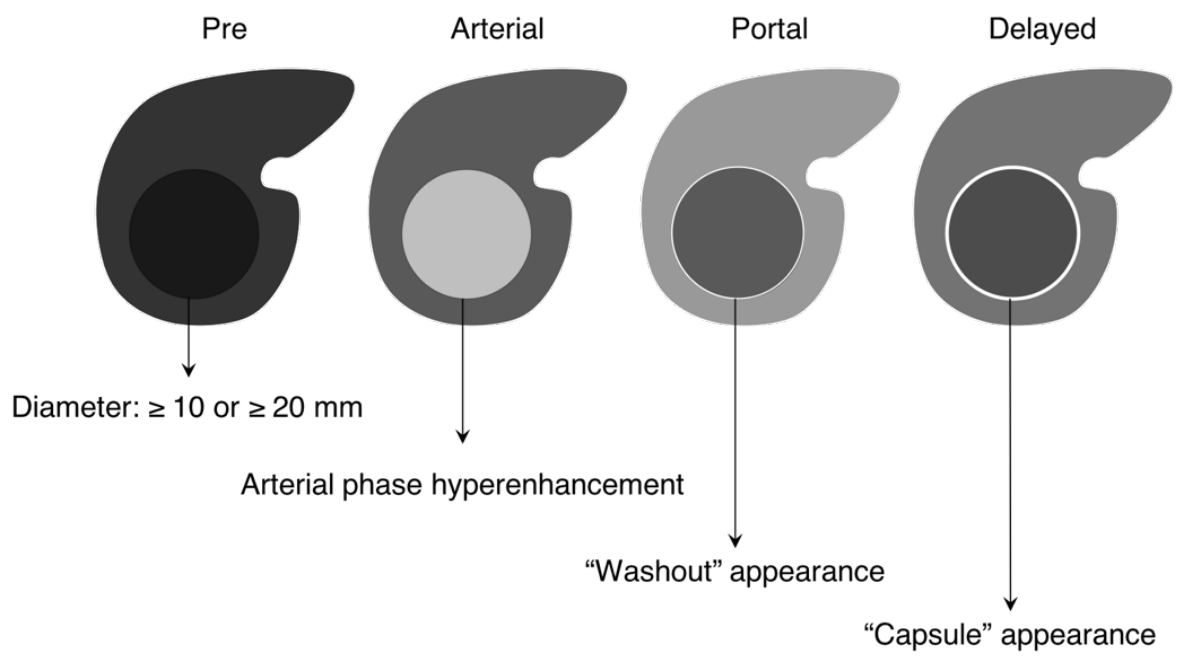

Figure 2.8 Schematic representation of LI-RADS major criteria for hepatocellular carcinoma diagnosis. Courtesy of Dr. An Tang. 


\section{Chapter 2. Hepatocellular Carcinoma}

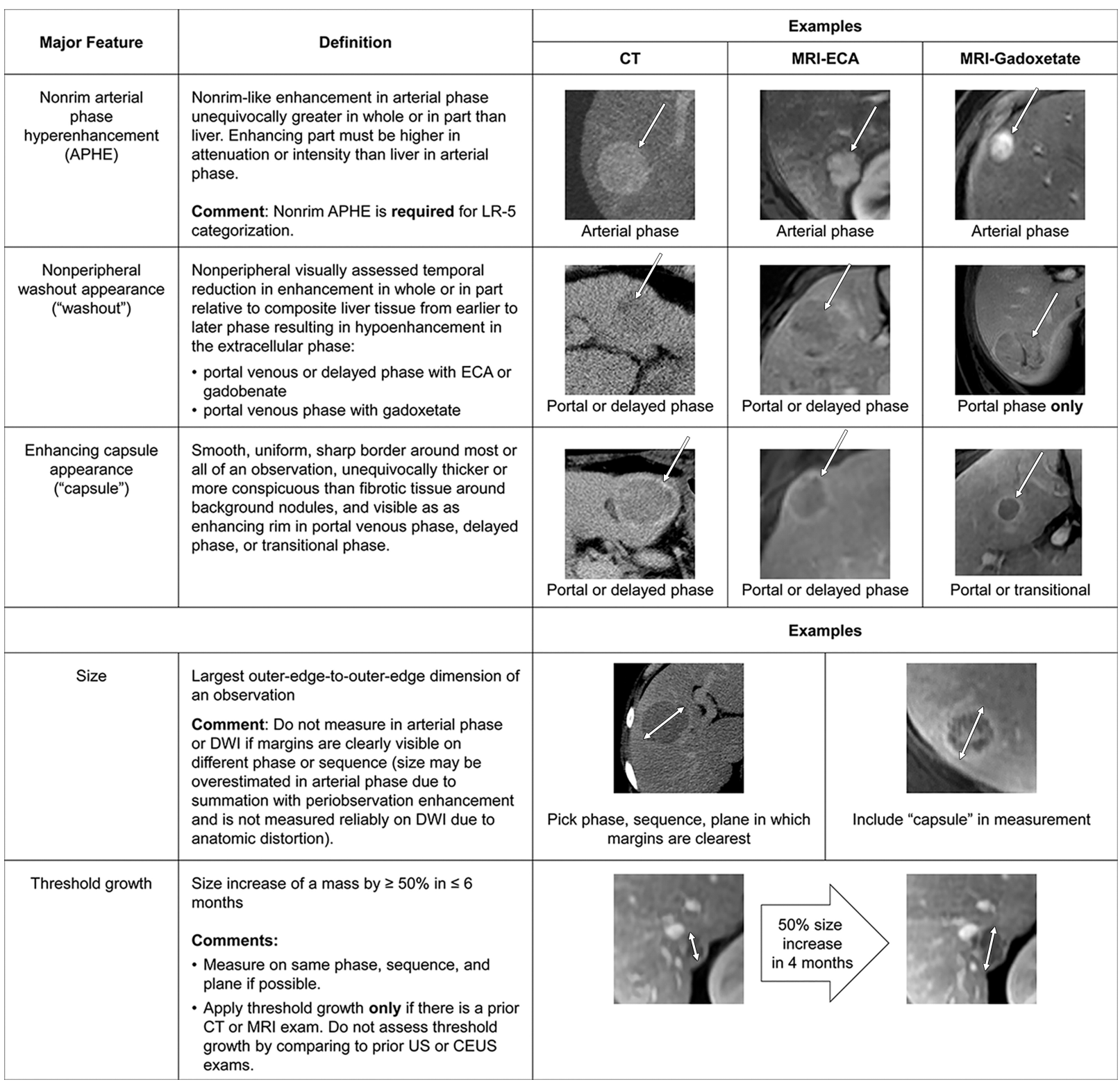

Figure 2.9 Summary of CT and MRI diagnostic Liver Imaging Reporting and Data

System major features. Reproduced with permission from Chernyak et al. [86].

$\mathrm{APHE}=$ arterial phase hyperenhancement, CEUS = contrast-enhanced US, DWI = diffusion-weighted imaging, ECA = extracellular contrast agent. 


\subsection{Management}

HCC management depends upon the degree of the underlying liver dysfunction and the size of the tumor. The traditional tumor node metastasis (TNM) staging system has shown significant limitations in classifying HCC patients [87, 88]. Several new systems were proposed to address HCC staging [44, 56, 88-93] (Table 2.2), none of them with universal acceptance.

The Barcelona Clinic Liver Cancer Staging (BCLC) system is the most used in clinical practice and is the recommended staging system by North American guidelines $[12,13,56,65]$. It will be described in the next sections along with the treatment options according to its classification.

Table 2.2 Hepatocellular Carcinoma Staging Systems

\begin{tabular}{lccc}
\hline Classification & Type & Stages & Reference \\
\hline Okuda Stage & System 3 & Stage I, II, III & {$[44]$} \\
\hline French & Score 3 & A: 0 point & {$[93]$} \\
& & B: $1-5$ points & \\
& & C: $\geq 6$ points & \\
\hline CLIP & Score 7 & $0,1,2,3,4,5,6$ & {$[92]$} \\
\hline BCLC staging & Staging 5 & $0:$ Very early & {$[56]$} \\
& & A: Early &
\end{tabular}




\begin{tabular}{lccc}
\hline & & B: Intermediate & \\
& & C: Advanced & \\
& & D: End-stage & \\
\hline CUPI & Score 3 & Low risk: score $\leq 1$ & {$[91]$} \\
& & Intermediate: score 2-7 & \\
& & High: score $\geq 8$ & \\
\hline TNM staging & System 3 & Stage I, II, III & [88] \\
\hline JIS & Score 4 & Stage I, II, III, IV & [90] \\
\hline ER & System 2 & ER wild-type & [89] \\
& & ER variant &
\end{tabular}

BCLC = Barcelona Clinic Liver Cancer Staging, CLIP = Cancer of the Liver Italian Program, CUPI $=$ Chinese University Prognostic Index, ER = estrogen receptor, $\mathrm{JIS}=$ Japan Integrated Staging Score, TNM = tumor node metastasis.

\subsubsection{Barcelona Clinic Liver Cancer Staging (BCLC)}

The BCLC system was designed based on the results of several cohort studies and randomized controlled trials [56, 94, 95]. This system takes into account characteristics related to tumor stage (Okuda staging system, which takes into account the tumor size, the presence of ascites, and the values of albumin and bilirubin), liver functional status (Child-Pugh score, patients classified as Child-Pugh A or B have, respectively, least severe and moderately severe liver disease [compensated cirrhosis], 
while those classified as Child-Pugh $\mathrm{C}$ have severe liver disease [decompensated cirrhosis]), physical status (performance status test [PST], recorded from 0 [fully active] to 5 [dead]), and cancer-related symptoms to classify HCC patients into four categories: early, intermediate, advanced, and terminal (Figure 2.10).

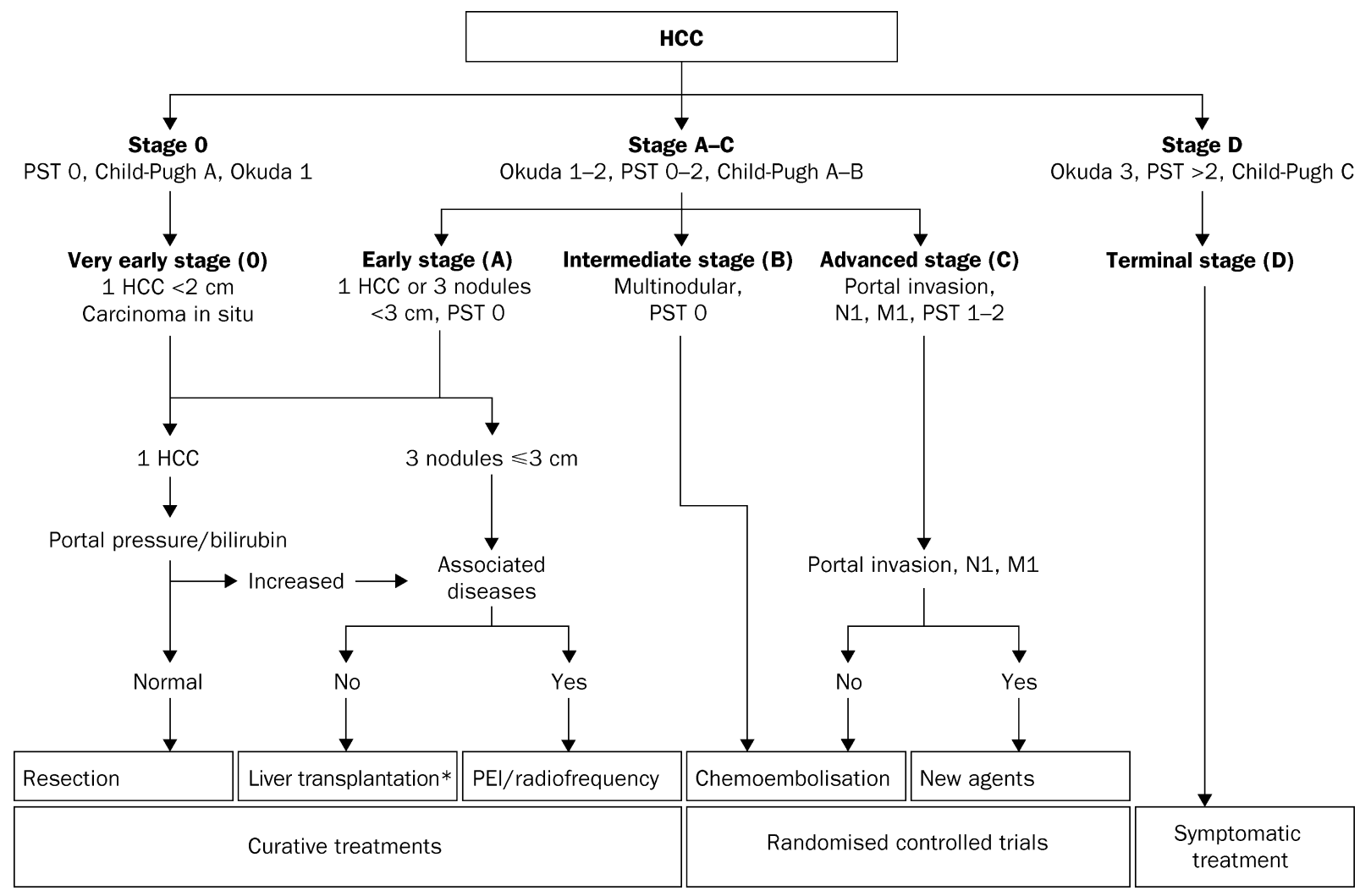

Figure 2.10 Barcelona Clinic Liver Cancer Staging (BCLC) classification and treatment schedule. Reproduced with permission from Llovet et al. [94]. ${ }^{*}$ Cadaveric liver transplantation or living donor liver transplantation. HCC $=$ hepatocellular carcinoma, $\mathrm{PEI}=$ percutaneous ethanol injection, $\mathrm{PST}=$ performance status test. 


\section{Chapter 2. Hepatocellular Carcinoma}

The BCLC has already been validated as the best staging system for patients with early HCC; however, some important limitations have been identified [96, 97]. The main points of disagreement are: (1) the non-inclusion of The Milano/Mazzaferro criteria for liver transplantation (LT) (patients with solitary tumor $\leq 5 \mathrm{~cm}$ or up to three tumors all $\leq 3 \mathrm{~cm}$ should be considered for LT; with the BCLC system, only some patients with three nodules $\leq 3 \mathrm{~cm}$ should undergo LT) [88] and (2) the nonconsideration of liver resection as a treatment option for some subgroups of patients who may benefit from this approach (including some patients with early and intermediate-stage $\mathrm{HCC}$ [ [98].

\subsubsection{Early-Stage HCC (BCLC O-A)}

This category is comprised of patients who are eligible for potentially curative therapies, including liver resection, $L T$, and radiofrequency ablation (RFA).

Liver resection remains the optimal treatment for $\mathrm{HCC}$ in patients with normal liver function; however, the efficacy depends on the ability to achieve a complete resection that leaves an adequate liver remnant [37]. Furthermore, since the liver remnant may maintain precancerous disease, the recurrence is possible $[99,100]$.

The recurrence after LT is less frequent compared to liver resection $[99,100]$. However, this advantage is counterbalanced by the long-term complications associated with transplants, such as graft rejection and immunosuppression [37]. Furthermore, the wait for a transplant can last months, even years, due to the shortage of organ donors. 


\section{Chapter 2. Hepatocellular Carcinoma}

During this period, the risk of tumor progression and dropout may be as high as $25 \%$ [101].

RFA is based on the use of a high-frequency alternating current transferred from the tip of an electrode into the tissue. The oscillating current induces movement of the ions within the tissue, resulting in frictional heating. When the temperature surpasses $60^{\circ} \mathrm{C}$, the cells surrounding the electrode begin to die, generating necrosis. RFA is an alternative to liver resection, especially if the lesion is solitary and small [102]. It can also be used as a bridge therapy in patients waiting for $\mathrm{LT}$, resulting in a decrease in the dropout rate secondary to tumor progression [103].

\subsubsection{Intermediate-Stage $H C C$ (BCLC B)}

Patients at this stage are eligible for transarterial chemoembolization (TACE). This approach is based on the fact that $\mathrm{HCC}>2 \mathrm{~cm}$ has a blood supply derived from the hepatic artery. The injection of a chemotherapeutic agent produces arterial embolization, resulting in ischemia and necrosis of the tumor. However, TACE is not considered a curative therapy $[104,105]$. The therapy outcome depends on the initial tumor burden, tumor biology, baseline hepatic function, and the initial response [37]. Primarily, TACE therapy aims to extend overall survival and avoid dropout of patients on the waiting list for $L T[104,106]$.

\subsubsection{Advanced-Stage HCC (BCLC C)}

Patients with advanced-stage HCC should undergo systemic therapy. To date, sorafenib is the only agent that demonstrated a statistically significant, although 
modest, survival benefit $[107,108]$. The sorafenib molecule is a multikinase inhibitor; it acts by inhibiting the cellular proliferation and the angiogenesis.

\subsubsection{End-Stage HCC (BCLC D)}

These patients have a dismal prognostic, with a median survival of less than 3 to 4 months [52]. At this point, patients should receive palliative support, including management of pain, nutrition, and psychological support [109]. 


\section{Economic Analysis in Health Care}

\subsection{Introduction to Economic Analysis}

New health technologies or medications in health care may offer an increase in desirable outcomes when compared with the current practices. However, these options are typically more expensive when newly introduced. Economic analysis in health care aims to evaluate if the additional benefit of an intervention is compensated by the increase in cost through answering the following question: are we satisfied that the health resources should be spent in this way rather than in some other ways? [11]. Economic analysis is considered an important tool in public health, mainly because of the limitations in health care budgets and the increase in health expenditures [110] (Figure 3.1). 


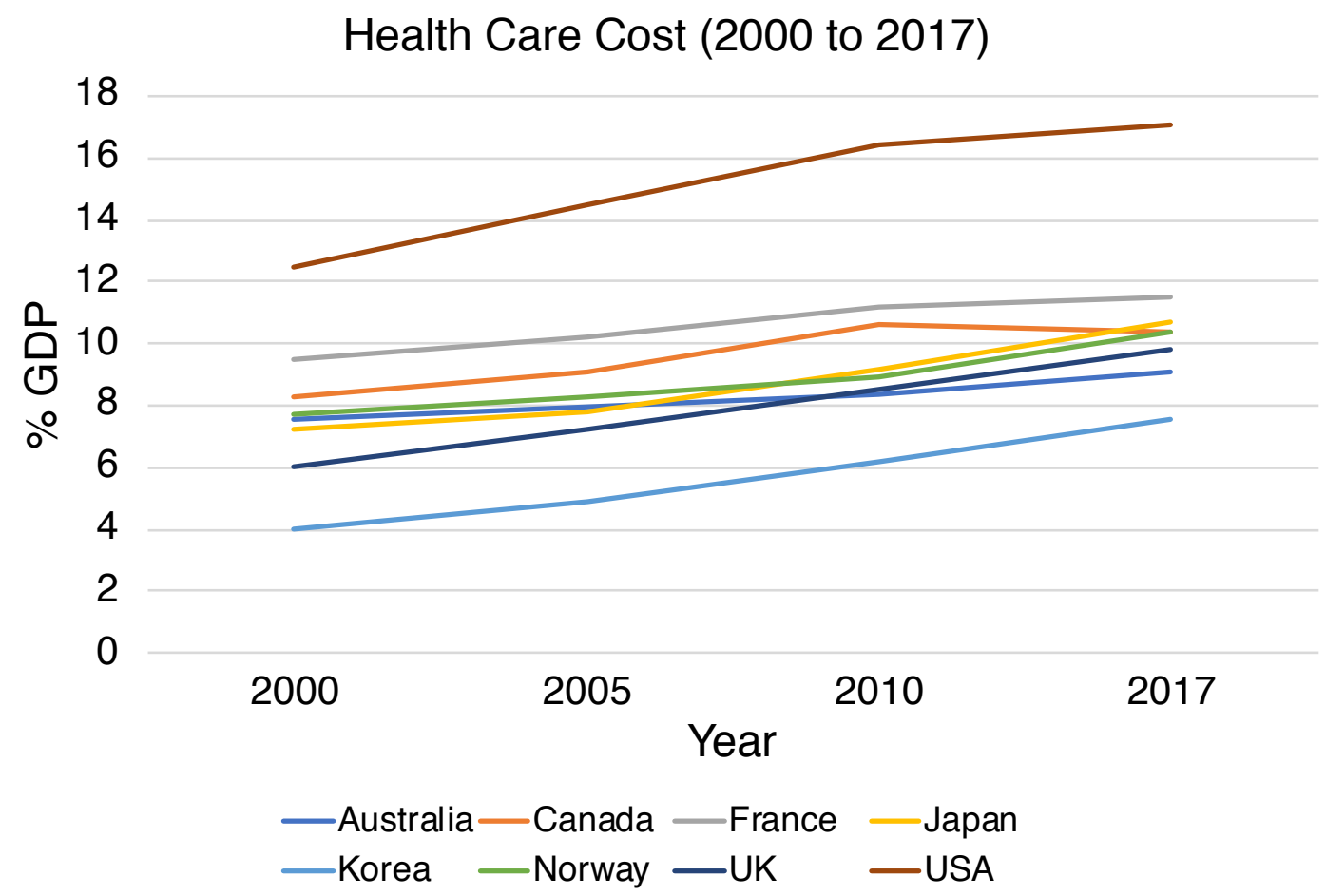

Figure 3.1 Health care cost in selected countries as a percentage of gross domestic product. Data extracted from the World Health Organization Global Health Expenditure Database [110]. GDP = gross domestic product.

Physicians could consider that letting cost influence clinical decisions or policies is unethical [111]. However, in health economics, the term "cost" has more than a simple monetary connotation. It represents the loss of potential benefits when one intervention is chosen over another, called the "opportunity cost." For example, imagine that the directors of a hospital have Can $\$ 1,000,000$ (Canadian dollars) to spend. They could use the money to build an operating room or to buy a new MRI machine. The loss of benefits related to the surgeries that were not performed, if the directors had preferred to buy the MRI machine, or the loss of benefits associated with the imaging 
diagnostics that were not performed, if the directors had preferred to build the operating room, is the opportunity cost. This concept is linked to the notion of scarcity of resources. If there is no scarcity, there is no opportunity cost.

At the patient level, economic analysis is also important. By taking into consideration the relationship between benefits and costs, physicians can ensure the best possible care for their patients while respecting the responsible allocation of public resources [112]. It is essential to underline that economic analysis should not be the only criteria for deciding which alternative to choose; patients preferences and physicians experience should also be considered [113]. However, it can be another source of information when physicians discuss management options with patients and colleagues. In the following sections, a basic description of economic analysis will be presented. The understanding of these sections will hopefully help physicians to incorporate economic concepts into their practice.

\subsection{Types of Economic Analysis}

\subsubsection{Cost-Effectiveness Analysis (CEA)}

The CEA is characterized by the measurement of gains in natural units of health, such as cures, lives saved, or decrease in blood glucose or blood pressure. The results of such analyses are given in terms cost per unit of outcome (for example, Can $\$ 5,000$ per cure). However, given that the outcomes of different technologies can be measured in different units (for example $\mathrm{mmol} / \mathrm{L}$ for blood glucose or $\mathrm{mmHg}$ for blood pressure), 
the CEA permits the comparison of two or more interventions only if the same units are used, which limits the application of this category of analysis. Further, it may be difficult for decision-makers to establish a willingness-to-pay (WTP) for such outcomes.

\subsubsection{Cost-Utility Analysis (CUA)}

The CUA is considered by some authors to be a subdivision of CEA [114]. The major difference between these economic analyses is that the CUA measures its health outcomes in a single generic unit, called quality-adjusted life year (QALY). The construction of this unit is based on patients' preferences according to the quality and the quantity of life [115] (see Measurement of Health below). Despite some limitations, especially regarding the subjectivity of how "quality" can be measured [116], the CUA is recommended as the most valuable economic analysis, since it allows comparisons across different conditions and interventions [117].

\subsubsection{Cost-Benefit Analysis (CBA)}

In the CBA analysis, costs and benefits are valued in monetary units. Differently, to the CEA and CUA, which aim to identify what is the best option to apply an existing budget, CBA answers whether or not it is worth to spending it [11]. Although popular in other fields, CBA is not commonly used in the health context due to ethical issues and difficulties related to measuring benefits in monetary terms [117].

\subsubsection{Cost-Minimization Analysis (CMA)}

The CMA is characterized by the comparison of interventions that are presumably identical in terms of all major clinical outcomes. The cost among the 
interventions evaluated is the only difference, and the intervention with the lowest-cost is considered the preference. Generally, a CMA is realized when the analysis of treatments tested in clinical trials results in non-inferiority or equivalence. Some authors consider that the CMA is a cost analysis rather than a complete economic analysis [114].

\subsection{Choosing the Population and Comparators}

While developing an economic analysis, researchers should define the target population and the comparators, since the cost-effectiveness of intervention could extensively vary according to both factors. The decision problem should be guided by the choice of population and comparators, being that it is considered good practice to consider the opinions of physicians and decision-makers [117].

To address the study objectives, an economic model should reflect the entire target population. However, important heterogeneities may be present inside a large group, such as the Canadian population. In this case, the researchers should identify which differences could play an essential role in the model development (for example, differences in the natural history of the studied disease or the effectiveness of interventions), in order to incorporate different parameter values according to distinct subgroups $[118,119]$.

The selection of comparators is also of the highest importance. Based on the Canadian Guidelines for the Economic Evaluation of Health Technologies, the most 
appropriate comparators are the standard of care (i.e. the interventions currently used in the Canadian context) and the technologies that are likely to be displaced by the intervention under investigation. Furthermore, considerations regarding the best supportive care should be made when new technologies are not fully adopted or represent uncertain value [117]. In principle, the comparators should be mutually exclusive (a patient with a given condition can only receive one intervention) [11]. They should be clearly described to allow for the identification of all relevant costs and outcomes [117].

\subsection{Perspective}

The perspective of an economic analysis should be related to the decision problem and consistent with both costs and outcomes. There are different possibilities of perspective (societal, public health payer, and private health payer) and costs and outcomes that are important from a given perspective may not be from another [11] (Table 3.1).

Because health economics is a science concerned with society's welfare, some authors argue that economic analysis should preferably evaluate technologies from the societal perspective $[120,121]$. The societal perspective is also considered to be the broadest approach since it incorporates all possible costs. Nevertheless, the perspective should always be directly related to the decision problem and, if necessary, be discussed with the organism that commissioned the analysis [117]. 
Table 3.1 Relevant Costs According to Different Perspectives

\begin{tabular}{l}
$\begin{array}{l}\text { Perspectives and Costs } \\
\text { Health Sector }\end{array}$ YES \\
\hline Other Sectors \\
\hline Patients and Families \\
Loss of Productivity \\
aThe public sector may also consider services others than the health services (broader \\
government payer perspective). In this case, costs related to other sectors should also \\
be considered [117]. \\
bDespite the Canadian guideline does not consider the loss of productivity as a relevant \\
cost under the private health payer perspective [117], we understand that costs linked \\
to loss of productivity due to reduced working capacity or costs to hire and train a \\
replacement worker may be relevant to the private sector.
\end{tabular}

\subsection{Time Horizon}

The time horizon is also relevant in economic analysis. It depends on the decision problem and can range from a few weeks to a lifetime period, according to the natural history of the condition [117, 122]. When modeling chronic diseases or when the interventions have an impact on mortality, for example, a lifetime horizon is most appropriate [117]. In all cases, the time horizon should be long enough to capture all 
significant differences between costs and outcomes of the evaluated interventions [123].

An inappropriately short time horizon can bias the results and compromise the analysis, as it may capture only a fraction of the costs and utilities associated with a given condition. For example, if one considers the cost and utility at the time "t2", only a portion of the utility would be captured, while the cost already reached its plateau. At this point, an economic analysis could state that the intervention would not be costeffective. Comparing the points "t2" and " 4 " it is possible to observe that in the last one there is an increase in the utility value, while the cost stays almost the same, changing the cost-effectiveness relation (Figure 3.2).

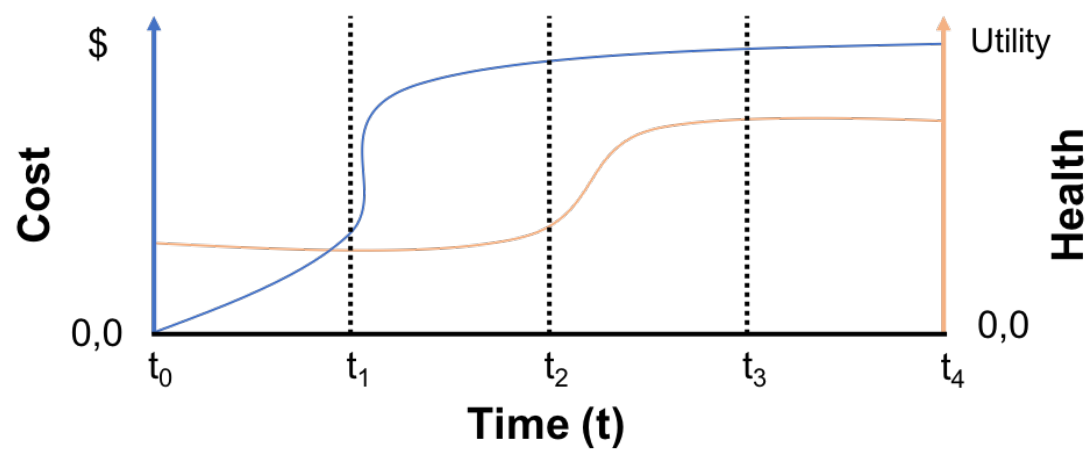

Figure 3.2 Influence of time horizon in economic analysis. 


\subsection{Measurement of Costs}

Drummond et al. [11] classified costs as: associated with the health sector, associated with other sectors (such as education and housing), paid for by patients and families (such as transportation and feeding), and related to loss of productivity. Economic evaluations may incorporate one or more of these costs, according to their perspectives.

\subsubsection{Costs versus Time (Adjusting and Discounting)}

Even when costs have the same monetary unit, they may not be comparable because of changes in price over time. To compensate for this effect, costs should be corrected by using the concepts of adjusting and discounting.

When using costs from the past, it is necessary to adjust them to the present. This can be done by multiplying the costs by the accumulated inflation of the period. Inflation is a key concept in economic studies, it represents the increase in prices over time and, consequently, the loss of purchasing power (for example, Can\$1,000 in 2000 purchased a higher percentage of goods or services than in 2017) (Figure 3.3). The decrease in prices (deflation) is also possible, but less common than inflation. 


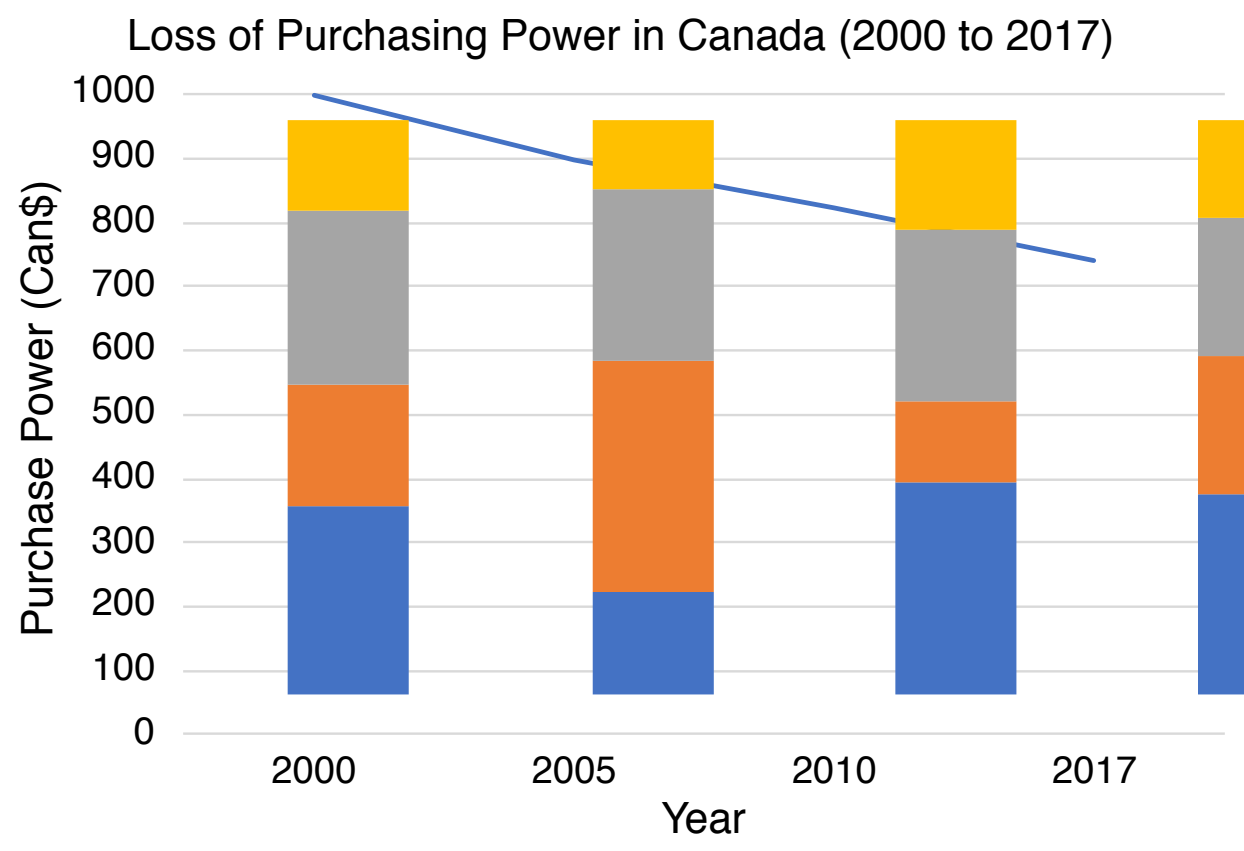

Figure 3.3 Schematic representation of loss of purchasing power in Canada. Data extracted from the Bank of Canada [124].

Similarly, economic evaluations that involve costs in the future require the application of a discount rate to reflect individuals' and society's preferences over time. Discounting makes present costs worth more than those occurring in the future. This is justified by the fact that individuals and society generally prefer to buy goods (i.e., equipment or procedures) and enjoy benefits in the present rather than wait for the future.

The principle of discounting is essential when evaluating health interventions where financial resources are consumed in the present while health benefits occur in the future [125]. The discounting rate changes according to society's preferences; in 
Canada, the recommended discounting rate is $1.5 \%$ per year [117]. As well as costs, outcomes should also be discounted [117].

\subsubsection{Cost Estimation}

When evaluating which sources to consider, the authors of economic evaluations should always reflect the jurisdiction of interest. Where important variations exist within the jurisdiction, the author should consider them when conducting the evaluation [117].

Micro-costing is considered the most accurate method to estimate the costs of a given intervention [11]. It involves the enumeration and the costing of every input of the technology that is being evaluated [126]. Other costs used in economic analysis are usually derived from government or private sector sources, or even from previous economic analyses. However, it is always important to highlight that the selected costs depend primarily on the perspective of the study.

\subsection{Measurement of Health}

In economic studies, the health outcomes can be measured according to the study objective (for example, number of days free of symptoms after the use of a new bronchodilator in asthmatic patients) and the type of economic analysis. Since this thesis is based on a cost-utility analysis, the following topics will explain how to measure health outcomes in this type of analysis. 


\subsubsection{The Concept of Utility}

As already mentioned, health economists created the concept of QALY to enable comparisons across a broader area of health care interventions. This outcome aims to summarize in a single measurement the impact of an intervention on the patient's quality and quantity of life. To generate QALYs, it is necessary to establish which are the health states of interest (for example, HCV infection, compensated cirrhosis, decompensated cirrhosis, and $\mathrm{HCC}$ ) and value the preference associated with each one of these states [115].

These qualities of life weights are called utilities and represent the general population's preferences for a specific health condition. Generally, a health condition is described for a healthy group of people, which represents the society (societal point of view), and it is valued from 0 (death) to 1 (perfect health) [115]. It is important to mention that utilities may also be measured considering patients and caregivers preferences. Furthermore, differences among populations and methods may influence health state valuation [127]. In the next paragraphs, three well-established methods to directly measure utilities will be described. There are also indirect methods to measure utilities (see The Concept of Health-Related Quality of Life below).

- Time trade-off: this method estimates preferences by asking participants to imagine two distinct situations (Figure 3.4): perfect health (situation 1) for a shorter time $\left(\mathrm{t}_{1}\right)$ and imperfect health (situation 2$)$ for a longer time (t $\mathrm{t}_{2}$. Then, participants have to indicate the point in which they are 
indifferent between the shorter period of perfect health ( $\left.\mathrm{t}_{1}\right)$ and the longer period of imperfect health $\left(t_{2}\right)$. The utility is calculated by dividing $t_{1}$ by $t_{2}$ [114].

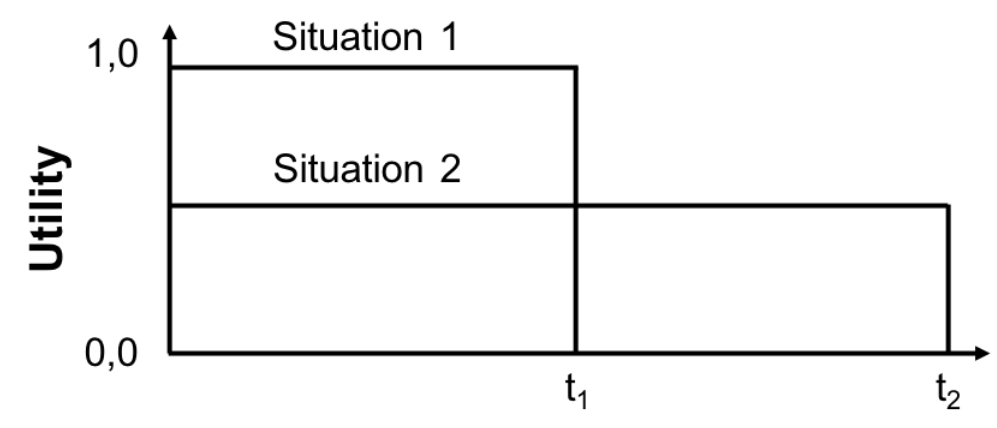

Time (t)

Figure 3.4 Schematic representation of the time trade-off method.

- Standard gamble: participants should choose between the certainty of remaining in an imperfect state of health chronically (situation 1) or gamble between re-establishing perfect health (probability $p$ ) or progress to death (probability 1-p) (situation 2) [115] (Figure 3.5). Then, participants have to indicate the probability "p" in which they are indifferent between the certainty and the hazard. The chronic health state utility is equal to the value of the probability "p." 


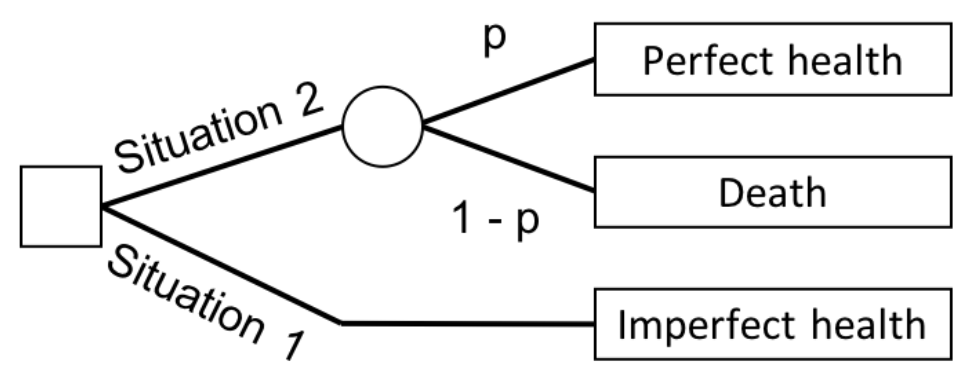

Figure 3.5 Schematic representation of the standard gamble method.

- Visual analogue scale: this method is constituted of a single line on a page with verbal and numerical descriptions at each end [128] (Figure 3.6). The top of the scale represents perfect health while the bottom indicates death, participants are asked to select a point between these two values according to their preferences. The visual analogue scale is the simplest method, usually used as a "warm-up" exercise before other methods [115]. 


\section{Utility Score Health Condition}

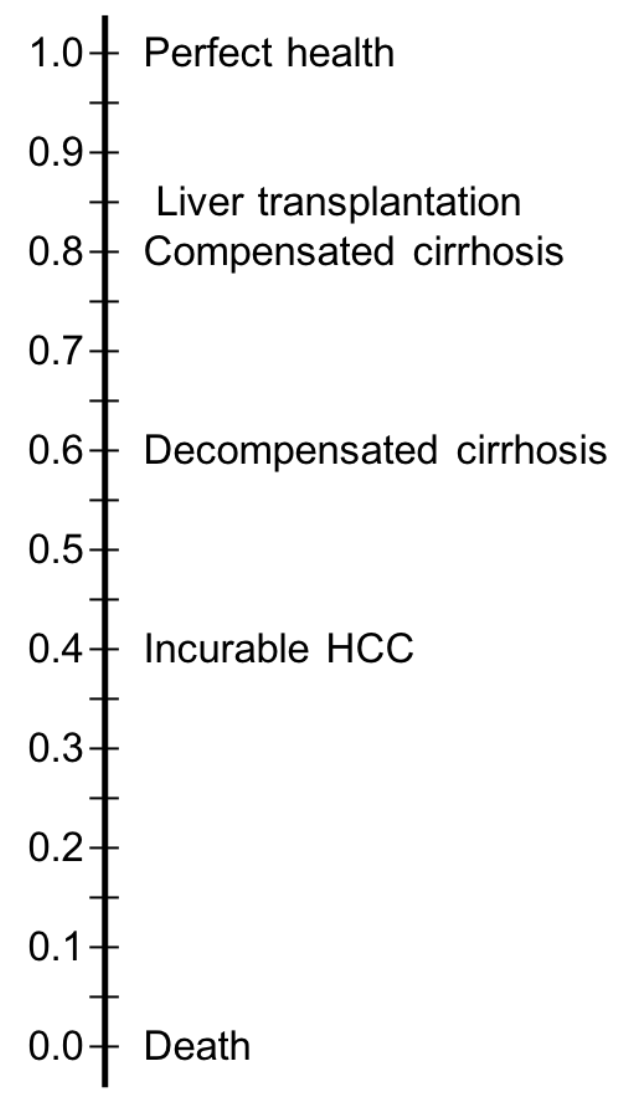

Figure 3.6 Schematic representation of visual analogue scale method.

\subsubsection{The Concept of Health-Related Quality of Life (HRQoL)}

Another methodology of assessing the quality of life is by applying HRQoL surveys. These instruments evaluate the patients' perspective and, usually, do not establish a general score. Instead, they produce multiple scores in different health dimensions, such as physical and social functioning, pain, and mental health [129]. Furthermore, it is possible for a given treatment to be superior in one health dimension and inferior in another. These aspects limit the application of HRQoL surveys in economic analysis [114]. 
To address these limitations, health economists concentrated their efforts in developing mathematical algorithms to summarize HRQoL multiple scores in one general score [130]. Given the complexity associated with directly measuring health utilities (i.e. time trade-off, standard gamble), it is recommended that researchers use utilities from an indirect method of measurement, such as the EQ-5D [117, 131].

The EQ-5D is a preference-based HRQoL instrument which evaluates the generic quality of life [132]. It is widely used in patient-reported outcome exercises, in population health studies, and in health technology assessment [131]. The EQ-5D instrument comprises five dimensions: mobility, self-care, usual activities, pain/discomfort, and anxiety/depression. The scores on these five dimensions can be converted to generate one summary score, varying from 0 to 1 , while evaluating the different dimensions [133].

\subsubsection{The Concept of Quality-Adjusted Life Year (QALY)}

QALYs are calculated by multiplying the utilities (quality weights) of each health state of interest by the duration of time spent in each state. For example, a patient that lives 2 years with decompensated cirrhosis (patient $A$, utility equals 0.6 ) will have a total of 1.2 QALYs, while a patient with decompensated cirrhosis who is submitted to a LT (patient B, utility equals 0.85 ) lives 10 years and will have a total of 8.5 QALYs (Figure 3.7). In this case, the LT added 7.3 QALYs (cross-hatched area) during the patient's $B$ life. 


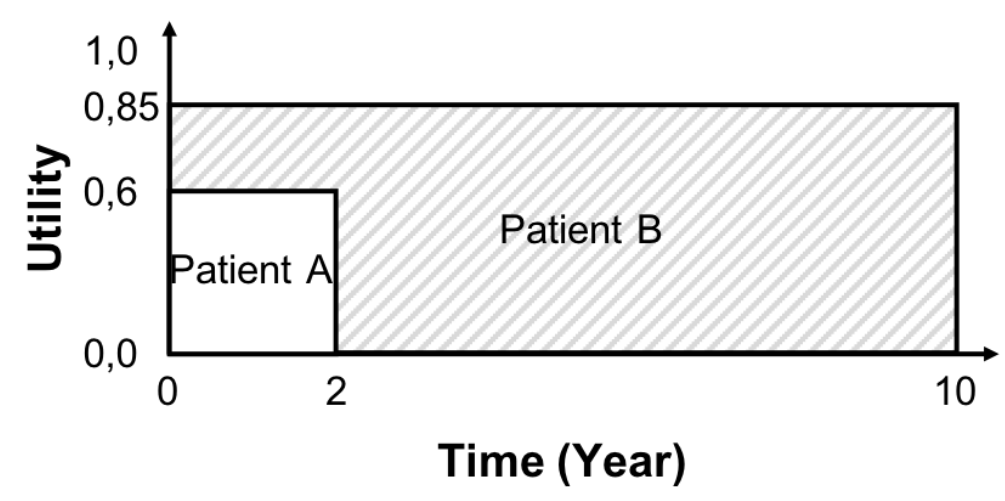

Figure 3.7 Schematic representation of quality-adjusted life year for a patient with decompensated cirrhosis (patient A) and decompensated cirrhosis submitted to a LT (patient B).

As well as costs discounting, outcomes (in this case QALYs) should also be discounted (see Measurement of Costs above). Costs and outcomes are usually discounted at a constant common rate (1.5\% per year in Canada) [117].

\subsection{Decision Analysis (Modeling)}

The conceptualization of a model is a critical component when developing an economic analysis. Modeling can be useful by extending the results of clinical trials, extrapolating intermediate clinical endpoints to final outcomes, and comparing different health technologies [134]. Different modeling techniques are used in economic analysis, including the decision tree, Markov modeling, and the discrete event simulation. 
Despite conceptual differences among the different possible modeling techniques, they should all follow a common pathway [114], which can be assisted by different types of software, like TreeAge Pro, R Statistical Software, or Microsoft Excel. In the following topics, the most common modeling techniques will be described.

\subsubsection{Decision Tree}

A decision tree is an analytical model in which distinct branches are used to represent potential outcomes for a cohort of patients. This model is frequently used to represent interventions that have distinct outcomes that can be measured at a specific time point [135]. The decision tree is built from left to right and starts from a root decision node, represented by a square. From this node, branches emanate to represent each competing comparator. These branches are linked to other nodes (chance nodes or end nodes). The chance nodes (circles) represent transitions between health conditions, while end nodes (triangles) represent the final outcome of interest for each competing comparator. A schematic decision tree is represented in Figure 3.8.

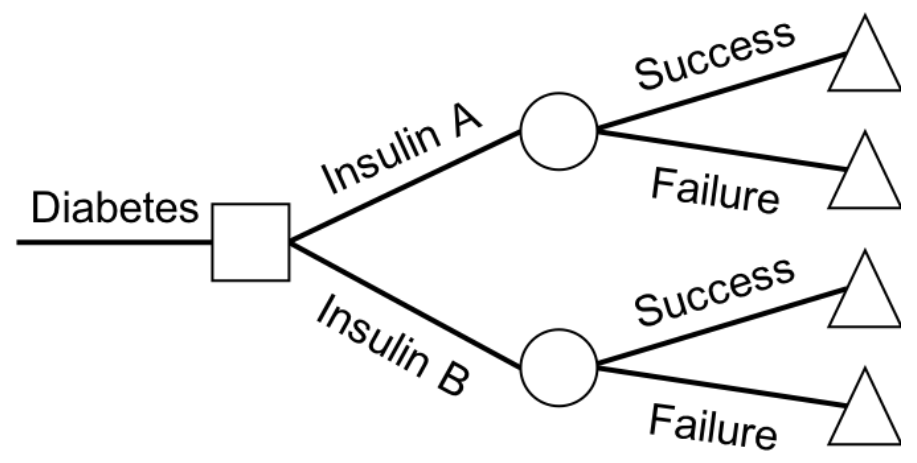

Figure 3.8 Schematic representation of a decision tree. 


\subsubsection{Markov Modeling}

The evaluation of many diseases and conditions needs a more extended period of follow-up to reach outcomes of interest. In these situations, patients may transition from one health state to another over time [114]. For example, in an economic analysis that compares two different treatments for hypertension (initial Markov health state), it would be important to evaluate as possible outcomes the development of complications, such as myocardial infarction, heart failure, stroke (Markov health states), and death (absorbing health state) (Figure 3.9). In other words, the Markov modeling can simulate the natural history of a given disease or condition over time, while incorporating the interventions evaluated by the economic analysis.

Besides choosing the health states that will be incorporated into the Markov model, it is necessary to define the duration and number of cycles (the time component), and the probability of transiting from one health state to another in each cycle. The transition probabilities may be constant over time (Markov chain) or differ depending on the cycle (Markov process) [11]. The most important limitation of Markov modeling is the assumption that the transitions probabilities do not depend on health states that the patient may have experienced previously, which makes certain conditions inaccurate. 


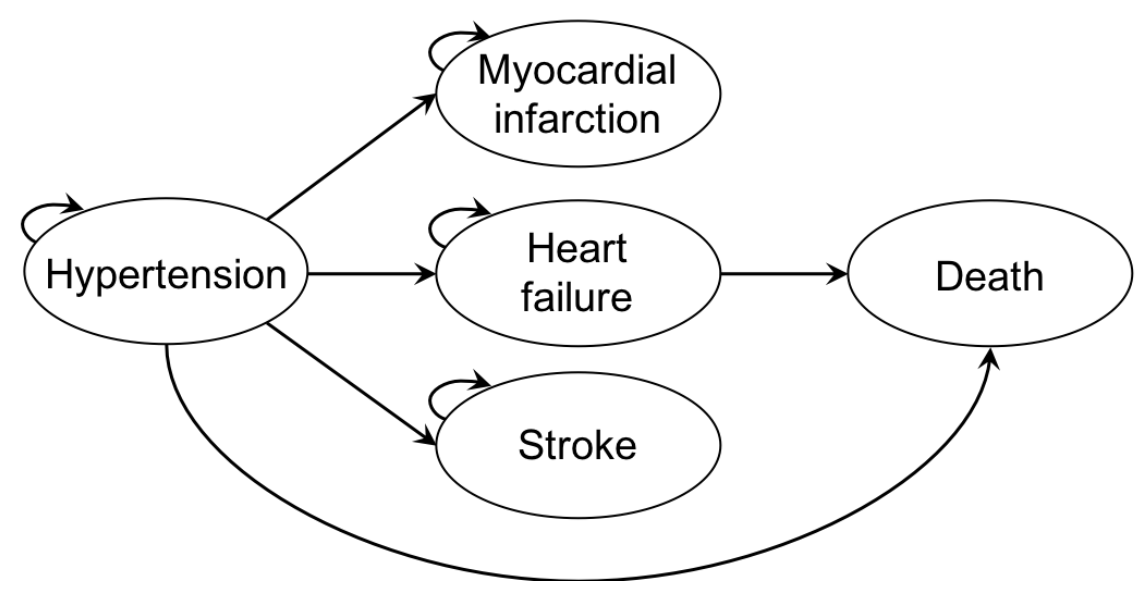

Figure 3.9 Schematic representation of a Markov model.

\subsubsection{Discrete Event Simulation (DES)}

In a DES, the experience of individuals is modelled over time in terms of the events that occur and the consequences of those events. To perform a DES, it is necessary to access the individual data of patients, which are not always available. [136]. Unlike Markov modeling, in which cycles have a fixed length, DES transitions between health states that may occur at varying times. DES is useful for modeling complex conditions with many possible types of events and health states or situations where the patient's history may impact on future events [137].

\subsection{Calculation and Interpretation of Results}

The results of economic analysis are calculated using the costs and probabilities incorporated into the model. To better explain how this calculation is made, we will 
demonstrate an imaginary scenario based on the explanation made by Rascati et al. [114]. A decision tree is used as an example is demonstrated in Figure 3.10. Probabilities and costs used in this example are described in Table 3.2.

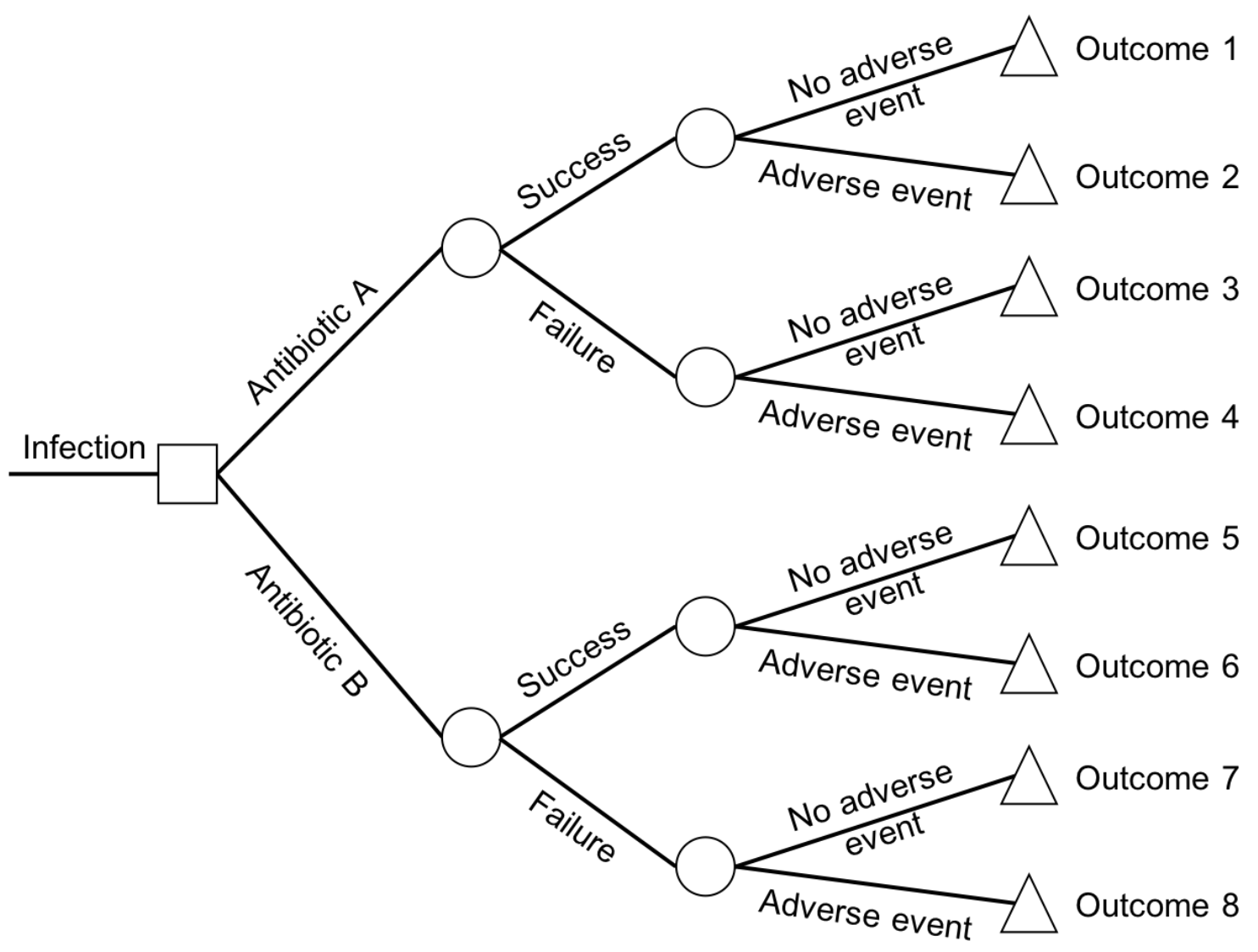

Figure 3.10 Decision tree used as an example to explain the calculations. 
Table 3.2 Probabilities and Costs Used to Explain the Calculations

\begin{tabular}{ccc}
\hline & Antibiotic A & Antibiotic B \\
\hline Probability of success & $90 \%$ & $80 \%$ \\
\hline Probability of failure & $10 \%$ & $20 \%$ \\
\hline Antibiotic cost & $\$ 600$ & $\$ 500$ \\
\hline Probability of adverse event & $10 \%$ & $15 \%$ \\
\hline Probability of no adverse event & $90 \%$ & $85 \%$ \\
\hline Cost of adverse event & $\$ 1,000$ & $\$ 1,000$
\end{tabular}

For each branch in the decision tree, the probability of a patient with infection to have an outcome (end nodes = triangles) is calculated by multiplying the probability of success (or failure) by the probability of adverse event (or no adverse event). The cost for each branch is calculated by adding the costs from the chance nodes (circles) until the end node. In order to estimate the total cost for each therapeutic option (antibiotic A and antibiotic B), cost and probability are multiplied for each branch and then added to generate the final value for each option (Table 3.3). 
Table 3.3 Calculation for the Example of Antibiotics

\begin{tabular}{|c|c|c|c|}
\hline Outcome & Probability & Cost & Probability $x$ \\
\hline
\end{tabular}

\section{Antibiotic A}

\begin{tabular}{lccc}
\hline Outcome 1 & $90 \% \times 90 \%=81 \%$ & $\$ 600$ & $\$ 486$ \\
\hline Outcome 2 & $90 \% \times 10 \%=9 \%$ & $\$ 600+\$ 1,000$ & $\$ 144$ \\
\hline Outcome 3 & $10 \% \times 90 \%=9 \%$ & $\$ 600$ & $\$ 54$ \\
\hline Outcome 4 & $10 \% \times 10 \%=1 \%$ & $\$ 600+\$ 1,000$ & $\$ 16$ \\
\hline Total cost & & & $\$ 700$
\end{tabular}

\section{Antibiotic B}

\begin{tabular}{lccc}
\hline Outcome 5 & $80 \% \times 85 \%=68 \%$ & $\$ 500$ & $\$ 340$ \\
\hline Outcome 6 & $80 \% \times 15 \%=12 \%$ & $\$ 500+\$ 1,000$ & $\$ 180$ \\
\hline Outcome 7 & $20 \% \times 85 \%=17 \%$ & $\$ 500$ & $\$ 85$ \\
\hline Outcome 8 & $20 \% \times 15 \%=3 \%$ & $\$ 500+\$ 1,000$ & $\$ 45$ \\
\hline Total cost & $100 \%$ & & $\$ 650$
\end{tabular}

Using antibiotic A may cost from $\$ 600$ (antibiotic A without adverse event) to $\$ 1,600$ (antibiotic A with adverse event), with a mean total cost of $\$ 700$. While using antibiotic B may cost from $\$ 500$ (antibiotic B without adverse event) to $\$ 1,500$ (antibiotic B without adverse event), with a mean total cost of $\$ 650$. Note that, while antibiotic $A$ has a higher probability of success than antibiotic B $(90 \%$ versus $80 \%)$, antibiotic $B$ is 
less costly (\$650 versus $\$ 700)$. To help decision-makers, economic analysis incorporates the incremental cost-effectiveness ratio (ICER). This ratio is calculated by dividing the difference in total costs (incremental cost) by the difference in effectiveness of the interventions evaluated (incremental effect). In the example, the ICER would be calculated as follows:

\section{ICER $=\Delta$ Costs $\div \Delta$ Outcomes $=$ $(\$ 700-\$ 650) \div(90 \%-80 \%)=$ $\$ 500$ per additional success}

If the decision-makers decided that it is worth expending $\$ 500$ more per additional success, then antibiotic A would be chosen over antibiotic B. This WTP threshold may vary depending on the intervention and the place where the analysis is being performed. Most national thresholds fall within the World Health Organization's recommended range of one-to-three times the per capita gross domestic product (GDP) [138].

While calculating the results, it is important to perform its validation. The validation process can be divided into internal and external validation [139]. Internal validation verifies the accuracy of all mathematical calculations. Preferably, it should be performed by an external researcher. In turn, external validation aims to determine whether the model estimates are coherent with external data sources, such as survival or mortality data [117]. 


\subsection{Sensitivity Analyses}

Sensitivity analyses aim to address the uncertainty of the parameters included in the model. They are concerned with the extent to which the estimated values reflect the "true values" [117]. To perform sensitivity analyses, parameter values are changed through maximum and minimum boundaries and results are calculated within this range. Deterministic and probabilistic sensitivity analyses will be described in the following topics.

\subsubsection{Deterministic Sensitivity Analysis}

The objective of a deterministic sensitivity analysis is to assess how results are sensitive to changes in parameter values [117]. Generally, the range of variation derives from values presented in the literature, for example, the $95 \% \mathrm{Cl}$ reported in clinical trials. The sensitivity analysis can be univariate (one-way), when each parameter varies separately, or multivariate, when two (two-way) or more parameters vary simultaneously [114]. The graphic representation (tornado diagram) of deterministic sensitivity analysis can be seen in Figure 4.5 in the following chapter.

\subsubsection{Probabilistic Sensitivity Analysis}

Probabilistic (or stochastic) sensitivity analysis also aims to address uncertainty. However, differently from deterministic sensitivity analysis, which simply uses a range of values as input, this technique involves the use of distribution curves in which input parameter values are selected by random sampling. Different distributions are 


\section{Chapter 3. Economic Analysis in Health Care}

generally appropriate for different types of parameters [85]. Whenever possible, the sensitivity analysis should be performed by using this method [117]. The graphic representation (acceptability curve) of probabilistic sensitivity analysis can be seen in Figure 4.6 in the following chapter. 


\section{Cost-Utility Analysis of Imaging for Surveillance and Diagnosis of Hepatocellular Carcinoma}

\subsection{Abstract}

\subsubsection{Objective}

The purpose of this study is to compare imaging-based surveillance and diagnostic strategies in patients at risk for HCC while taking into account technically inadequate examinations and patient compliance.

\subsubsection{Materials and Methods}

A Markov model simulated seven strategies for HCC surveillance and diagnosis in cirrhotic patients: strategy A, US for surveillance and CT for diagnosis; strategy B, US for surveillance and MRI for diagnosis; strategy $\mathrm{C}$, US for surveillance and CT for inadequate or positive surveillance; strategy D, US for surveillance and MRI for inadequate or positive surveillance; strategy $\mathrm{E}$, surveillance and diagnosis with $\mathrm{CT}$ followed by MRI for inadequate surveillance; strategy $F$, surveillance and diagnosis with MRI followed by CT for inadequate surveillance; and strategy G, surveillance with abbreviated $\mathrm{MRI}$ followed by $\mathrm{CT}$ for inadequate surveillance or MRI for positive surveillance. Two compliance scenarios were evaluated: optimal and conservative. For 
Chapter 4. Cost-Utility Analysis of Imaging for Surveillance and Diagnosis of Hepatocellular Carcinoma

each scenario, the most cost-effective strategy was based on a willingness-to-pay threshold of Can $\$ 50,000$ per QALY. Sensitivity analyses were performed.

\subsubsection{Results}

Base-case analysis revealed that strategy $E$ was the most cost-effective when compliance was optimal (Can $\$ 13,631 / \mathrm{QALY}$ ), and strategy $\mathrm{G}$ was the most costeffective when compliance was conservative (Can\$39,681/QALY). Sensitivity analyses supported the base-case analysis in the optimal compliance scenario, but several parameters altered the most cost-effective strategy in the conservative compliance scenario.

\subsubsection{Conclusion}

In an optimal compliance scenario, CT for HCC surveillance and diagnosis and MRI for inadequate CT was most cost-effective. In a conservative compliance scenario, abbreviated MRI may be an alternative to US-based surveillance.

\subsection{Introduction}

$\mathrm{HCC}$ is the sixth most common cancer and the second cause of cancer-related deaths worldwide [140]. In Canada, HCC is the only malignancy for which mortality is rising, a trend that is expected to continue through 2020 and beyond [141]. The implementation of surveillance programs targeting high-risk populations, such as cirrhotic patients, has led to the detection of $\mathrm{HCC}$ at earlier stages, when curative 
Chapter 4. Cost-Utility Analysis of Imaging for Surveillance and Diagnosis of Hepatocellular Carcinoma

therapies can be applied [142]. This strategy could reduce the mortality related to HCC, as demonstrated by a large randomized controlled trial [8].

North American guidelines recommend US surveillance every 6 months in atrisk patients $[12,13]$. Although US surveillance is feasible in patients with thin body habitus and without steatosis, it is challenging in obese or those with cirrhosis because of attenuation and heterogeneity of liver appearance, which limit the ability to assess the liver parenchyma $[143,144]$. Furthermore, cirrhosis is often accompanied by a diffusely nodular appearance of liver parenchyma that limits the ability to detect HCC lesions [143]. Alternately, CT, MRI, and abbreviated MRI (which is limited to two or three sequences for lesion detection) have been explored as alternative imaging modalities for HCC surveillance [17, 79-81, 145, 146], and may be used in selected patients who are likely to have inadequate US examinations [12].

Costs attributable to HCC account for a substantial financial burden, are higher when HCC is diagnosed at advanced stages, and are expected to increase until the HCC incidence reaches its peak [4, 7]. Given that health care systems are limited in their financial resources, competing surveillance strategies should be analyzed for their cost-effectiveness. Cost-utility studies, which incorporate the widely applicable QALY, a measure of health outcome, should guide policymakers in their decision to implement alternative surveillance strategies. Prior cost-utility studies that assessed HCC surveillance have not taken into consideration the effect of inconclusive surveillance imaging examinations and patient compliance simultaneously. In this era of imaging- 
Chapter 4. Cost-Utility Analysis of Imaging for Surveillance and Diagnosis of Hepatocellular Carcinoma

based surveillance and diagnosis of $\mathrm{HCC}$, there is a need to investigate the costeffectiveness of different surveillance algorithms.

Therefore, the purpose of this study was to compare imaging-based surveillance and diagnostic strategies in patients at risk for HCC, taking into account technically inadequate examinations and patient compliance.

\subsection{Materials and Methods}

\subsubsection{Model Structure and Population}

A decisional Markov model was developed using TreeAge Pro software (version 2017, TreeAge) to estimate the costs and QALYs associated with imaging-based surveillance and diagnostic strategies for HCC (Figure 4.1). This study was developed from a Canadian health care system perspective and followed the Canadian Guidelines for Economic Evaluation of Health Technologies [117]. 
Chapter 4. Cost-Utility Analysis of Imaging for Surveillance and Diagnosis of Hepatocellular Carcinoma

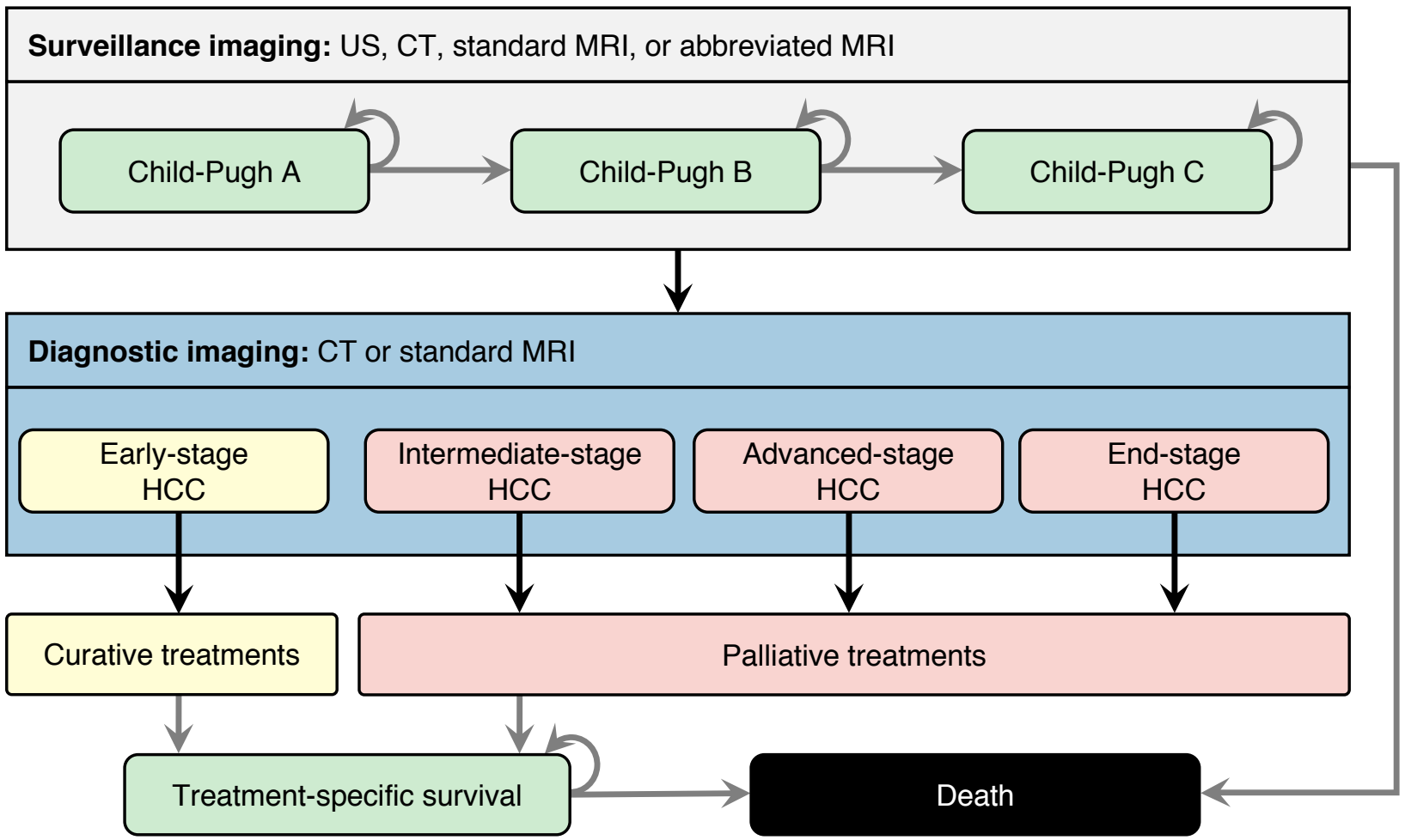

Figure 4.1 Simplified Markov model illustrating surveillance (gray box) and diagnostic imaging techniques (blue box) interposed on health states (green boxes) and temporary states (beige and pink boxes). Gray arrows indicate health state transitions, and black arrows indicate temporary state transitions (management of positive imaging results). $\mathrm{CT}=$ computed tomography, $\mathrm{HCC}=$ hepatocellular carcinoma, $\mathrm{MRI}=$ magnetic resonance imaging, US = ultrasound.

The simulated cohort of high-risk patients with cirrhosis underwent imagingbased surveillance every 6 months (cycle length). At baseline, patients began surveillance at the age of 50 years, the average age of cirrhosis diagnosis $[147,148]$. 
Chapter 4. Cost-Utility Analysis of Imaging for Surveillance and Diagnosis of Hepatocellular Carcinoma

To reflect the full potential of surveillance, an optimal scenario was evaluated, composed of patients with compensated cirrhosis (Child-Pugh class A) at entry, with an assumed patient compliance to surveillance rate of $100 \%$. A conservative scenario was also assessed, using the frequency of compensated cirrhosis and patient compliance to surveillance rates derived from systematic reviews [149, 150].

Imaging-based surveillance and diagnostic strategies and treatment options were superimposed onto the Markov model to reflect clinical options. At each cycle, patients could progress to decompensated cirrhosis (Child-Pugh B or C) or develop HCC or both. Patients with a positive surveillance result were submitted to a diagnostic imaging examination. Those with a positive diagnostic result were treated according to their HCC stage and Child-Pugh class (see Treatment Options subsection later). Survival after each treatment option was modeled. Patients with a negative surveillance or diagnostic result were reinvestigated in the next cycle. In the model, a new HCC could remain undetected until it was discovered by surveillance or the patient experienced symptoms; it was also possible for a patient to die with an undiagnosed HCC. Continued follow-up was made until all patients died (lifetime horizon). Both costs and outcomes were discounted at $1.5 \%$ per year [117]. Model validity was assessed comparing survival rates and diagnostic probabilities found in the model with results presented in published studies.

\subsubsection{Competing Imaging Strategies}

Seven surveillance and diagnostic strategies were investigated, relying on combinations of four imaging techniques: US, CT, MRI, and abbreviated MRI (Figure 
Chapter 4. Cost-Utility Analysis of Imaging for Surveillance and Diagnosis of Hepatocellular Carcinoma

4.2). Strategies A and B used US-based surveillance followed by CT and MRI, respectively, for diagnosis, without additional imaging for inadequate US surveillance examinations. These strategies are recommended by current guidelines [12, 13]. Alternative strategies C and D used US-based surveillance followed by CT and MRI, respectively, for technically inadequate or positive US surveillance. These strategies follow the current recommendations of using US as the first-line surveillance modality, albeit by offering alternative imaging in case of inadequate US [12]. Replacement strategies $\mathrm{E}$ and $\mathrm{F}$ used $\mathrm{CT}$ and $\mathrm{MRI}$, respectively, for surveillance, an approach that reflects the current practice in some North American centers. In cases of technically inadequate surveillance $\mathrm{CT}$ or $\mathrm{MRI}$, the other imaging modality was used for confirmation. Strategy G used abbreviated MRI as surveillance followed by CT for patients with technically inadequate surveillance examinations or MRI for diagnosis of positive surveillance results. This emergent approach was recently proposed in proofof-concept studies [79-81]. 
Chapter 4. Cost-Utility Analysis of Imaging for Surveillance and Diagnosis of Hepatocellular Carcinoma

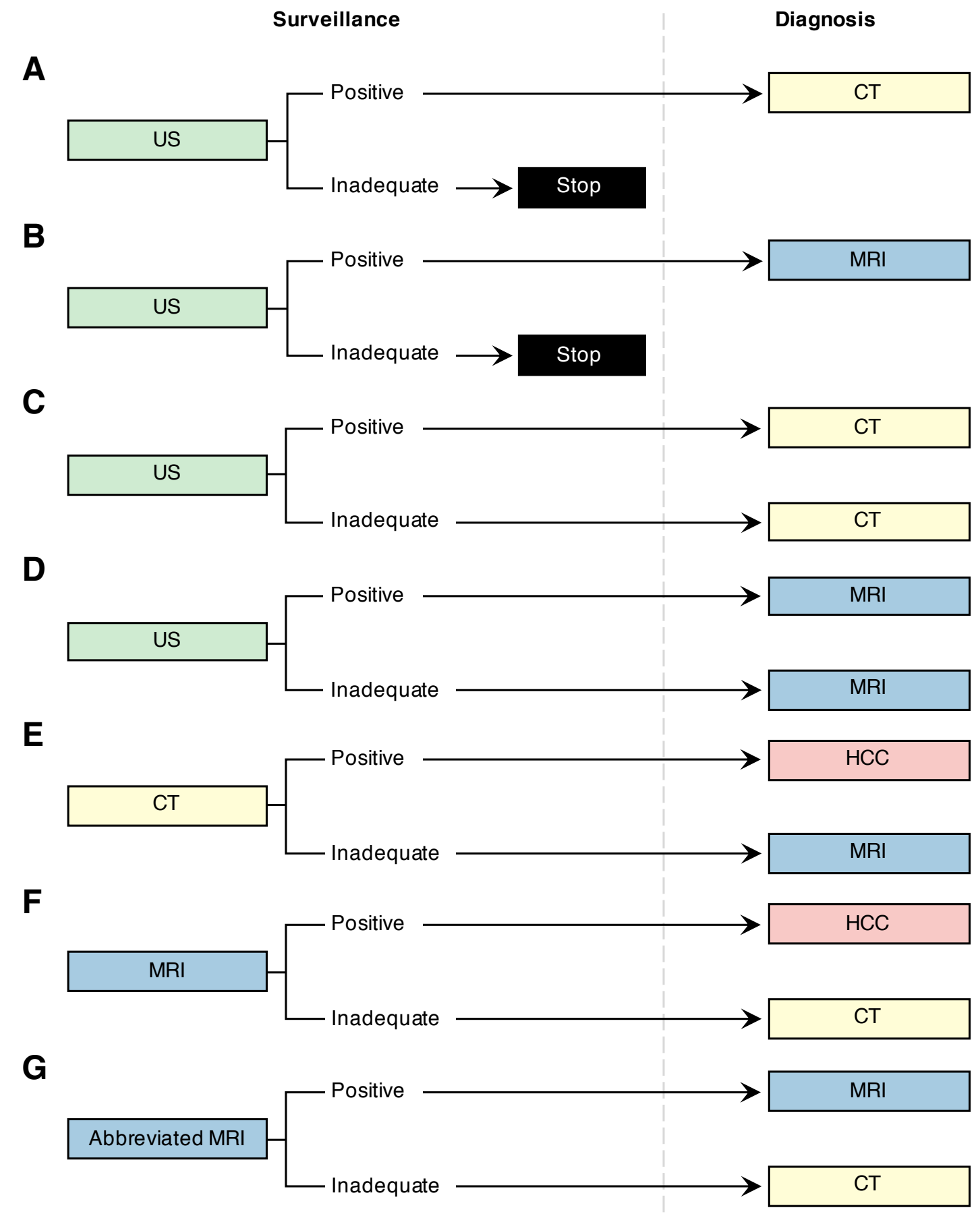

Figure 4.2 Chart of hepatocellular carcinoma (HCC) surveillance and diagnostic strategies $A-G . C T=$ computed tomography, $M R I=$ magnetic resonance imaging, US = ultrasound 
Chapter 4. Cost-Utility Analysis of Imaging for Surveillance and Diagnosis of Hepatocellular Carcinoma

\subsubsection{Treatment Options}

The treatments were modeled based on the Canadian consensus for the management and treatment of HCC [13] (Figure 4.3). Early-stage HCC could be treated with curative treatments, including liver resection, radiofrequency ablation, and LT. Intermediate-stage, advanced-stage, and end-stage HCCs received palliative treatments, such as transarterial chemoembolization, sorafenib, and symptomatic care. The relative proportion of patients eligible for each type of treatment was based on the distribution of treatments in participating North American centers of the international BRIDGE study [151].

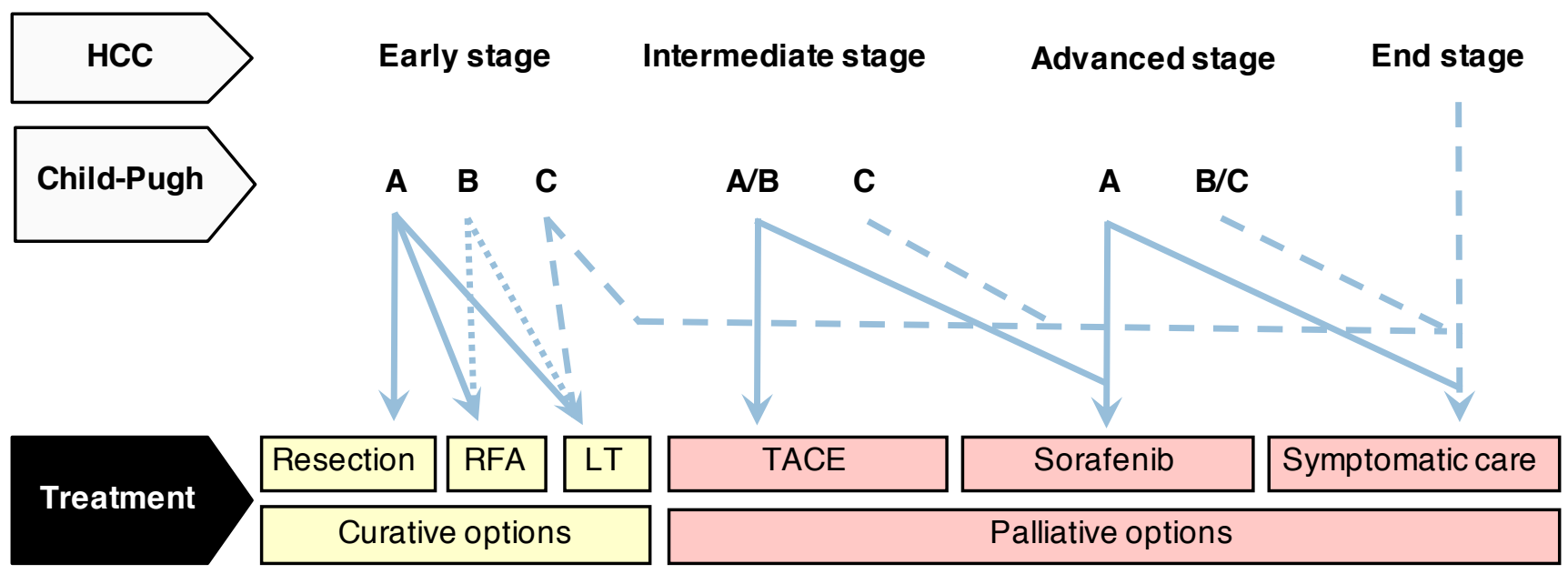

Figure 4.3 Schematic representation of treatment options according to hepatocellular carcinoma (HCC) stage and Child-Pugh class. Adapted with permission from Sherman et al. [13]. LT = liver transplantation, RFA = radiofrequency ablation, TACE $=$ transarterial chemoembolization . 
Chapter 4. Cost-Utility Analysis of Imaging for Surveillance and Diagnosis of Hepatocellular Carcinoma

\subsubsection{Model Parameter Estimates}

A literature research was performed to identify all relevant data that informed the parameters used in our model (Table 4.1 and Table 4.2). Preference was given to meta-analyses, systematic reviews, and clinical trials. Transition probabilities were calculated based on the approach outlined by Miller and Homan for converting rates over time [152]. HCC incidences were based on the threshold incidence for efficacy of surveillance in cirrhotic patients (1.5\%/year) [12] and incidence of HCC reported in the literature [153].

Sensitivity and specificity of US, CT, and MRI were derived from a meta-analysis which pooled estimates of diagnostic performance according to imaging modalities, setting (surveillance and nonsurveillance), and unit of analysis (per patient and per lesion) [78]. Sensitivity and specificity of abbreviated MRI were derived from proof-ofconcept studies [80, 81]. The selected values for US inadequacy were derived from a retrospective study by Simmons et al. [14]. CT and MRI technical failure rates were estimated from studies that assessed frequency of contrast extravasation and claustrophobia, respectively. Contraindication to contrast due to renal dysfunction was also considered [154]. 
Chapter 4. Cost-Utility Analysis of Imaging for Surveillance and Diagnosis of Hepatocellular Carcinoma

Table 4.1 Initial Parameters and Transition Probabilities

\begin{tabular}{lcc}
\hline Parameters & Base Case (Range) & References \\
\hline Discount rate & $1.5(0-5)$ & {$[117]$} \\
\hline Age at entry (y) & $50(40-60)$ & {$[147,148]$} \\
\hline Cirrhosis progression & $5(4-7)$ & {$[150,155]$} \\
\hline HCC incidence & $3(1.5-8)$ & {$[12,153]$} \\
\hline HCC progression & $40(20-70)$ & {$[15,156]$} \\
\hline Incidental or symptomatic early- & $30(0-50)$ & {$[60]$} \\
and intermediate-stage HCC & & Assumption \\
\hline Incidental or symptomatic & $100(50-100)$ & \\
advanced and end-stage HCC & & Assumption \\
\hline Optimal surveillance scenario & & Assumption \\
\hline Child-Pugh class A at entry & 100 & 100 \\
\hline Surveillance compliance & &
\end{tabular}

\section{Conservative surveillance}

scenario

\begin{tabular}{lcc}
\hline Child-Pugh class A at entry & $29(18-50)$ & {$[150]$} \\
Surveillance compliance & $52(38-66)$ & {$[149]$} \\
\hline Mortality & 5 & {$[150]$} \\
\hline Child-Pugh class A $(1 \mathrm{y})^{\mathrm{a}}$ & 20 & {$[150]$} \\
\hline Child-Pugh class B $(1 \mathrm{y})^{\mathrm{a}}$ & &
\end{tabular}


Chapter 4. Cost-Utility Analysis of Imaging for Surveillance and Diagnosis of Hepatocellular Carcinoma

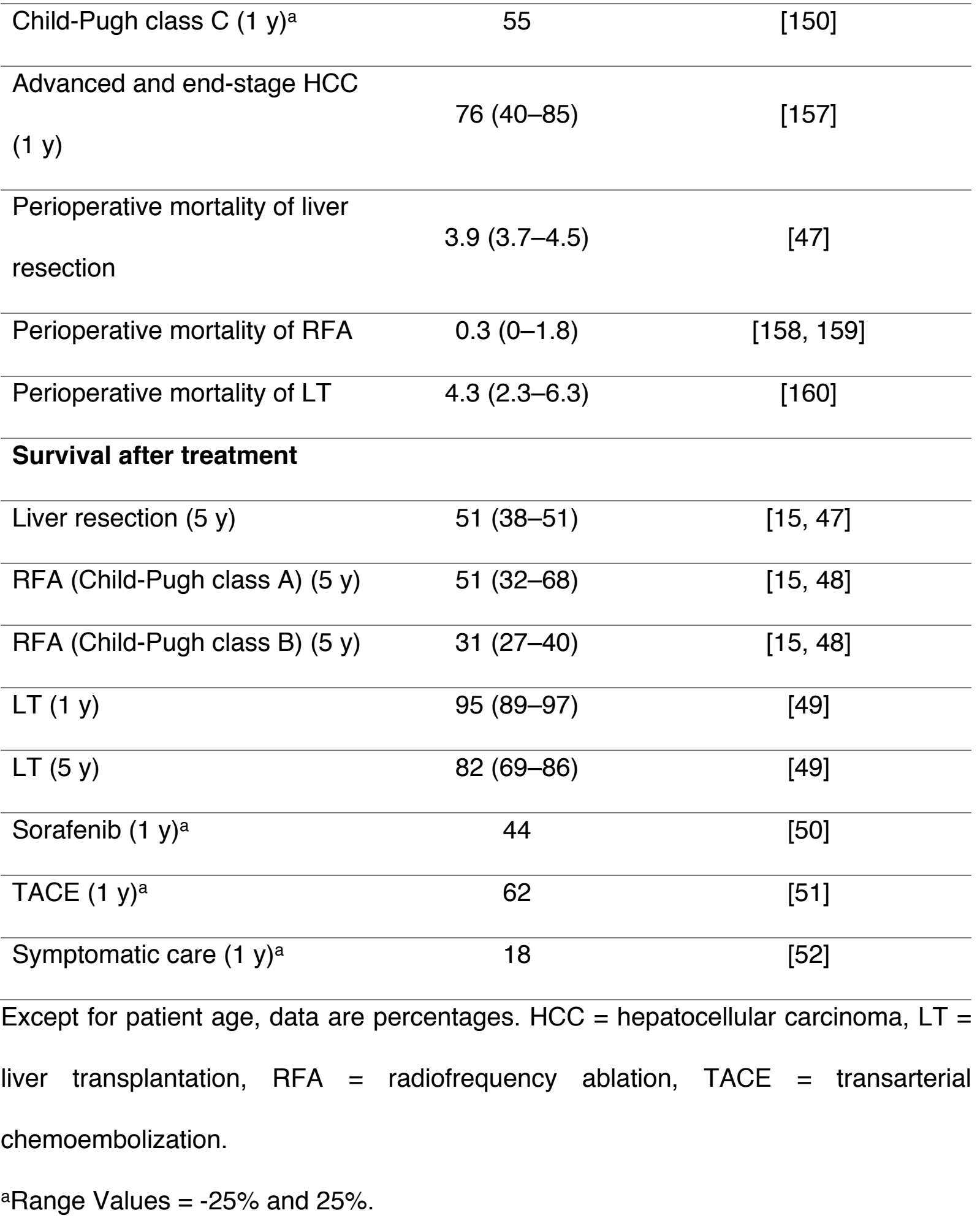


Chapter 4. Cost-Utility Analysis of Imaging for Surveillance and Diagnosis of Hepatocellular Carcinoma

Table 4.2 Imaging Techniques Characteristics

\begin{tabular}{|c|c|c|}
\hline Parameters & $\begin{array}{l}\text { Base Case } \\
\text { (Range) }\end{array}$ & References \\
\hline Surveillance US sensitivity & $78(60-89)$ & [78] \\
\hline Surveillance US specificity & $89(80-94)$ & [78] \\
\hline US technically inadequate rate & $16(0-39)$ & [14] \\
\hline Surveillance CT sensitivity & $84(59-95)$ & [78] \\
\hline Surveillance CT specificity & $99(86-100)$ & [78] \\
\hline Diagnostic CT sensitivity & $76(72-80)$ & [78] \\
\hline Diagnostic CT specificity & $89(84-93)$ & [78] \\
\hline CT technically inadequate rate & $0.7(0.2-0.9)$ & [161-163] \\
\hline Renal dysfunction frequency & $5(0-32)$ & [154] \\
\hline Surveillance MRI sensitivity & $89(82-93)$ & [78] \\
\hline Surveillance MRI specificity & $86(79-91)$ & [78] \\
\hline Diagnostic MRI sensitivity & $83(80-86)$ & [78] \\
\hline Diagnostic MRI specificity & $87(79-93)$ & [78] \\
\hline $\begin{array}{l}\text { Surveillance abbreviated MRI } \\
\text { sensitivity }\end{array}$ & $81(71-91)$ & {$[80,81]$} \\
\hline $\begin{array}{l}\text { Surveillance abbreviated MRI } \\
\text { specificity }\end{array}$ & $96(90-98)$ & {$[80,81]$} \\
\hline MRI technically inadequate rate & $1.2(0.5-1.2)$ & {$[164,165]$} \\
\hline
\end{tabular}


Chapter 4. Cost-Utility Analysis of Imaging for Surveillance and Diagnosis of Hepatocellular Carcinoma

\begin{tabular}{lcc}
\hline Biopsy specificity & $100(80-100)$ & {$[15]$} \\
\hline Biopsy sensitivity & $62(50-100)$ & {$[166]$}
\end{tabular}

Data are percentages. $\mathrm{CT}=$ computed tomography, $\mathrm{MRI}=$ magnetic resonance imaging, US = ultrasound.

\subsubsection{Costs and Utilities}

Costs incorporated into the model were preferably derived from published literature specific to the Canadian health care system (Table 4.3). Values that were not available from Canadian references were converted using a conversion rate of Can $\$ 1.29$ (Canadian dollars) per American dollar or Can $\$ 1.74$ per British pound. Costs of imaging modalities were microcosted from the Ontario Physicians Service [167], the Manitoba Physicians Manual [168], and the Régie de l'assurance maladie du Québec [169] (Table 4.4). The cost of abbreviated MRI was also microcosted (Table 4.5), assuming in the base case an acquisition time of 10 minutes $[79,80]$. In the sensitivity analyses, the acquisition time varied from 5 to 15 minutes. All costs are of 2017 and were adjusted for inflation to 2017 when needed using the national inflation index [124].

Table 4.3 Health-Care Costs and Utilities

Parameters Base Case (Range) References

\section{Costs}

(Canadian dollars, Can\$) 
Chapter 4. Cost-Utility Analysis of Imaging for Surveillance and Diagnosis of Hepatocellular Carcinoma

\begin{tabular}{|c|c|c|}
\hline US & $86(68-261)$ & Table 4.4 \\
\hline CT & $140(105-147)$ & Table 4.4 \\
\hline MRI & $419(351-484)$ & Table 4.4 \\
\hline Abbreviated MRI & $262(158-368)$ & Table 4.5 \\
\hline Liver biopsy & $995(500-1,990)$ & [15] \\
\hline Specialist consultation & $159(106-159)$ & [167] \\
\hline False positive follow-up & $1,800(900-3,600)$ & [15] \\
\hline Liver resectiona $^{\mathrm{a}}$ & 25,917 & [170] \\
\hline $\mathrm{RFA}^{\mathrm{a}}$ & 20,260 & [170] \\
\hline TACE $^{a}$ & 16,658 & [171] \\
\hline Sorafenib & $\begin{array}{c}54,923(50,696- \\
59,149)\end{array}$ & [172] \\
\hline Symptomatic care $^{a}$ & 5,000 & [170] \\
\hline LT (1 y) & $\begin{array}{c}124,204(67,420- \\
180,988)\end{array}$ & [4] \\
\hline LT (long term) & $\begin{array}{c}25,000(18,756- \\
31,260)\end{array}$ & [173] \\
\hline
\end{tabular}

\section{Utilities}

Child-Pugh class A cirrhosis $\quad 0.80(0.64-0.96) \quad[174,175]$

Child-Pugh classes B and C

cirrhosis

$0.60(0.48-0.72)$

$[174,175]$ 
Chapter 4. Cost-Utility Analysis of Imaging for Surveillance and Diagnosis of Hepatocellular Carcinoma

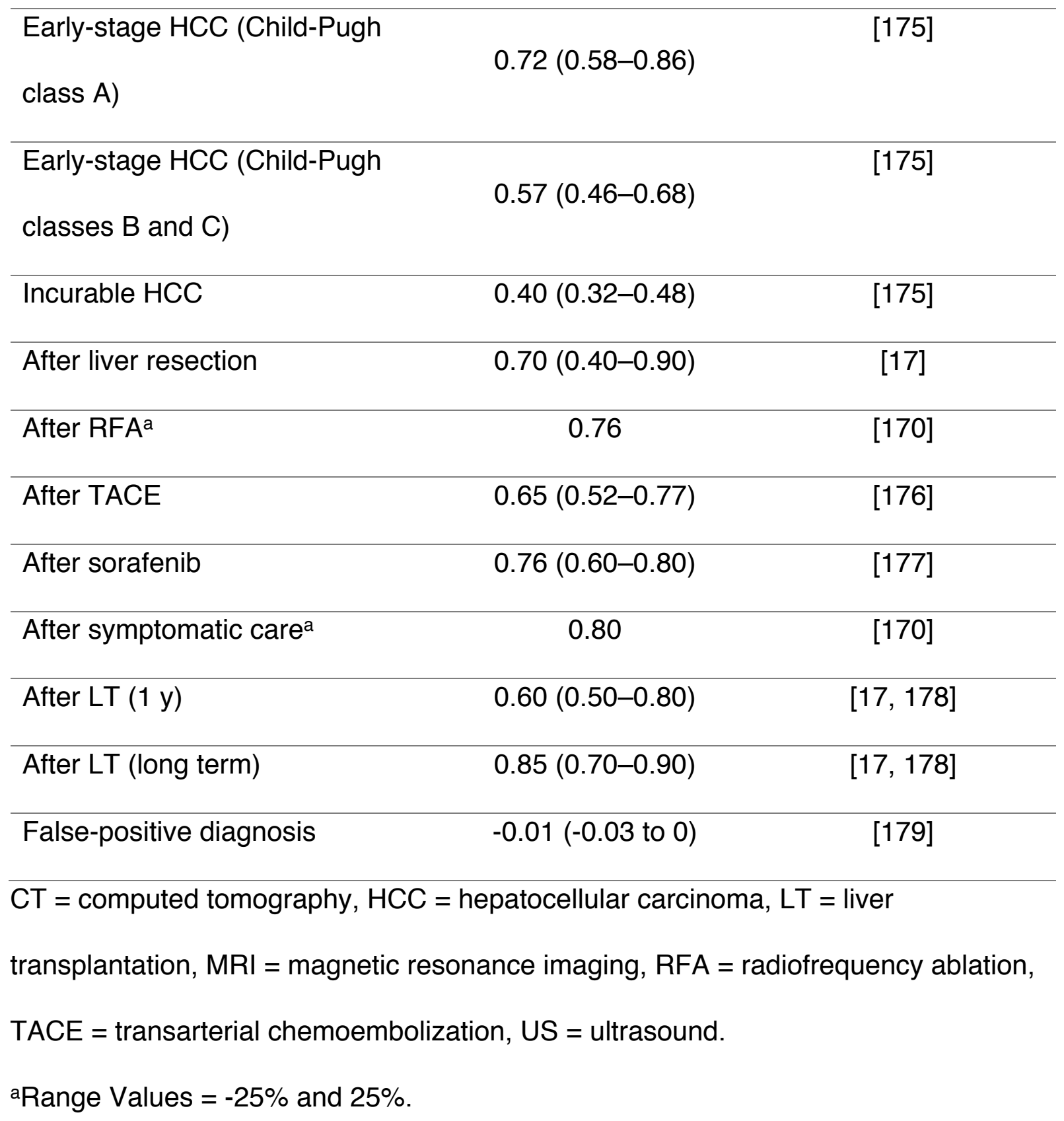


Chapter 4. Cost-Utility Analysis of Imaging for Surveillance and Diagnosis of Hepatocellular Carcinoma

Table 4.4 Micro-Costing of Ultrasound, Computed Tomography, and Magnetic

Resonance Imaging Examinations

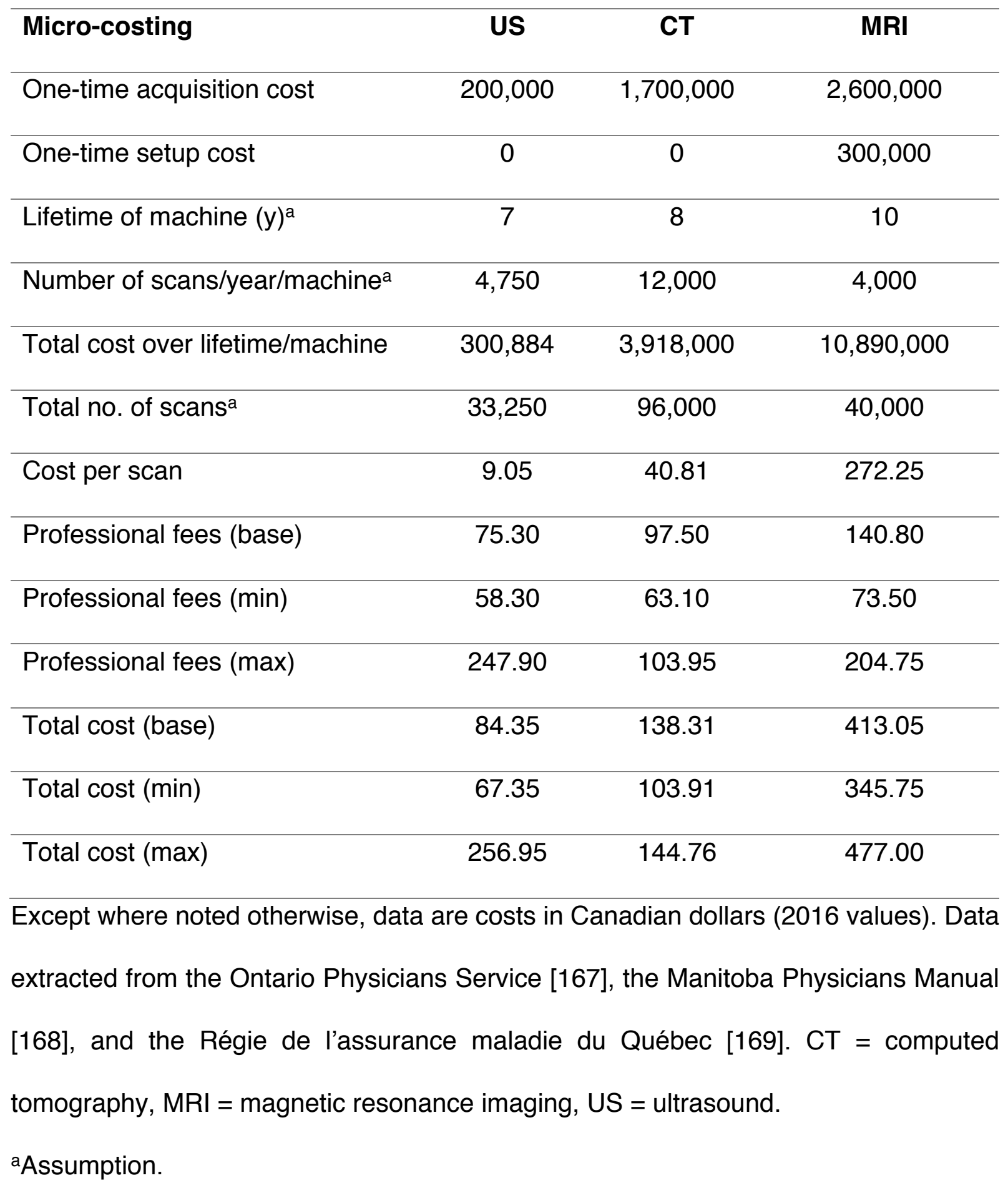


Chapter 4. Cost-Utility Analysis of Imaging for Surveillance and Diagnosis of Hepatocellular Carcinoma

Table 4.5 Micro-Costing of Abbreviated Magnetic Resonance Imaging According to Acquisition Times

\begin{tabular}{|c|c|c|c|}
\hline Micro-costing & 5 minutes & 10 minutes & 15 minutes \\
\hline One-time acquisition cost & $2,600,000$ & $2,600,000$ & $2,600,000$ \\
\hline One-time setup cost & 300,000 & 300,000 & 300,000 \\
\hline Lifetime of machine $(y)^{a}$ & 10 & 10 & 10 \\
\hline No. of scans/year/machine ${ }^{a}$ & 24,000 & 12,000 & 8,000 \\
\hline $\begin{array}{l}\text { Total cost over } \\
\text { lifetime/machine }\end{array}$ & $19,730,000$ & $14,426,000$ & $12,658,000$ \\
\hline Total scans ${ }^{a}$ & 240,000 & 120,000 & 80,000 \\
\hline Cost per scan & 82.21 & 120.22 & 158.23 \\
\hline Professional fees (base) & 140.80 & 140.80 & 140.80 \\
\hline Professional fees (mini) & 73.50 & 73.50 & 73.50 \\
\hline Professional fees (max) & 204.75 & 204.75 & 204.75 \\
\hline Total cost (base) & 223.01 & 261.02 & 299.03 \\
\hline Total cost ( $\mathrm{min})$ & 155.71 & 193.72 & 231.73 \\
\hline Total cost (max) & 286.96 & 324.97 & 362.98 \\
\hline $\begin{array}{l}\text { Except where noted otherwise } \\
\text { extracted from the Ontario } \mathrm{Ph} \\
\text { [168], and the Régie de l'assu }\end{array}$ & $\begin{array}{l}\text { ata are costs } \\
\text { cians Service } \\
\text { ce maladie d }\end{array}$ & $\begin{array}{l}\text { nadian dollar } \\
\text { the Manitob } \\
\text { [169]. }\end{array}$ & $\begin{array}{l}6 \text { values). D } \\
\text { ysicians Man }\end{array}$ \\
\hline
\end{tabular}


Chapter 4. Cost-Utility Analysis of Imaging for Surveillance and Diagnosis of Hepatocellular Carcinoma

A systematic review [174] and a previous cost-effectiveness study [175] provided the data for utilities associated with compensated (Child-Pugh class A) and decompensated (Child-Pugh classes B and C) cirrhosis, as well as HCC stages. Utility data for survival after each treatment option were obtained from different studies [17, 170, 176-178]. A disutility was applied to patients with a false-positive diagnosis to simulate the stress and anxiety associated with an incorrect test result. Utility values for health states are reported in Table 4.3.

\subsubsection{Base-Case Analysis}

Costs, QALYs, and ICERs were calculated for each strategy. The ICER was calculated by dividing the difference in cost by the difference in QALYs compared with the previous less costly and less effective strategy. In the Canadian health care setting, there is not a WTP threshold per se, but rather a range from Can $\$ 20,000$ to Can $\$ 100,000$ per QALY to be considered according to the context [180]. Our study considered a WTP threshold of Can $\$ 50,000$ per QALY, in accordance with previous Canadian studies that assessed the cost-effectiveness of screening interventions [181, 182]. A strategy is considered dominated when it results in a higher cost and lower QALY gain in comparison to another strategy.

\subsubsection{Sensitivity Analyses}

The robustness of our results was assessed in terms of deterministic and probabilistic sensitivity analyses. A one-way deterministic sensitivity analysis was performed using a range of values taken from the published literature for the majority 
Chapter 4. Cost-Utility Analysis of Imaging for Surveillance and Diagnosis of Hepatocellular Carcinoma

of parameters. For parameters without a known interval, sensitivity analysis was performed using a range of $25 \%$ around the base-case estimates, a commonly used approach in pharmacoeconomic analyses [183]. The top five parameters with the greatest effect on ICER were selected for each scenario in the deterministic sensitivity analysis. A probabilistic analysis was performed following the methodology suggested by Briggs et al. [123].

\subsection{Results}

\subsubsection{Base-Case Analyses}

Cost-utility analysis and cost-utility curves are demonstrated in Table 4.6 and Figure 4.4. In the optimal surveillance scenario (100\% patients with Child-Pugh class A disease at entry and 100\% compliance), strategy A (US for surveillance and CT for diagnosis) costs Can $\$ 18,305$ per person with a total utility value of 7.269 QALYs over the patient's lifetime. Strategy E (surveillance and diagnosis with CT followed by MRI for inadequate surveillance) required Can $\$ 1,963$ more per person but also delivered an incremental effectiveness of 0.144 QALYs. This option was found to be the most cost-effective strategy according to the WTP threshold of Can $\$ 50,000 / Q A L Y$, with an ICER of Can\$13,631/QALY. 
Chapter 4. Cost-Utility Analysis of Imaging for Surveillance and Diagnosis of Hepatocellular Carcinoma

Table 4.6 Cost-Utility Analysis

\begin{tabular}{lccccc}
\hline & Cost & & Incremental & Incremental & ICER \\
Strategy & (Can\$) & & Cost (Can\$) & Effectiveness & \\
& & & & (QALY) & (Can\$/QALY)
\end{tabular}

\section{Optimal Scenario}

(100\% Child-Pugh A patients at entry and $100 \%$ surveillance compliance)

A. Surveillance:
US
18,305
7.269

Diagnosis: CT

E. Surveillance:

\section{CT}

If inadequate

surveillance:

$$
\begin{array}{llll}
20,268 & 7.413 & 1,963 & 0.144
\end{array}
$$

13,631

MRI

Diagnosis: CT

F. Surveillance:

MRI

If inadequate

$27,561 \quad 7.424$

7,293

0.011

663,000

surveillance: CT

Diagnosis: MRI

\section{Conservative Scenario}

(29\% Child-Pugh A patients at entry and $52 \%$ surveillance compliance) 
Chapter 4. Cost-Utility Analysis of Imaging for Surveillance and Diagnosis of Hepatocellular Carcinoma

A. Surveillance:
US
9,286
4.300

Diagnosis: CT

C. Surveillance:

US

$\begin{array}{llllll}\text { If inadequate } & 10,400 & 4.332 & 1,114 & 0.032 & 35,108\end{array}$

surveillance: $\mathrm{CT}$

Diagnosis: CT

G. Surveillance:

abbreviated

MRI

If inadequate

$11,273 \quad 4.354$

873

0.022

39,681

surveillance: CT

Diagnosis: MRI

Incremental cost-effectiveness ratio (ICER) was calculated for each strategy by dividing the difference in cost (Canadian dollars, Can\$) by the difference in qualityadjusted life years (QALYs) compared with the previous less costly and less effective strategy. Dominated strategies were not included in the table. CT = computed tomography, $\mathrm{MRI}=$ magnetic resonance imaging, $\mathrm{US}=$ ultrasound. 
Chapter 4. Cost-Utility Analysis of Imaging for Surveillance and Diagnosis of Hepatocellular Carcinoma
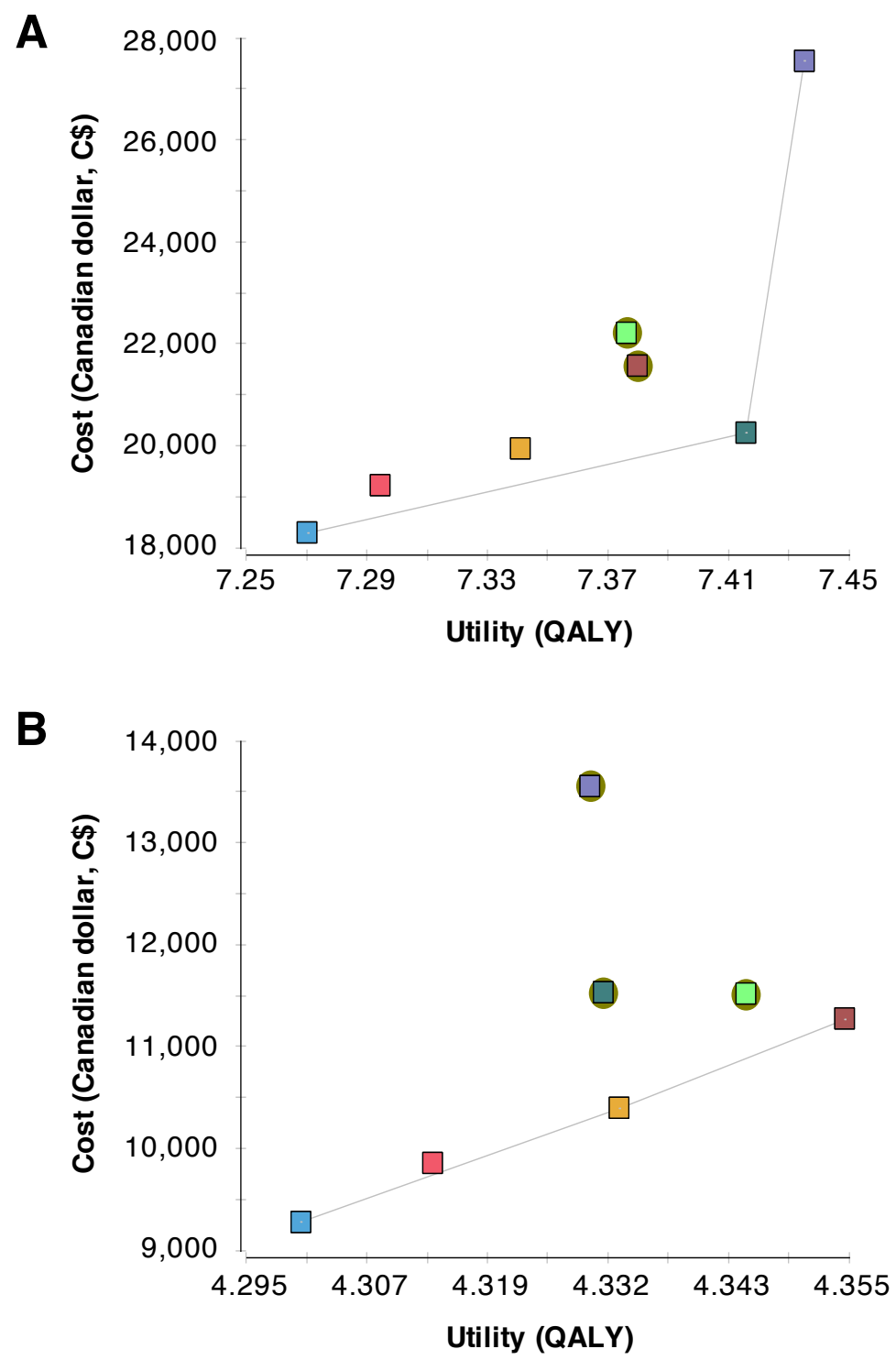

\footnotetext{
$\square$ A. Surveillance (US), diagnosis (CT)

$\square$ B. Surveillance (US), diagnosis (MRI)

$\square$ C. Surveillance (US), inadequate surveillance (CT), diagnosis (CT)

$\square$ D. Surveillance (US), inadequate surveillance (MRI), diagnosis (MRI)

$\square$ E. Surveillance (CT), inadequate surveillance (MRI), diagnosis (CT)

$\square$ F. Surveillance (MRI), inadequate surveillance (CT), diagnosis (MRI)

$\square-$ G. Surveillance (abbreviated MRI), inadequate surveillance (CT), diagnosis (MRI)

- dominated

+ undominated
}

Figure 4.4 Cost-utility curves. A and B, Graphs show cost-utility curves for optimal (A) and conservative $(B)$ surveillance scenarios. $C T=$ computed tomography, $M R I=$ magnetic resonance imaging, QALY = quality-adjusted life year, $U S=$ ultrasound. 
Chapter 4. Cost-Utility Analysis of Imaging for Surveillance and Diagnosis of Hepatocellular Carcinoma

In the conservative surveillance scenario (29\% patients with Child-Pugh class A disease at entry and $52 \%$ surveillance compliance), strategy A costs Can $\$ 9,286$ per person with a total utility value of 4.300 QALYs over the patient's lifetime. Strategy C (US for surveillance and CT for inadequate or positive surveillance) required Can $\$ 1,114$ more per person but also delivered an incremental effectiveness of 0.032 QALYs, with a calculated ICER of Can $\$ 35,108 /$ QALY. Strategy G (surveillance with abbreviated MRI followed by $\mathrm{CT}$ for inadequate surveillance or MRI for positive surveillance) required Can $\$ 873$ more per person and delivered an incremental effectiveness of 0.022 QALYs when compared with strategy C. This option was found to be the most cost-effective strategy according to the WTP threshold, with an ICER of Can\$39,681/QALY.

Model validity was assessed by comparing model predictions with literature values of 1- and 2-year survival for Child-Pugh class A cirrhosis, 3-year survival for surveillance-detected and non-surveillance-detected HCCs, and probability of earlystage HCC detection among patients who underwent or did not undergo surveillance (Table 4.7).

Table 4.7 Model Validation

\section{Parameters}

Model Prediction Literature Values

(Strategy $A^{a}$ )

(References)

1-year survival for Child-Pugh A cirrhosis

$94 \%$

95\% [150] 
Chapter 4. Cost-Utility Analysis of Imaging for Surveillance and Diagnosis of Hepatocellular Carcinoma

2-year survival for Child-Pugh A cirrhosis

$89 \%$

$90 \%[150]$

3-year survival for surveillance-detected

HCCs

$54 \% \quad 51 \%[60]$

3-year survival for symptomatic/incidental

HCCs

$30 \% \quad 28 \%[60]$

\section{Early-stage HCC among patients who}

underwent surveillance

$78 \%$

$71 \%[60]$

Early-stage HCC among patients that did

not undergo surveillance

$38 \% \quad 30 \%[60]$

$\mathrm{HCC}=$ hepatocellular carcinoma.

aUS for surveillance and CT for diagnosis.

\subsubsection{Deterministic Sensitivity Analyses}

Figure 4.5 summarizes one-way sensitivity analyses for optimal and conservative surveillance scenarios. In the optimal scenario, only the surveillance CT sensitivity could exceed the WTP threshold. If the surveillance CT sensitivity was $95 \%$, the ICER would be Can\$11,186/QALY. At a lower limit of 59\%, the ICER increased to Can\$52,321/QALY. 
Chapter 4. Cost-Utility Analysis of Imaging for Surveillance and Diagnosis of Hepatocellular Carcinoma

A

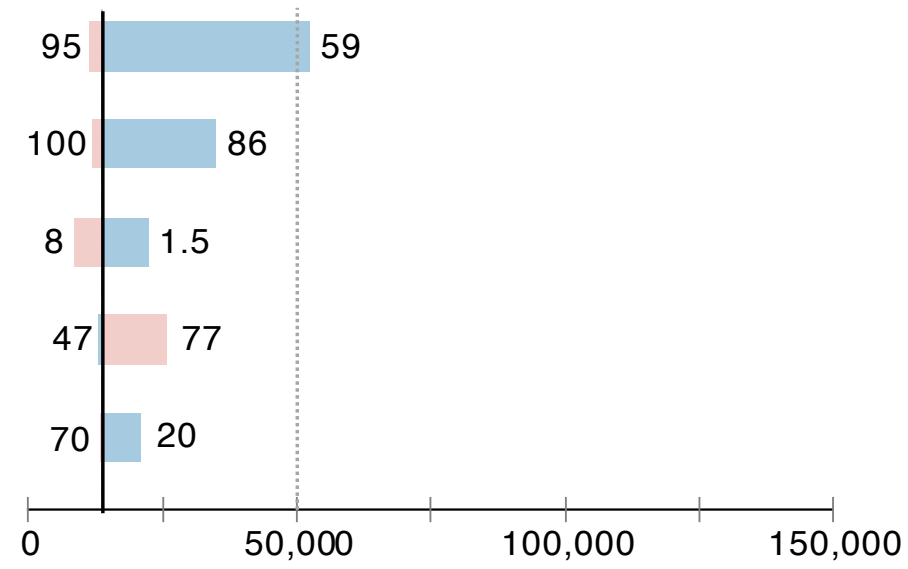

B

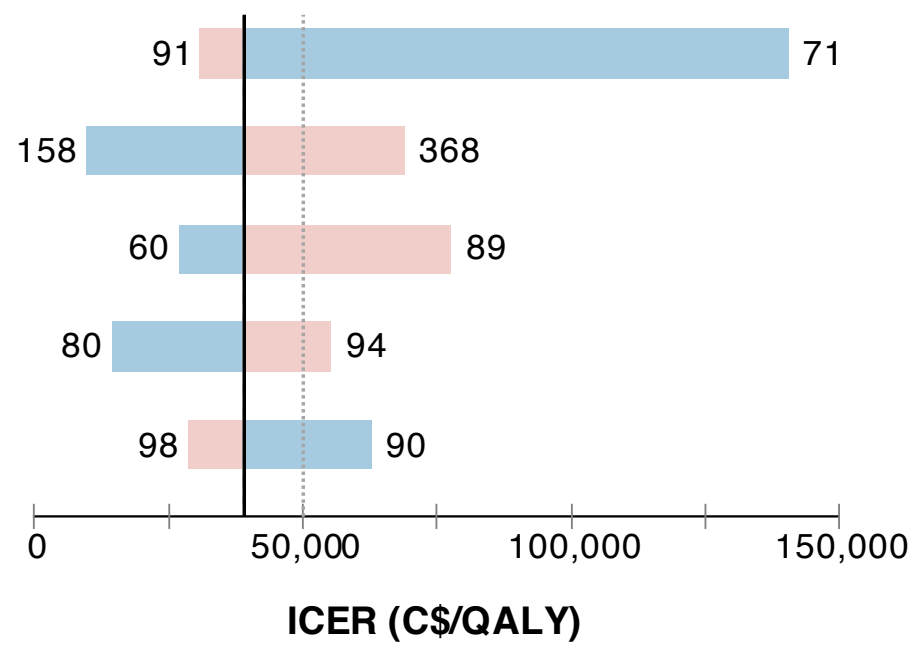

Surveillance CT sensitivity (\%)

Surveillance CT specificity (\%)

Annual HCC incidence (\%)

Annual survival after TACE (\%)

Annual HCC progression (\%)

Surveillance abbreviated MRI sensitivity (\%)

Abbreviated MRI cost (C\$)

Surveillance US sensitivity (\%)

Surveillance US specificity (\%)

Surveillance abbreviated MRI specificity (\%)

Figure 4.5 One-way sensitivity analyses. A and B, Graphs show analyses for optimal (strategy E vs strategy A; A) and conservative (strategy G vs strategy C; B) surveillance scenarios. Black lines represent expected incremental costeffectiveness ratio (ICER) values. Dotted gray lines represent willingness-to-pay threshold. Costs are shown in Canadian dollar (Can\$). HCC = hepatocellular carcinoma, TACE $=$ transarterial chemoembolization, ICER $=$ incremental costeffectiveness ratio, US = ultrasound, $\mathrm{QALY}=$ quality-adjusted life year . 
Chapter 4. Cost-Utility Analysis of Imaging for Surveillance and Diagnosis of Hepatocellular Carcinoma

In the conservative scenario, all the top five parameters could exceed the WTP threshold: the sensitivity, specificity, and cost for abbreviated MRI and the sensitivity and specificity for surveillance US. The sensitivity of abbreviated MRI for surveillance varied from $71 \%$ to $91 \%$, leading to ICER values ranging from Can $\$ 140,556 / Q A L Y$ to Can $\$ 30,435 / Q A L Y$. The abbreviated MRI cost varied from Can $\$ 158$ to Can $\$ 368$, leading to ICER values ranging from Can\$9,483/QALY to Can $\$ 68,791 / \mathrm{QALY}$. This range of costs includes the values of 5-minute (Can\$158-293), 10-minute (Can\$198331), and 15-minute (Can\$236-368) abbreviated MRI protocols. The surveillance US sensitivity varied from $60 \%$ to $89 \%$, leading to ICER values ranging from Can\$26,704/QALY to Can\$77,489/QALY. The specificity of surveillance US varied from $80 \%$ to $94 \%$, leading to ICER values ranging from Can $\$ 14,261$ to Can $\$ 55,129$. The specificity of abbreviated MRI for surveillance varied from $90 \%$ to $98 \%$, leading to ICER values ranging from Can $\$ 62,671$ to Can $\$ 28,529$.

\subsubsection{Probabilistic Sensitivity Analyses}

Figure 4.6 summarizes the probabilistic sensitivity analyses for both optimal and conservative surveillance scenarios. This analysis evaluates the impact of uncertainty using distribution curves for each parameter instead of value ranges. In the optimal surveillance scenario, strategy E was the most likely cost-effective strategy, with a probability of $73 \%$ at the WTP threshold. In the conservative surveillance scenario, strategy G was the most likely cost-effective strategy, with a probability of $79 \%$ at the WTP threshold. 
Chapter 4. Cost-Utility Analysis of Imaging for Surveillance and Diagnosis of Hepatocellular Carcinoma
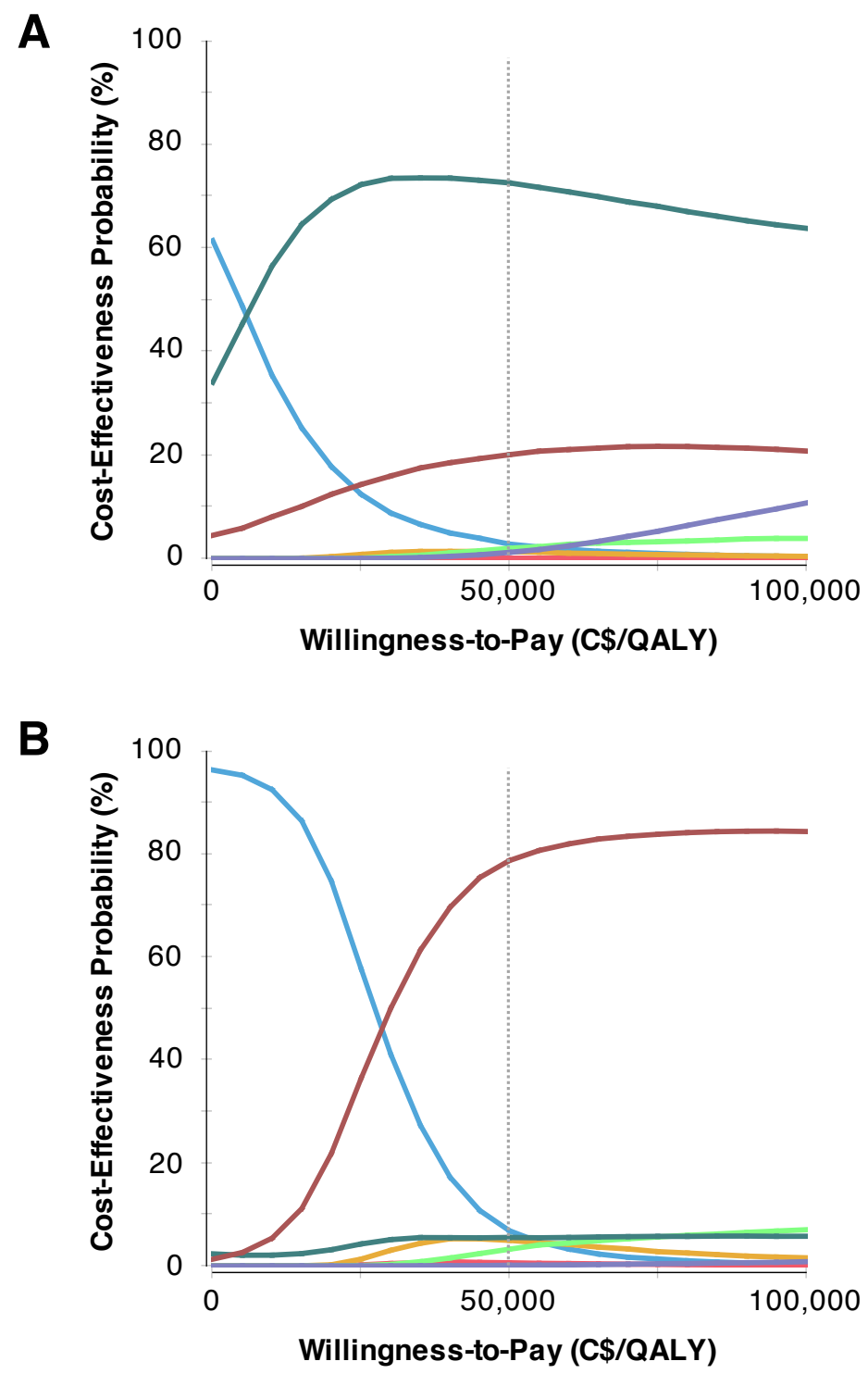

A. Surveillance (US), diagnosis (CT)

B. Surveillance (US), diagnosis (MRI)

C. Surveillance (US), inadequate surveillance (CT), diagnosis (CT)

D. Surveillance (US), inadequate surveillance (MRI), diagnosis (MRI)

E. Surveillance (CT), inadequate surveillance (MRI), diagnosis (CT)

F. Surveillance (MRI), inadequate surveillance (CT), diagnosis (MRI)

G. Surveillance (abbreviated $M R I)$, inadequate surveillance (CT), diagnosis (MRI)

Figure 4.6 Acceptability curves after 10,000 iterations. A and B, Graphs show acceptability curves (A) and conservative (B) surveillance scenarios. Dotted gray lines represent willingness-to-pay threshold. Costs are shown in Canadian dollars (Can\$). QALY = quality-adjusted life year, US = ultrasound. 
Chapter 4. Cost-Utility Analysis of Imaging for Surveillance and Diagnosis of Hepatocellular Carcinoma

\subsection{Discussion}

This study complements prior cost-effectiveness studies on HCC surveillance [15-18] by comparing US, CT, MRI, and abbreviated MRI as options for HCC surveillance and by taking into account the effect of inconclusive surveillance imaging examinations and patient compliance. Our model relied on current knowledge of hepatocarcinogenesis, clinical practice guidelines for the treatment of $\mathrm{HCC}$, and performance of imaging tests from a meta-analysis. The incidence, transition probabilities, costs, and utilities were based on a literature review. Furthermore, the validity of our model was supported by similarities between predicted values and data found in the literature.

To evaluate the full effect of surveillance, an optimal scenario was assessed, where all patients started surveillance when they had compensated cirrhosis (ChildPugh class A) and the compliance to surveillance was $100 \%$. However, because liver fibrosis and compensated cirrhosis are asymptomatic conditions, a large number of patients may be unaware of their condition [147]. Furthermore, the HCC surveillance compliance is suboptimal, with an overall rate of only $52 \%$ [149]. Thus, a conservative scenario analysis was also modeled.

As expected, all strategies in the optimal scenario delivered more QALYs than in the conservative scenario. This finding corroborates the importance of surveillance in improving health outcomes and justifies the development of programs to increase compliance. A mailed outreach program conducted by Singal et al. [184] and a clinical 
Chapter 4. Cost-Utility Analysis of Imaging for Surveillance and Diagnosis of Hepatocellular Carcinoma

reminder program implemented by Beste et al. [185], for example, had encouraging results, but further efforts are still needed.

In the optimal surveillance scenario, the most cost-effective strategy was strategy E (surveillance and diagnosis with CT followed by MRI for inadequate surveillance). According to deterministic sensitivity analysis, strategy E exceeded the WTP threshold only if the sensitivity of surveillance CT decreased to nearly $59 \%$. Such a low sensitivity has been reported only in the evaluation of lesions smaller than $10 \mathrm{~mm}$ [78], for which current guidelines do not recommend additional investigation or shortterm follow-up management [12]. Hence, the results of the base-case analysis were essentially confirmed by the sensitivity analyses at the WTP threshold.

Strategies relying on a single examination for both surveillance and diagnosis (such as strategy E) are prone to higher rates of false-positive diagnoses. This is a legitimate concern, because false-positive diagnoses may expose healthy patients to psychologic stress and treatment risks and increase their health care expenditures $[186,187]$. Furthermore, patients on the LT waiting list may receive additional exception points for $\mathrm{HCC}$ on the basis of a false-positive diagnosis. Hence, the choice of imagingbased surveillance and diagnostic strategies may have downstream effects on organ allocation [188].

In the conservative surveillance scenario, the most cost-effective strategy was G (surveillance with abbreviated MRI followed by $\mathrm{CT}$ for inadequate surveillance or MRI for positive surveillance). According to deterministic sensitivity analysis, strategy $G$ exceeded the WTP threshold depending on the sensitivity and specificity of abbreviated 
Chapter 4. Cost-Utility Analysis of Imaging for Surveillance and Diagnosis of Hepatocellular Carcinoma

MRI in a surveillance setting and the cost of the abbreviated MRI. Of note, the abbreviated MRI cost is directly related to the examination duration. An abbreviated MRI protocol could reduce the current 20- to 40 -minute examination time to only 5-15 minutes [79-81]. According to our results, a 15-minute abbreviated MRI would not be cost-effective, whereas a 5- or 10-minute abbreviated MRI protocol had the potential to be cost-effective. Also, if the sensitivity and specificity of surveillance US were higher than the base-case estimates, strategy $\mathrm{G}$ may become less cost-effective than strategy C (US for surveillance and CT for inadequate or positive surveillance). Interestingly, the probabilistic sensitivity analysis also favored strategy G at a WTP threshold of Can $\$ 50,000 / Q A L Y$.

Abbreviated MRI protocols aim to offer a lower-cost alternative to MRI while preserving the advantages of MRI technique, such as high contrast and absence of ionizing radiation. However, to date, only retrospective simulations have assessed this emergent approach [79-81]. Further prospective or randomized studies may be required to assess the diagnostic performance of abbreviated MRI in an HCC surveillance setting before the introduction of this approach in large population-based surveillance programs.

There are limitations to our study. There is a knowledge gap in the literature concerning the costs and utilities associated with false-positive diagnoses of HCC. The cost of follow-up for a false-positive diagnosis of HCC was based on values reported by Andersson et al. [15], whereas the disutility associated with a false-positive diagnosis was based on a cost-effectiveness study of patients undergoing evaluation 
Chapter 4. Cost-Utility Analysis of Imaging for Surveillance and Diagnosis of Hepatocellular Carcinoma

for coronary artery disease [179]. Thus, our model may overestimate the costeffectiveness of strategies that use the same imaging modality for surveillance and diagnosis (which are prone to higher rates of false-positive diagnosis). Another limitation was that abbreviated MRI sensitivity and specificity were derived from retrospective simulations. Furthermore, some values incorporated into the model were assumed by the authors or derived from American and British sources and may not reflect the Canadian perspective. Finally, concerns regarding radiation associated with CT were not modeled. Although one may consider unacceptable the cumulative radiation burden associated with a surveillance program, we understand that the radiation exposure is less important for the population undergoing HCC surveillance due to its age and life expectancy [189].

\subsection{Conclusion}

In conclusion, in a scenario that assumes optimal patient compliance and takes into account inconclusive imaging examinations, CT for HCC surveillance and diagnosis and MRI for inadequate CT was most cost-effective. However, in a scenario that assumes conservative patient compliance and also takes into account inconclusive imaging examinations, abbreviated MRI may be a cost-effective alternative to the current US-surveillance practice. Before implementing a surveillance program incorporating imaging modalities other than US, future studies should address the economic burden associated with false-positive HCC diagnoses. Also, future 
Chapter 4. Cost-Utility Analysis of Imaging for Surveillance and Diagnosis of Hepatocellular Carcinoma

prospective trials should assess the accuracy of abbreviated MRI examinations in a surveillance setting. 


\section{Conclusion}

$\mathrm{HCC}$ is a significant complication associated with chronic liver disease. It is the sixth most common cancer and the fourth cause of cancer-related deaths worldwide [1]. Despite the existence of well-established surveillance recommendations [12, 13, 64], the clinical practice may be challenging. Several subgroups, such as obese patients, those with Child-Pugh B or C cirrhosis, or NAFLD-related cirrhosis, are subject to inadequate US surveillance [14]. The research in this dissertation emerged from the need to evaluate which is the most cost-effective surveillance strategy for these patients.

To reach this objective, we developed a Markov model using TreeAge Pro software. Seven strategies were compared relying on the combinations of four imaging techniques: US, CT, MRI, and abbreviated MRI. Our model was validated by comparing model predictions with literature values $[60,150]$.

Considering the inconclusive imaging examinations, our results demonstrated that $\mathrm{CT}$ for HCC surveillance and diagnosis and MRI for inadequate $\mathrm{CT}$ is the most cost-effective strategy in scenarios with optimal patient compliance. However, in scenarios with low patient compliance, abbreviated MRI for HCC surveillance, followed by MRI for diagnosis, or CT for inadequate abbreviated MRI, is the most cost-effective alternative to the current US-surveillance practice. 
By performing this economic analysis, we realized that an individual approach, considering the clinical particularities of the patients, is more cost-effective than the current "one-size-fits-all" strategy. New technologies have introduced us to the era of individualized medicine, particularly in the oncological field. Our findings support this perspective and are in accordance with previously published studies [18, 190, 191].

We anticipate that centers located in low-income regions may experience difficulties in implementing the new approach suggested by our work, which is based on the use of more expensive imaging modalities. However, in centers where these modalities are already available, the results presented in this research could guide physicians to adopt the best possible practice tailored to their patient's body habitus and prior history of technically inadequate examinations.

I hope that the results presented here may positively impact the lives of those who live with liver disease and help to mitigate the social and economic burden associated with HCC. Furthermore, I would like to encourage those who are interested in this subject to perform studies that address the gaps still present in the literature, such as the economic burden associated with false-positive HCC diagnoses and the accuracy of abbreviated MRI in the surveillance setting. 


\section{Bibliography}

\section{Bibliography}

1. Ferlay J, Ervik M, Lam F, et al. Global cancer observatory: cancer today (2018). International Agency for Reseach on Cancer. gco.iarc.fr/today/help. Published 2018. Accessed 27 September, 2018

2. De P, Dryer D, Otterstatter MC, Semenciw R. Canadian trends in liver cancer: a brief clinical and epidemiologic overview. Curr Oncol 2013; $20: e 40-43$

3. Dyer Z, Peltekian K, van Zanten SV. Review article: the changing epidemiology of hepatocellular carcinoma in Canada. Aliment Pharmacol Ther 2005; 22:17-22

4. Myers RP, Krajden M, Bilodeau M, et al. Burden of disease and cost of chronic hepatitis C infection in Canada. Can J Gastroenterol Hepatol 2014; 28:243-250

5. Modelling the incidence and prevalence of hepatitis $C$ infection and its sequelae in Canada, 2007. Public Health Agency of Canada website. www.canada.ca/en/public-health/services/infectious-diseases/surveillanceepidemiology-sexually-transmitted-infections-hep-b-c/modelling-incidenceprevalence-hepatitis-infection-sequelae.html. Published March 2010. Accessed October 23, 2018

6. Mantovani LG, Strazzabosco M. Healthcare costs associated with hepatocellular carcinoma and the value of care. Hepatology 2013; 58:1213-1214 


\section{Bibliography}

7. Thein $\mathrm{HH}$, Isaranuwatchai $\mathrm{W}$, Campitelli MA, et al. Health care costs associated with hepatocellular carcinoma: a population-based study. Hepatology 2013; $58: 1375-1384$

8. Zhang BH, Yang BH, Tang ZY. Randomized controlled trial of screening for hepatocellular carcinoma. J Cancer Res Clin Oncol 2004; 130:417-422

9. Yang JD, Mannalithara A, Piscitello AJ, et al. Impact of surveillance for hepatocellular carcinoma on survival in patients with compensated cirrhosis. Hepatology 2018; 68:78-88

10. Mittal S, Kanwal F, Ying J, et al. Effectiveness of surveillance for hepatocellular carcinoma in clinical practice: A United States cohort. Journal of Hepatology 2016; 65:1148-1154

11. Drummond MF, Sculpher MJ, Claxton K, et al. Methods for the economic evaluation of health care programmes, 4th ed. Oxford, UK: Oxford Univesity Press, 2015

12. Marrero JA, Kulik LM, Sirlin C, et al. Diagnosis, staging, and management of hepatocellular carcinoma: 2018 practice guidance by the American Association for the Study of Liver Diseases. Hepatology 2018; 68:723-750

13. Sherman M, Burak K, Maroun J, et al. Multidisciplinary Canadian consensus recommendations for the management and treatment of hepatocellular carcinoma. Curr Oncol 2011; 18:228-240 


\section{Bibliography}

14. Simmons O, Fetzer DT, Yokoo T, et al. Predictors of adequate ultrasound quality for hepatocellular carcinoma surveillance in patients with cirrhosis. Aliment Pharmacol Ther 2017; 45:169-177

15. Andersson KL, Salomon JA, Goldie SJ, Chung RT. Cost effectiveness of alternative surveillance strategies for hepatocellular carcinoma in patients with cirrhosis. Clin Gastroenterol Hepatol 2008; 6:1418-1424

16. Thompson Coon J, Rogers G, Hewson P, et al. Surveillance of cirrhosis for hepatocellular carcinoma: a cost-utility analysis. Br J Cancer 2008; 98:11661175

17. Arguedas MR, Chen VK, Eloubeidi MA, Fallon MB. Screening for hepatocellular carcinoma in patients with hepatitis C cirrhosis: a cost-utility analysis. Am J Gastroenterol 2003; 98:679-690

18. Goossens N, Singal AG, King LY, et al. Cost-Effectiveness of risk score-stratified hepatocellular carcinoma screening in patients with cirrhosis. Clin Transl Gastroenterol 2017; 8:e101

19. Schiff ER, Maddrey WC, Sorrell MF. Schiff's Diseases of the Liver. WileyBlackwell, 2011

20. Canadian Cancer Statistics Advisory Commitee. Canadian Cancer Statistics 2013. Canadian Cancer Society website. cancer.ca/Canadian-CancerStatistics-2013-EN. Published May 2013. Accessed November 6, 2018 


\section{Bibliography}

21. Canadian Cancer Statistics Advisory Commitee. Canadian Cancer Statistics 2018. Canadian Cancer Society website. cancer.ca/Canadian-CancerStatistics-2018-EN. Published June 2018. Accessed December 3, 2018

22. Parkin DM, Bray F, Ferlay J, Pisani P. Global cancer statistics, 2002. CA Cancer J Clin 2005; 55:74-108

23. El-Serag HB, Davila JA, Petersen NJ, McGlynn KA. The continuing increase in the incidence of hepatocellular carcinoma in the United States: an update. Ann Intern Med 2003; 139:817-823

24. El-Serag HB, Rudolph KL. Hepatocellular carcinoma: epidemiology and molecular carcinogenesis. Gastroenterology 2007; 132:2557-2576

25. Hashim D, Boffetta P, La Vecchia C, et al. The global decrease in cancer mortality: trends and disparities. Ann Oncol 2016; 27:926-933

26. Ghouri YA, Mian I, Rowe JH. Review of hepatocellular carcinoma: epidemiology, etiology, and carcinogenesis. J Carcinog 2017; 16:1

27. Zhang DY, Friedman SL. Fibrosis-dependent mechanisms of hepatocarcinogenesis. Hepatology 2012; 56:769-775

28. C, Akinyemiju T, Abera S, Ahmed M, et al. The burden of primary liver cancer and underlying etiologies from 1990 to 2015 at the global, regional, and national level: results from the Global Burden of Disease Study 2015. JAMA Oncol 2017; 3:1683-1691

29. Bosch FX, Ribes J, Diaz M, Cleries R. Primary liver cancer: worldwide incidence and trends. Gastroenterology 2004; 127:S5-S16 


\section{Bibliography}

30. Zampino R, Boemio A, Sagnelli C, et al. Hepatitis B virus burden in developing countries. World J Gastroenterol 2015; 21:11941-11953

31. Papatheodoridis GV, Hadziyannis E, Tsochatzis E, et al. Serum apoptotic caspase activity in chronic hepatitis $\mathrm{C}$ and nonalcoholic fatty liver disease. J Clin Gastroenterol 2010; 44:e87-95

32. Sung JJ, Tsoi KK, Wong VW, Li KC, Chan HL. Meta-analysis: treatment of hepatitis B infection reduces risk of hepatocellular carcinoma. Aliment Pharmacol Ther 2008; 28:1067-1077

33. Chang MH, Chen CJ, Lai MS, et al. Universal hepatitis B vaccination in Taiwan and the incidence of hepatocellular carcinoma in children. Taiwan Childhood Hepatoma Study Group. N Engl J Med 1997; 336:1855-1859

34. Yoshizawa H. Hepatocellular carcinoma associated with hepatitis C virus infection in Japan: projection to other countries in the foreseeable future. Oncology 2002; 62 Suppl 1:8-17

35. Lok AS, Everhart JE, Wright EC, et al. Maintenance peginterferon therapy and other factors associated with hepatocellular carcinoma in patients with advanced hepatitis C. Gastroenterology 2011; $140: 840-849$; quiz e812

36. McGlynn KA, London WT. Epidemiology and natural history of hepatocellular carcinoma. Best Pract Res Clin Gastroenterol 2005; 19:3-23

37. Reau N, Poordad FF. Primary liver cancer: surveillance, diagnosis, and treatment. Humana Press, 2012 


\section{Bibliography}

38. Van der Meer AJ, Veldt BJ, Feld JJ, et al. Association between sustained virological response and all-cause mortality among patients with chronic hepatitis C and advanced hepatic fibrosis. JAMA 2012; 308:2584-2593

39. George SL, Bacon BR, Brunt EM, et al. Clinical, virologic, histologic, and biochemical outcomes after successful HCV therapy: a 5-year follow-up of 150 patients. Hepatology 2009; 49:729-738

40. Bosch FX, Ribes J, Borras J. Epidemiology of primary liver cancer. Semin Liver Dis 1999; 19:271-285

41. Welzel TM, Graubard BI, Zeuzem S, et al. Metabolic syndrome increases the risk of primary liver cancer in the United States: a study in the SEER-Medicare database. Hepatology $2011 ; 54: 463-471$

42. Mittal S, El-Serag HB. Epidemiology of hepatocellular carcinoma: consider the population. J Clin Gastroenterol 2013; 47 Suppl:S2-6

43. Tang A, Hallouch O, Chernyak V, Kamaya A, Sirlin CB. Epidemiology of hepatocellular carcinoma: target population for surveillance and diagnosis. Abdominal radiology (New York) 2018; 43:13-25

44. Okuda K, Ohtsuki $\mathrm{T}$, Obata $\mathrm{H}$, et al. Natural history of hepatocellular carcinoma and prognosis in relation to treatment. Study of 850 patients. Cancer 1985; $56: 918-928$

45. Trevisani F, Cantarini MC, Wands JR, Bernardi M. Recent advances in the natural history of hepatocellular carcinoma. Carcinogenesis 2008; 29:1299-1305 


\section{Bibliography}

46. Hamilton JP. Epigenetic mechanisms involved in the pathogenesis of hepatobiliary malignancies. Epigenomics 2010; 2:233-243

47. Llovet JM, Fuster J, Bruix J. Intention-to-treat analysis of surgical treatment for early hepatocellular carcinoma: resection versus transplantation. Hepatology 1999; 30:1434-1440

48. Lencioni R, Cioni D, Crocetti L, et al. Early-stage hepatocellular carcinoma in patients with cirrhosis: long-term results of percutaneous image-guided radiofrequency ablation. Radiology 2005; 234:961-967

49. She WH, Chan ACY, Cheung TT, et al. Survival outcomes of liver transplantation for hepatocellular carcinoma in patients with normal, high, and very high preoperative alpha-fetoprotein levels. World J Hepatol 2018; 10:308-318

50. Nakano M, Tanaka M, Kuromatsu R, et al. Sorafenib for the treatment of advanced hepatocellular carcinoma with extrahepatic metastasis: a prospective multicenter cohort study. Cancer Med 2015; 4:1836-1843

51. Wang P, Sheng L, Wang G, et al. Association of transarterial chemoembolization with survival in patients with unresectable hepatocellular carcinoma. Mol Clin Oncol 2014; 2:203-206

52. Cabibbo G, Enea M, Attanasio M, et al. A meta-analysis of survival rates of untreated patients in randomized clinical trials of hepatocellular carcinoma. Hepatology 2010; 51:1274-1283

53. El-Serag HB, Mason AC. Rising incidence of hepatocellular carcinoma in the United States. N Engl J Med 1999; 340:745-750 


\section{Bibliography}

54. Sugano S, Miyoshi K, Suzuki T, et al. Intrahepatic arteriovenous shunting due to hepatocellular carcinoma and cirrhosis, and its change by transcatheter arterial embolization. Am J Gastroenterol 1994; 89:184-188

55. Kew MC, Dos Santos HA, Sherlock S. Diagnosis of primary cancer of the liver. Br Med J 1971; 4:408-411

56. Llovet JM, Bru C, Bruix J. Prognosis of hepatocellular carcinoma: the BCLC staging classification. Semin Liver Dis 1999; 19:329-338

57. Fitzmorris P, Singal AK. Surveillance and diagnosis of hepatocellular carcinoma. Gastroenterol Hepatol 2015; 11:38-46

58. Meissner HI, Smith RA, Rimer BK, et al. Promoting cancer screening: learning from experience. Cancer 2004; 101:1107-1117

59. Singal AG, Mittal S, Yerokun OA, et al. Hepatocellular carcinoma screening associated with early tumor detection and improved survival among patients with cirrhosis in the US. Am J Med 2017; 130:1099-1106 e1091

60. Singal AG, Pillai A, Tiro J. Early detection, curative treatment, and survival rates for hepatocellular carcinoma surveillance in patients with cirrhosis: a metaanalysis. PLoS Med 2014; 11:e1001624

61. Collier J, Sherman M. Screening for hepatocellular carcinoma. Hepatology 1998; 27:273-278

62. Tanaka N, Ichijo T, Okiyama W, et al. Laparoscopic findings in patients with nonalcoholic steatohepatitis. Liver Int 2006; 26:32-38 


\section{Bibliography}

63. Trevisani F, De Notariis S, Rapaccini G, et al. Semiannual and annual surveillance of cirrhotic patients for hepatocellular carcinoma: effects on cancer stage and patient survival (Italian experience). Am J Gastroenterol 2002; $97: 734-744$

64. European Association for the Study of the Liver. EASL clinical practice guidelines: management of hepatocellular carcinoma. J Hepatol 2018; 69:182236

65. Burak KW, Sherman M. Hepatocellular carcinoma: consensus, controversies, and future directions. A report from the Canadian Association for the Study of the Liver Hepatocellular Carcinoma Meeting. Can J Gastroenterol Hepatol 2015; 29:178-184

66. Lin OS, Keeffe EB, Sanders GD, Owens DK. Cost-effectiveness of screening for hepatocellular carcinoma in patients with cirrhosis due to chronic hepatitis C. Aliment Pharmacol Ther 2004; 19:1159-1172

67. Sarasin FP, Giostra E, Hadengue A. Cost-effectiveness of screening for detection of small hepatocellular carcinoma in western patients with Child-Pugh class A cirrhosis. Am J Med 1996; 101:422-434

68. Fattovich G, Giustina G, Sanchez-Tapias J, et al. Delayed clearance of serum HBsAg in compensated cirrhosis B: relation to interferon alpha therapy and disease prognosis. European Concerted Action on Viral Hepatitis (EUROHEP). Am J Gastroenterol 1998; 93:896-900 


\section{Bibliography}

69. Bruix J, Sherman M. Management of hepatocellular carcinoma: an update. Hepatology 2011; 53:1020-1022

70. Kew MC. Epidemiology of chronic hepatitis B virus infection, hepatocellular carcinoma, and hepatitis B virus-induced hepatocellular carcinoma. Pathol Biol (Paris) 2010; 58:273-277

71. Sakuma K, Saitoh N, Kasai M, et al. Relative risks of death due to liver disease among Japanese male adults having various statuses for hepatitis B $\mathrm{s}$ and $\mathrm{e}$ antigen/antibody in serum: a prospective study. Hepatology 1988; 8:1642-1646

72. Beasley RP, Lin CC, Chien CS, et al. Geographic distribution of HBsAg carriers in China. Hepatology 1982; 2:553-556

73. Kew MC, Macerollo P. Effect of age on the etiologic role of the hepatitis B virus in hepatocellular carcinoma in blacks. Gastroenterology 1988; 94:439-442

74. Yu MW, Chang HC, Liaw YF, et al. Familial risk of hepatocellular carcinoma among chronic hepatitis B carriers and their relatives. J Natl Cancer Inst 2000; 92:1159-1164

75. Maxim LD, Niebo R, Utell MJ. Screening tests: a review with examples. Inhal Toxicol 2014; 26:811-828

76. Boal Carvalho P, Pereira E. Imagiological diagnosis of gastrointestinal diseases - diagnostic criteria of hepatocellular carcinoma. GE Port J Gastroenterol 2015; 22:153-160

77. Nowicki TK, Markiet K, Szurowska E. Diagnostic imaging of hepatocellular carcinoma - a pictorial essay. Curr Med Imaging Rev 2017; 13:140-153 


\section{Bibliography}

78. Chou R, Cuevas C, Fu R, et al. Imaging techniques for the diagnosis of hepatocellular carcinoma: a systematic review and meta-analysis. Ann Intern Med 2015; 162:697-711

79. Lee JY, Huo EJ, Weinstein S, et al. Evaluation of an abbreviated screening MRI protocol for patients at risk for hepatocellular carcinoma. Abdom Radiol (NY) $2018 ; 43: 1627-1633$

80. Besa C, Lewis S, Pandharipande PV, et al. Hepatocellular carcinoma detection: diagnostic performance of a simulated abbreviated MRI protocol combining diffusion-weighted and T1-weighted imaging at the delayed phase post gadoxetic acid. Abdom Radiol (NY) 2017; 42:179-190

81. Marks RM, Ryan A, Heba ER, et al. Diagnostic per-patient accuracy of an abbreviated hepatobiliary phase gadoxetic acid-enhanced MRI for hepatocellular carcinoma surveillance. AJR Am J Roentgenol 2015; 204:527535

82. Singal AG, Conjeevaram HS, Volk ML, et al. Effectiveness of hepatocellular carcinoma surveillance in patients with cirrhosis. Cancer Epidemiol Biomarkers Prev 2012; 21:793-799

83. Tang A, Bashir MR, Corwin MT, et al. Evidence supporting LI-RADS major features for CT- and MR imaging-based diagnosis of hepatocellular carcinoma: a systematic review. Radiology 2018; 286:29-48

84. Elsayes KM, Hooker JC, Agrons MM, et al. 2017 version of LI-RADS for CT and MR imaging: an update. Radiographics 2017; 37:1994-2017 


\section{Bibliography}

85. American College of Radiology. Liver imaging reporting and data system version 2018. American College of Radiology website. www.acr.org/ClinicalResources/Reporting-and-Data-Systems/LI-RADS/CT-MRI-LI-RADS-v2018.

Published July 2018. Accessed November 15, 2018

86. Arslanoglu A, Seyal AR, Sodagari F, et al. Current guidelines for the diagnosis and management of hepatocellular carcinoma: a comparative review. AJR Am J Roentgenol 2016; 207:W88-W98

87. Pons F, Varela M, Llovet JM. Staging systems in hepatocellular carcinoma. HPB (Oxford) 2005; 7:35-41

88. Vauthey JN, Lauwers GY, Esnaola NF, et al. Simplified staging for hepatocellular carcinoma. J Clin Oncol 2002; 20:1527-1536

89. Villa E, Colantoni A, Camma C, et al. Estrogen receptor classification for hepatocellular carcinoma: comparison with clinical staging systems. J Clin Oncol $2003 ; 21: 441-446$

90. Kudo M, Chung H, Osaki Y. Prognostic staging system for hepatocellular carcinoma (CLIP score): its value and limitations, and a proposal for a new staging system, the Japan Integrated Staging Score (JIS score). J Gastroenterol 2003; 38:207-215

91. Leung TW, Tang AM, Zee B, et al. Construction of the Chinese University Prognostic Index for hepatocellular carcinoma and comparison with the TNM staging system, the Okuda staging system, and the Cancer of the Liver Italian 


\section{Bibliography}

Program staging system: a study based on 926 patients. Cancer 2002; 94:17601769

92. Prospective validation of the CLIP score: a new prognostic system for patients with cirrhosis and hepatocellular carcinoma. The Cancer of the Liver Italian Program (CLIP) Investigators. Hepatology 2000; 31:840-845

93. Chevret S, Trinchet JC, Mathieu D, et al. A new prognostic classification for predicting survival in patients with hepatocellular carcinoma. Groupe d'Etude et de Traitement du Carcinome Hepatocellulaire. J Hepatol 1999; 31:133-141

94. Llovet JM, Burroughs A, Bruix J. Hepatocellular carcinoma. Lancet 2003; 362:1907-1917

95. Bruix J, Llovet JM. Prognostic prediction and treatment strategy in hepatocellular carcinoma. Hepatology 2002; 35:519-524

96. Torzilli G, Belghiti J, Kokudo N, et al. A snapshot of the effective indications and results of surgery for hepatocellular carcinoma in tertiary referral centers: is it adherent to the EASL/AASLD recommendations?: an observational study of the HCC East-West study group. Ann Surg 2013; 257:929-937

97. Liu CL, Fan ST, Lo CM, et al. Management of spontaneous rupture of hepatocellular carcinoma: single-center experience. J Clin Oncol 2001; 19:37253732

98. Llovet JM, Di Bisceglie AM, Bruix J, et al. Design and endpoints of clinical trials in hepatocellular carcinoma. J Natl Cancer Inst 2008; 100:698-711 


\section{Bibliography}

99. Margarit C, Escartin A, Castells L, et al. Resection for hepatocellular carcinoma is a good option in Child-Turcotte-Pugh class A patients with cirrhosis who are eligible for liver transplantation. Liver Transpl 2005; 11:1242-1251

100. Bigourdan JM, Jaeck D, Meyer N, et al. Small hepatocellular carcinoma in Child A cirrhotic patients: hepatic resection versus transplantation. Liver Transpl 2003; 9:513-520

101. Yao FY, Ferrell L, Bass NM, et al. Liver transplantation for hepatocellular carcinoma: comparison of the proposed UCSF criteria with the Milan criteria and the Pittsburgh modified TNM criteria. Liver Transpl 2002; 8:765-774

102. Livraghi T, Meloni F, Di Stasi M, et al. Sustained complete response and complications rates after radiofrequency ablation of very early hepatocellular carcinoma in cirrhosis: is resection still the treatment of choice? Hepatology $2008 ; 47: 82-89$

103. Lee MW, Raman SS, Asvadi NH, et al. Radiofrequency ablation of hepatocellular carcinoma as bridge therapy to liver transplantation: a 10-year intention-to-treat analysis. Hepatology 2017; 65:1979-1990

104. Llovet JM, Bruix J. Systematic review of randomized trials for unresectable hepatocellular carcinoma: chemoembolization improves survival. Hepatology $2003 ; 37: 429-442$

105. Arii S, Yamaoka Y, Futagawa S, et al. Results of surgical and nonsurgical treatment for small-sized hepatocellular carcinomas: a retrospective and 


\section{Bibliography}

nationwide survey in Japan. The Liver Cancer Study Group of Japan. Hepatology 2000; 32:1224-1229

106. Coletta M, Nicolini D, Benedetti Cacciaguerra A, et al. Bridging patients with hepatocellular cancer waiting for liver transplant: all the patients are the same? Transl Gastroenterol Hepatol 2017; 2:78

107. Cheng AL, Kang YK, Chen Z, et al. Efficacy and safety of sorafenib in patients in the Asia-Pacific region with advanced hepatocellular carcinoma: a phase III randomised, double-blind, placebo-controlled trial. Lancet Oncol 2009; 10:25-34

108. Llovet JM, Ricci S, Mazzaferro V, et al. Sorafenib in advanced hepatocellular carcinoma. N Engl J Med 2008; 359:378-390

109. Kumar M, Panda D. Role of supportive care for terminal stage hepatocellular carcinoma. J Clin Exp Hepatol 2014; 4:S130-139

110. World Health Organization. Global Health Expenditure Database. World Health Organization website. apps.who.int/nha/database/Home/Index/en. Published April 2019. Accessed 3 April, 2019

111. Williams A. Cost-effectiveness analysis: is it ethical? J Med Ethics 1992; 18:711

112. Matjasko JL, Cawley JH, Baker-Goering MM, Yokum DV. Applying behavioral economics to public health policy: illustrative examples and promising directions. Am J Prev Med 2016; 50:S13-S19

113. Jamison DT, Breman JG, Measham AR, et al. Priorities in Health. Washington (DC), 2006 


\section{Bibliography}

114. Rascati KL. Essentials of Pharmacoeconomics, 2nd ed. Lippincott Williams \& Wilkins, 2014

115. Whitehead SJ, Ali S. Health outcomes in economic evaluation: the QALY and utilities. Br Med Bull 2010; 96:5-21

116. Pettitt DA, Naughton B, Roscoe A, et al. The limitations of QALY: a literature review. J Stem Cell Res Ther 2010; 6:207

117. Canadian Agency for Drugs and Technologies in Health. Guidelines for the economic evaluation of health technologies: Canada, 4th ed. Canadian Agency for Drugs and Technologies in Health website. www.cadth.ca/about-cadth/howwe-do-it/methods-and-guidelines/guidelines-for-the-economic-evaluation-ofhealth-technologies-canada. Published March 2017. Accessed February 6, 2019

118. Sculpher M. Subgroups and heterogeneity in cost-effectiveness analysis. Pharmacoeconomics 2008; 26:799-806

119. Phelps CE. Good technologies gone bad: how and why the cost-effectiveness of a medical intervention changes for different populations. Med Decis Making $1997 ; 17: 107-117$

120. Byford S, Raftery J. Perspectives in economic evaluation. BMJ 1998; 316:15291530

121. Jonsson B. Ten arguments for a societal perspective in the economic evaluation of medical innovations. Eur J Health Econ 2009; 10:357-359 


\section{Bibliography}

122. McGhan WF, Al M, Doshi JA, et al. The ISPOR good practices for quality improvement of Cost-Effectiveness Research Task Force Report. Value Health $2009 ; 12: 1086-1099$

123. Briggs $\mathrm{AH}$, Claxton $\mathrm{K}$, Sculpher MJ. Making decision models probabilistic. In: Briggs AH, Claxton K, Sculpher MJ, eds. Decision modelling for health economic evaluation. Oxford, UK: Oxford University Press, 2006:77-120

124. Bank of Canada. Inflation calculator. Bank of Canada website. www.bankofcanada.ca/rates/related/inflation-calculator. Accessed October 18, 2017

125. Severens JL, Milne RJ. Discounting health outcomes in economic evaluation: the ongoing debate. Value Health 2004; 7:397-401

126. Xu X, Grossetta Nardini HK, Ruger JP. Micro-costing studies in the health and medical literature: protocol for a systematic review. Syst Rev 2014; 3:47

127. McDonough CM, Tosteson AN. Measuring preferences for cost-utility analysis: how choice of method may influence decision-making. Pharmacoeconomics $2007 ; 25: 93-106$

128. Parkin D, Devlin N. Is there a case for using visual analogue scale valuations in cost-utility analysis? Health Econ 2006; 15:653-664

129. Karimi M, Brazier J. Health, health-related quality of life, and quality of life: what is the difference? Pharmacoeconomics 2016; 34:645-649

130. Bottomley A, Flechtner $\mathrm{H}$, Efficace $\mathrm{F}$, et al. Health related quality of life outcomes in cancer clinical trials. Eur J Cancer 2005; 41:1697-1709 


\section{Bibliography}

131. Devlin NJ, Brooks R. EQ-5D and the EuroQol Group: past, present, and future. Appl Health Econ Health Policy 2017; 15:127-137

132. Balestroni G, Bertolotti G. [EuroQol-5D (EQ-5D): an instrument for measuring quality of life]. Monaldi Arch Chest Dis 2012; 78:155-159

133. EQ-5D Instruments, About EQ-5D. EQ-5D website. https://euroqol.org/eq-5dinstruments/. Accessed May 20, 2019

134. Sun X, Faunce T. Decision-analytical modelling in health-care economic evaluations. Eur J Health Econ 2008; 9:313-323

135. McCullough AJ. The clinical features, diagnosis and natural history of nonalcoholic fatty liver disease. Clinics in liver disease 2004; 8:521-533

136. Caro JJ, Moller J, Getsios D. Discrete event simulation: the preferred technique for health economic evaluations? Value Health 2010; 13:1056-1060

137. Discrete event simulation. York Health Economics Consortium website. https://www.yhec.co.uk/glossary/discrete-event-simulation. Published 2016. Accessed December 10, 2018

138. Cameron D, Ubels J, Norstrom F. On what basis are medical cost-effectiveness thresholds set? Clashing opinions and an absence of data: a systematic review. Glob Health Action 2018; 11:1447828

139. Eddy DM, Hollingworth W, Caro JJ, et al. Model transparency and validation: a report of the ISPOR-SMDM Modeling Good Research Practices Task Force-7. Med Decis Making 2012; 32:733-743 


\section{Bibliography}

140. Ferenci $P$, Fried M, Labrecque D, et al. Hepatocellular carcinoma (HCC): a global perspective. J Clin Gastroenterol 2010; 44:239-245

141. Canadian Liver Foundation. Liver disease in Canada: a crisis in the making. Canadian Liver Foundation website. www.liver.ca/wp-content/uploads/2017/09/ CLF_LiverDiseaselnCanada_Synopsis_E.pdf. Published March 2013. Accessed August 20, 2017

142. Yuen MF, Cheng CC, Lauder IJ, et al. Early detection of hepatocellular carcinoma increases the chance of treatment: Hong Kong experience. Hepatology 2000; 31:330-335

143. Del Poggio P, Olmi S, Ciccarese F, et al. Factors that affect efficacy of ultrasound surveillance for early stage hepatocellular carcinoma in patients with cirrhosis. Clin Gastroenterol Hepatol 2014; 12:1927-1933 e1922

144. Uppot RN, Sahani DV, Hahn PF, et al. Effect of obesity on image quality: fifteenyear longitudinal study for evaluation of dictated radiology reports. Radiology $2006 ; 240: 435-439$

145. Kim SY, An J, Lim YS, et al. MRI with liver-specific contrast for surveillance of patients with cirrhosis at high risk of hepatocellular carcinoma. JAMA Oncol $2017 ; 3: 456-463$

146. Sutherland T, Watts J, Ryan M, et al. Diffusion-weighted MRI for hepatocellular carcinoma screening in chronic liver disease: direct comparison with ultrasound screening. J Med Imaging Radiat Oncol 2017; 61:34-39 


\section{Bibliography}

147. Scaglione S, Kliethermes S, Cao G, et al. The epidemiology of cirrhosis in the United States: a population-based study. J Clin Gastroenterol 2015; 49:690-696

148. Ratib S, West J, Crooks CJ, Fleming KM. Diagnosis of liver cirrhosis in England, a cohort study, 1998-2009: a comparison with cancer. Am J Gastroenterol 2014; 109:190-198

149. Zhao C, Jin $\mathrm{M}$, Le RH, et al. Poor adherence to hepatocellular carcinoma surveillance: a systematic review and meta-analysis of a complex issue. Liver Int 2018; 38:503-514

150. D'Amico G, Garcia-Tsao G, Pagliaro L. Natural history and prognostic indicators of survival in cirrhosis: a systematic review of 118 studies. J Hepatol 2006; $44: 217-231$

151. Park JW, Chen M, Colombo M, et al. Global patterns of hepatocellular carcinoma management from diagnosis to death: the BRIDGE study. Liver Int 2015; $35: 2155-2166$

152. Miller DK, Homan SM. Determining transition probabilities: confusion and suggestions. Med Decis Making 1994; 14:52-58

153. Fattovich G, Stroffolini T, Zagni I, Donato F. Hepatocellular carcinoma in cirrhosis: incidence and risk factors. Gastroenterology 2004; 127:S35-50

154. Choi YJ, Kim JH, Koo JK, et al. Prevalence of renal dysfunction in patients with cirrhosis according to ADQI-IAC working party proposal. Clin Mol Hepatol 2014; 20:185-191 


\section{Bibliography}

155. Dienstag JL, Ghany MG, Morgan TR, et al. A prospective study of the rate of progression in compensated, histologically advanced chronic hepatitis C. Hepatology 2011; 54:396-405

156. Taouli B, Goh JS, Lu Y, et al. Growth rate of hepatocellular carcinoma: evaluation with serial computed tomography or magnetic resonance imaging. $J$ Comput Assist Tomogr 2005; 29:425-429

157. Khalaf N, Ying J, Mittal S, et al. Natural history of untreated hepatocellular carcinoma in a US cohort and the role of cancer surveillance. Clin Gastroenterol Hepatol 2017; 15:273-281 e271

158. Dhir M, Lyden ER, Smith LM, Are C. Comparison of outcomes of transplantation and resection in patients with early hepatocellular carcinoma: a meta-analysis. HPB (Oxford) 2012; 14:635-645

159. Livraghi T, Solbiati L, Meloni MF, et al. Treatment of focal liver tumors with percutaneous radio-frequency ablation: complications encountered in a multicenter study. Radiology 2003; 226:441-451

160. Mazzaferro V, Regalia E, Doci R, et al. Liver transplantation for the treatment of small hepatocellular carcinomas in patients with cirrhosis. N Engl J Med 1996; 334:693-699

161. Wang CL, Cohan $\mathrm{RH}$, Ellis JH, et al. Frequency, management, and outcome of extravasation of nonionic iodinated contrast medium in 69,657 intravenous injections. Radiology 2007; 243:80-87 


\section{Bibliography}

162. Federle MP, Chang PJ, Confer S, Ozgun B. Frequency and effects of extravasation of ionic and nonionic CT contrast media during rapid bolus injection. Radiology 1998; 206:637-640

163. Cohan $\mathrm{RH}$, Bullard MA, Ellis JH, et al. Local reactions after injection of iodinated contrast material: detection, management, and outcome. Acad Radiol 1997;

\section{$4: 711-718$}

164. Eshed I, Althoff CE, Hamm B, Hermann KG. Claustrophobia and premature termination of magnetic resonance imaging examinations. J Magn Reson Imaging 2007; 26:401-404

165. Sarji SA, Abdullah BJ, Kumar G, et al. Failed magnetic resonance imaging examinations due to claustrophobia. Australas Radiol 1998; 42:293-295

166. Forner A, Vilana R, Ayuso C, et al. Diagnosis of hepatic nodules $20 \mathrm{~mm}$ or smaller in cirrhosis: prospective validation of the noninvasive diagnostic criteria for hepatocellular carcinoma. Hepatology 2008; 47:97-104

167. Canadian Ministry of Health and Long Term Care. Schedule of benefits: physicians services under the Health Insurance Act. Canadian Ministry of Health and Long Term Care website. www.health.gov.on.ca/en/pro/programs/ohip/sob/ physserv/sob_master20160401.pdf. Published December 22, 2015. Accessed September 10, 2017

168. The Minister of Health, Manitoba, Canada. Manitoba physician's manual. The Minister of Health website. www.gov.mb.ca/health/documents/physmanual.pdf. Published April 2016. Accessed September 12, 2017 


\section{Bibliography}

169. Ministry of Health and Social Services, Quebec, Canada. Régie de l'assurance maladie du Québec (RAMQ): addendum 4-radiologie diagnostique. Ministry of Health and Social Services website. www.ramq.gouv.qc.ca/SiteCollection Documents/professionnels/manuels/150-facturation-specialistes/030_v_radio_ diagnos_acte_spec.pdf. Published January 2016. Accessed September 14, 2017

170. McKay A, Kutnikoff T, Taylor M. A cost-utility analysis of treatments for malignant liver tumours: a pilot project. HPB (Oxford) 2007; 9:42-51

171. Fateen W, Khan F, O'Neill RJ, et al. Healthcare costs of transarterial chemoembolization in the treatment of hepatocellular carcinoma. J Hepatocell Carcinoma 2017; 4:123-130

172. Muszbek N, Shah S, Carroll S, et al. Economic evaluation of sorafenib in the treatment of hepatocellular carcinoma in Canada. Curr Med Res Opin 2008; 24:3559-3569

173. El Saadany S, Coyle D, Giulivi A, Afzal M. Economic burden of hepatitis C in Canada and the potential impact of prevention. Results from a disease model. Eur J Health Econ 2005; 6:159-165

174. McLernon DJ, Dillon J, Donnan PT. Health-state utilities in liver disease: a systematic review. Med Decis Making 2008; 28:582-592

175. Cucchetti A, Trevisani F, Cescon M, et al. Cost-effectiveness of semi-annual surveillance for hepatocellular carcinoma in cirrhotic patients of the Italian Liver Cancer population. J Hepatol 2012; 56:1089-1096 


\section{Bibliography}

176. Cucchetti A, Trevisani F, Cappelli A, et al. Cost-effectiveness of doxorubicineluting beads versus conventional trans-arterial chemo-embolization for hepatocellular carcinoma. Dig Liver Dis 2016; 48:798-805

177. Camma C, Cabibbo G, Petta S, et al. Cost-effectiveness of sorafenib treatment in field practice for patients with hepatocellular carcinoma. Hepatology 2013; $57: 1046-1054$

178. Bennett WG, Inoue Y, Beck JR, et al. Estimates of the cost-effectiveness of a single course of interferon-alpha $2 \mathrm{~b}$ in patients with histologically mild chronic hepatitis C. Ann Intern Med 1997; 127:855-865

179. Priest VL, Scuffham PA, Hachamovitch R, Marwick TH. Cost-effectiveness of coronary computed tomography and cardiac stress imaging in the emergency department: a decision analytic model comparing diagnostic strategies for chest pain in patients at low risk of acute coronary syndromes. JACC Cardiovasc Imaging 2011; 4:549-556

180. Laupacis A, Feeny D, Detsky AS, Tugwell PX. How attractive does a new technology have to be to warrant adoption and utilization? Tentative guidelines for using clinical and economic evaluations. CMAJ 1992; 146:473-481

181. Ten Haaf K, Tammemagi MC, Bondy SJ, et al. Performance and costeffectiveness of computed tomography lung cancer screening scenarios in a population-based setting: a microsimulation modeling analysis in Ontario, Canada. PLoS Med 2017; 14:e1002225 


\section{Bibliography}

182. Telford JJ, Levy AR, Sambrook JC, et al. The cost-effectiveness of screening for colorectal cancer. CMAJ 2010; 182:1307-1313

183. Mittmann N, Stout NK, Lee P, et al. Total cost-effectiveness of mammography screening strategies. Health Rep 2015; 26:16-25

184. Singal AG, Tiro JA, Marrero JA, et al. Mailed outreach program increases ultrasound screening of patients with cirrhosis for hepatocellular carcinoma. Gastroenterology 2017; 152:608-615 e604

185. Beste LA, loannou GN, Yang Y, et al. Improved surveillance for hepatocellular carcinoma with a primary care-oriented clinical reminder. Clin Gastroenterol Hepatol 2015; 13:172-179

186. Barratt AL. Cancer screening--benefits, harms, and making an informed choice. Aust Fam Physician 2006; 35:39-42

187. Lafata JE, Simpkins J, Lamerato L, et al. The economic impact of false-positive cancer screens. Cancer Epidemiol Biomarkers Prev 2004; 13:2126-2132

188. Bittermann T, Goldberg DS, Bauer CM, Khungar V. Characterizing the risk of false-positive hepatocellular carcinoma in recipients transplanted with T2 MELD exceptions. Transplantation 2017; 101:1099-1105

189. Brenner DJ, Shuryak I, Einstein AJ. Impact of reduced patient life expectancy on potential cancer risks from radiologic imaging. Radiology 2011; 261:193-198

190. Singal AG, El-Serag HB. Hepatocellular carcinoma from epidemiology to prevention: translating knowledge into practice. Clin Gastroenterol Hepatol $2015 ; 13: 2140-2151$ 


\section{Bibliography}

191. Goossens N, Bian CB, Hoshida Y. Tailored algorithms for hepatocellular carcinoma surveillance: is one-size-fits-all strategy outdated? Curr Hepatol Rep $2017 ; 16: 64-71$

192. Lima PH, Fan B, Berube J, et al. Cost-utility analysis of imaging for surveillance and diagnosis of hepatocellular carcinoma. AJR Am J Roentgenol 2019:1-9 
Appendix

\section{Appendix}

Appendix 1 Manuscript: Cost-Utility Analysis of Imaging for Surveillance and Diagnosis of Hepatocellular Carcinoma.

Published in the American Journal of Roentgenology [192]. Full text reproduced with permission from the licensed content publisher and all co-authors. 


\section{Cost-Utility Analysis of Imaging for Surveillance and Diagnosis of Hepatocellular Carcinoma}

Paulo Henrique Lima ${ }^{1,2}$

Boyan Fan²

Joshua Bérubé2

Milena Cerny ${ }^{1,2}$

Damien Olivié2

Jeanne-Marie Giard ${ }^{3}$

Catherine Beauchemin 4

An Tang ${ }^{1,2}$

Keywords: cost-effectiveness, early detection, liver cancer, liver imaging, Markov model

doi.org/10.2214/AJR.18.20341

Received July 6, 2018; accepted after revision January 29, 2019.

Based on a presentation at the International Society for Magnetic Resonance in Medicine 2017 annual meeting, Honolulu, HI.

Supported by a New Researcher Startup Grant from the Centre de recherche du Centre hospitalier de l'Université de Montréal to A. Tang. P. H. Lima was supported by Bourse $C$ de l'Université de Montréal, Bourse de recrutement aux études supérieures de la Faculté de médecine de l'Université de Montréal, and Bourse de formation en recherche en Sciences biomédicales 2017-2018 du Centre de recherche du Centre hospitalier de l'Université de Montréal. A. Tang was supported by a Chercheur-Boursier Junior 2 from the Fonds de Recherche du Québec en Santé and Fondation de I'association des radiologistes du Québec (FROS-ARO 34939).

${ }^{1}$ Centre de recherche du Centre hospitalier de I'Université de Montréal, Montréal, QC, Canada.

${ }^{2}$ Department of Radiology, Radio-Oncology, and Nuclear Medicine, Centre hospitalier de I'Université de Montréal, 1000 Rue Saint-Denis D03.5431, Montréal, OC $\mathrm{H} 2 \mathrm{X}$ OC1, Canada, Address correspondence to A. Tang (an.tang@umontreal.ca).

${ }^{3}$ Department of Hepatology, Centre hospitalier de I'Université de Montréal, Montréal, QC, Canada.

${ }^{4}$ Faculty of Pharmacy, Université de Montréal, Montréal, 0C, Canada.

Supplemental Data

Available online at www.ajronline.org.

AJR2019; 213:1-9

0361-803X/19/2131-1

(C) American Roentgen Ray Society

OBJECTIVE. The purpose of this study is to compare imaging-based surveillance and diagnostic strategies in patients at risk for hepatocellular carcinoma (HCC) while taking into account technically inadequate examinations and patient compliance.

MATERIALS AND METHODS. A Markov model simulated seven strategies for HCC surveillance and diagnosis in patients with cirrhosis: strategy A, ultrasound (US) for surveillance and CT for diagnosis; strategy B, US for surveillance and complete MRI for diagnosis; strategy C, US for surveillance and CT for inadequate or positive surveillance; strategy D, US for surveillance and complete MRI for inadequate or positive surveillance; strategy E, surveillance and diagnosis with CT followed by complete MRI for inadequate surveillance; strategy F, surveillance and diagnosis with complete MRI followed by CT for inadequate surveillance; and strategy G, surveillance with abbreviated MRI followed by CT for inadequate surveillance or complete MRI for positive surveillance. Two compliance scenarios were evaluated: optimal and conservative. For each scenario, the most cost-effective strategy was based on a willingness-to-pay threshold of $\$ 50,000$ (Canadian) per quality-adjusted life year (QALY). Sensitivity analyses were performed.

RESULTS. Base-case analysis revealed that strategy E was the most cost-effective when compliance was optimal ( $\$ 13,631 / \mathrm{QALY})$, and strategy $\mathrm{G}$ was the most cost-effective when compliance was conservative (\$39,681/QALY). Sensitivity analyses supported the base-case analysis in the optimal compliance scenario, but several parameters altered the most cost-effective strategy in the conservative compliance scenario.

CONCLUSION. In an optimal compliance scenario, CT for HCC surveillance and diagnosis and complete MRI for inadequate $\mathrm{CT}$ was most cost-effective. In a conservative compliance scenario, abbreviated MRI may be an alternative to US-based surveillance.

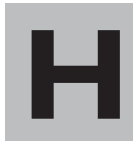

epatocellular carcinoma (HCC) is the sixth most common cancer and the second leading cause of cancer-related deaths worldwide [1]. In Canada, HCC is the only malignancy for which mortality is increasing, a trend that is expected to continue through 2020 and beyond [2]. The implementation of surveillance programs targeting high-risk populations, such as patients with cirrhosis, has led to the detection of HCC at earlier stages, when curative therapies can be applied [3]. This strategy could reduce the mortality related to HCC, as shown by a large randomized controlled trial [4].

North American guidelines recommend ultrasound (US) surveillance every 6 months in at-risk patients [5, 6]. Although US surveillance is feasible in patients with thin body habitus and without steatosis, it is challeng- ing in obese patients or those with cirrhosis because of attenuation and heterogeneity of liver appearance, which limit the ability to assess the liver parenchyma [7, 8]. Furthermore, cirrhosis is often accompanied by a diffusely nodular appearance of liver parenchyma that limits the ability to detect HCC lesions [7]. Alternately, CT, MRI, and abbreviated MRI (which is limited to two or three sequences for lesion detection) have been explored as alternative imaging modalities for HCC surveillance [9-14] and may be used in selected patients who are likely to have inadequate US examinations [5].

Costs attributable to HCC account for a substantial financial burden, are higher when $\mathrm{HCC}$ is diagnosed at advanced stages, and are expected to increase until the HCC incidence reaches its peak $[15,16]$. Given that health care systems are limited in their financial re- 


\section{Lima et al.}

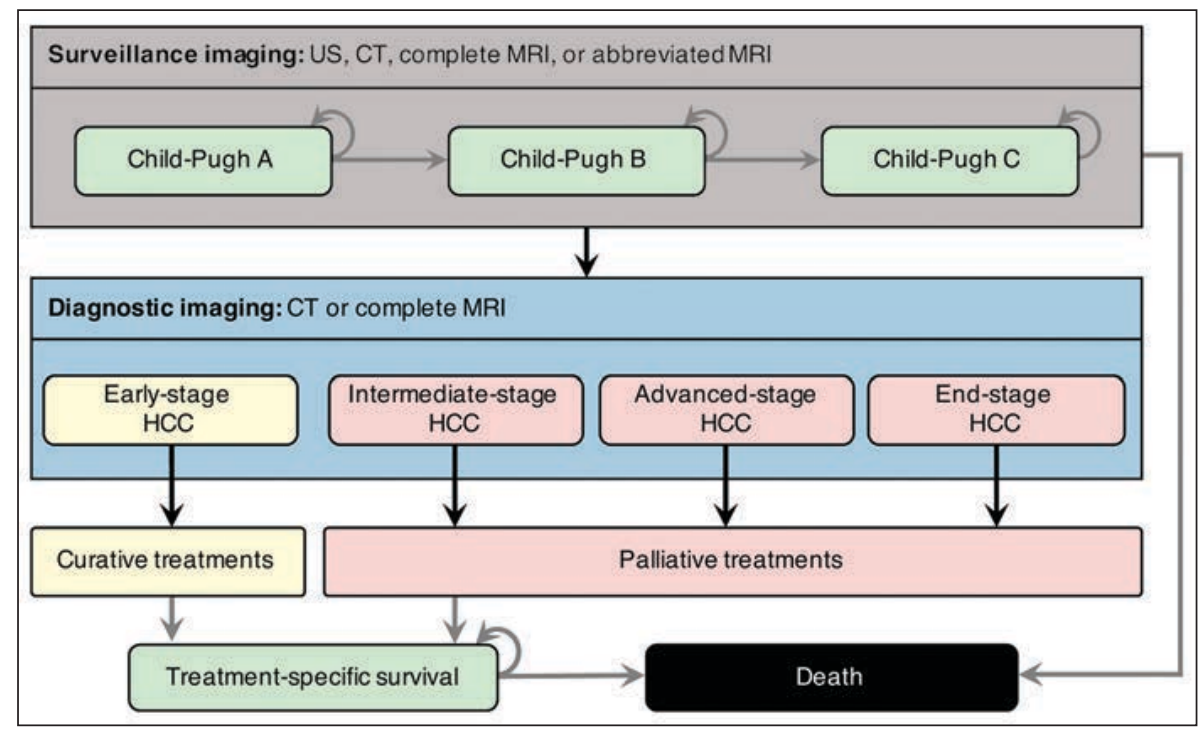

Fig. 1-Simplified Markov model illustrating surveillance (gray box) and diagnostic imaging techniques (blue box) interposed on health states (green boxes) and temporary states (beige and pink boxes). Gray arrows indicate health state transitions, and black arrows indicate temporary state transitions (management of positive imaging results). US = ultrasound, HCC = hepatocellular carcinoma.

sources, competing surveillance strategies should be analyzed for their cost-effectiveness. Cost-utility studies, which incorporate the widely applicable quality-adjusted life year (QALY), a measure of health outcome, should guide policymakers in their decision to implement alternative surveillance strategies. Prior cost-utility studies that assessed HCC surveillance have not taken into consideration the effect of inconclusive surveillance imaging examinations and patient compliance simultaneously. In this era of imagingbased surveillance and diagnosis of HCC, there is a need to investigate the cost-effectiveness of different surveillance algorithms.

Therefore, the purpose of this study was to compare imaging-based surveillance and diagnostic strategies in patients at risk for HCC, taking into account technically inadequate examinations and patient compliance.

\section{Materials and Methods \\ Model Structure and Population}

A decisional Markov model was developed using TreeAge Pro software (version 2017, TreeAge) to estimate the costs and QALYs associated with imaging-based surveillance and diagnostic strategies for HCC (Fig. 1). This study was developed from a Canadian health care system perspective and followed the Canadian Guideline for Economic Evaluation of Health Technologies [17].

The simulated cohort of high-risk patients with cirrhosis underwent imaging-based surveillance every 6 months (cycle length). At baseline, patients posed onto the Markov model to reflect clinical options. At each cycle, patients could progress to decompensated cirrhosis (Child-Pugh class B or C) or develop HCC or both. Patients with a positive surveillance result were submitted to a diagnostic imaging examination. Those with a positive diagnostic result were treated according to their HCC stage and Child-Pugh class (see the Treatment Options subsection later). Survival after each treatment option was modeled. Patients with a negative surveillance or diagnostic result were reinvestigated in the next cycle. In the model, a new HCC could remain undetected until it was discovered by surveillance or the patient experienced symptoms; it was also possible for a patient to die with an undiagnosed HCC. Continued follow-up was made until all patients died (lifetime horizon). Both costs and outcomes were discounted at $1.5 \%$ per year [17]. Model validity was assessed comparing survival rates and diagnostic probabilities found in the model with results presented in published studies.

\section{Competing Imaging Strategies}

Seven surveillance and diagnostic strategies were investigated, relying on combinations of four imaging techniques: US, CT, complete MRI, and abbreviated MRI (see Fig. S1, which can be viewed in the $A J R$ electronic supplement to this article, available at www.ajronline.org). Strategies A and B used US-based surveillance followed by CT and complete MRI, respectively, for diagnosis, without additional imaging for inadequate US surveillance examinations. These strategies are recommended by current guidelines $[5,6]$. Alternative strategies C and D used USbased surveillance followed by $\mathrm{CT}$ and complete Imaging-based surveillance and diagnostic strategies and treatment options were superim-

\section{TABLE I: Initial Parameters and Transition Probabilities}

\begin{tabular}{l|c|c}
\hline \multicolumn{1}{c|}{ Parameter } & $\begin{array}{c}\text { Base Case } \\
\text { (Range) }\end{array}$ & References \\
\hline Discount rate & $1.5(0-5)$ & {$[17]$} \\
Age at entry (y) & $50(40-60)$ & {$[18,19]$} \\
Cirrhosis progression & $5(4-7)$ & {$[21,52]$} \\
HCC incidence & $3(1.5-8)$ & {$[5,24]$} \\
HCC progression & $40(20-70)$ & {$[44,53]$} \\
Incidental or symptomatic early- and intermediate-stage HCC & $30(0-50)$ & {$[54]$} \\
Incidental or symptomatic advanced and end-stage HCC & $100(50-100)$ & Assumption \\
Optimal surveillance scenario & & Assumption \\
Child-Pugh class A at entry & 100 & Assumption \\
Surveillance compliance & 100 & {$[21]$} \\
Conservative surveillance scenario & & {$[20]$} \\
\hline
\end{tabular}

(Table 1 continues on next page) 
Cost-Utility Analysis of Imaging for HCC

TABLE I: Initial Parameters and Transition Probabilities (continued)

\begin{tabular}{|c|c|c|}
\hline Parameter & $\begin{array}{c}\text { Base Case } \\
\text { (Range) }\end{array}$ & References \\
\hline \multicolumn{3}{|l|}{ Mortality } \\
\hline Child-Pugh class $A(1 \mathrm{y})^{\mathrm{a}}$ & 5 & [21] \\
\hline Child-Pugh class $B(1 \mathrm{y})^{\mathrm{a}}$ & 20 & [21] \\
\hline Child-Pugh class $\mathrm{C}(1 \mathrm{y})^{\mathrm{a}}$ & 55 & [21] \\
\hline Advanced and end-stage $\mathrm{HCC}(1 \mathrm{y})$ & $76(40-85)$ & [55] \\
\hline Perioperative mortality of liver resection & $3.9(3.7-4.5)$ & [56] \\
\hline Perioperative mortality of RFA & $0.3(0-1.8)$ & {$[57,58]$} \\
\hline Perioperative mortality of liver transplantation & $4.3(2.3-6.3)$ & [59] \\
\hline \multicolumn{3}{|l|}{ Survival after treatment } \\
\hline Liver resection $(5 \mathrm{y})$ & $51(38-51)$ & {$[44,56]$} \\
\hline RFA (Child-Pugh class A) ( 5 y) & $51(32-68)$ & {$[44,60]$} \\
\hline RFA (Child-Pugh class B) (5 y) & $31(27-40)$ & {$[44,60]$} \\
\hline Liver transplantation (1 y) & $95(89-97)$ & [61] \\
\hline Liver transplantation ( $5 \mathrm{y}$ ) & $82(69-86)$ & [61] \\
\hline Sorafenib $(1 \mathrm{y})^{\mathrm{a}}$ & 44 & [62] \\
\hline $\operatorname{TACE}(1 \mathrm{y})^{\mathrm{a}}$ & 62 & [63] \\
\hline Symptomatic care $(1 \mathrm{y})^{\mathrm{a}}$ & 18 & [64] \\
\hline
\end{tabular}

Note-Except for patient age, data are percentages. $\mathrm{HCC}=$ hepatocellular carcinoma, RFA = radiofrequency ablation, TACE $=$ transarterial chemoembolization .

aRange values $=-25 \%$ and $25 \%$.

TABLE 2: Imaging Techniques Characteristics

\begin{tabular}{l|c|c}
\hline \multicolumn{1}{c|}{ Parameter } & $\begin{array}{c}\text { Base Case } \\
\text { (Range) }\end{array}$ & References \\
\hline Surveillance US sensitivity & $78(60-89)$ & {$[25]$} \\
Surveillance US specificity & $89(80-94)$ & {$[25]$} \\
US technically inadequate rate & $16(0-39)$ & {$[26]$} \\
Surveillance CT sensitivity & $84(59-95)$ & {$[25]$} \\
Surveillance CT specificity & $99(86-100)$ & {$[25]$} \\
Diagnostic CT sensitivity & $76(72-80)$ & {$[25]$} \\
Diagnostic CT specificity & $89(84-93)$ & {$[25]$} \\
CT technically inadequate rate & $0.7(0.2-0.9)$ & {$[65-67]$} \\
Renal dysfunction frequency & $5(0-32)$ & {$[27]$} \\
Surveillance complete MRI sensitivity & $89(82-93)$ & {$[25]$} \\
Surveillance complete MRI specificity & $86(79-91)$ & {$[25]$} \\
Diagnostic complete MRI sensitivity & $83(80-86)$ & {$[25]$} \\
Diagnostic complete MRI specificity & $87(79-93)$ & {$[25]$} \\
Surveillance abbreviated MRI sensitivity & $81(71-91)$ & {$[12,13]$} \\
Surveillance abbreviated MRI specificity & $96(90-98)$ & {$[12,13]$} \\
MRI technically inadequate rate & $1.2(0.5-1.2)$ & {$[68,69]$} \\
Biopsy specificity & $100(80-100)$ & {$[44]$} \\
Biopsy sensitivity & $62(50-100)$ & {$[70]$} \\
\hline Note-Data are & &
\end{tabular}

Note—Data are percentages. US = ultrasound.
MRI, respectively, for technically inadequate or positive US surveillance. These strategies follow the current recommendations of using US as the first-line surveillance modality, albeit by offering alternative imaging in case of inadequate US [5]. Replacement strategies E and F used CT and complete MRI, respectively, for surveillance, an approach that reflects the current practice in some North American centers. In cases of technically inadequate surveillance CT or MRI, the other imaging modality was used for confirmation. Strategy G used abbreviated MRI as surveillance followed by CT for patients with technically inadequate surveillance examinations or complete MRI for diagnosis of positive surveillance results. This emergent approach was recently proposed in proof-of-concept studies [11-13].

\section{Treatment Options}

The treatments were modeled on the basis of the Canadian consensus for the management and treatment of HCC [6] (Fig. S2, which can be viewed in the AJR electronic supplement to this article, available at www.ajronline.org). Early-stage HCC could be treated with curative treatments, including liver resection, radiofrequency ablation, and liver transplantation. Intermediate-stage, advanced-stage, and end-stage HCCs received palliative treatments, such as transarterial chemoembolization, sorafenib, and symptomatic care. The relative proportion of patients eligible for each type of treatment was based on the distribution of treatments in participating North American centers of the international BRIDGE study [22].

\section{Model Parameter Estimates}

A literature search was performed to identify all relevant data that informed the parameters used in our model (Tables 1 and 2). Preference was given to meta-analyses, systematic reviews, and clinical trials. Transition probabilities were calculated according to the approach outlined by Miller and Homan [23] for converting rates over time. HCC incidences were based on the threshold incidence for efficacy of surveillance in patients with cirrhosis (1.5\%/year) [5] and the incidence of HCC reported in the literature [24].

Sensitivity and specificity of US, CT, and complete MRI were derived from a meta-analysis that pooled estimates of diagnostic performance according to imaging modalities, setting (surveillance and nonsurveillance), and unit of analysis (per patient and per lesion) [25]. Sensitivity and specificity of abbreviated MRI were derived from proof-of-concept studies [12, 13]. The selected values for US inadequacy were derived from a ret- 


\section{Lima et al.}

TABLE 3: Health Care Costs and Utilities

\begin{tabular}{|c|c|c|}
\hline Parameter & Base Case (Range) & References \\
\hline \multicolumn{3}{|l|}{ Costs (Canadian dollars) } \\
\hline US & $86(68-261)$ & Table S3 \\
\hline СT & $140(105-147)$ & Table S3 \\
\hline Complete MRI & $419(351-484)$ & Table S3 \\
\hline Abbreviated MRI & $262(158-368)$ & Table S4 \\
\hline Liver biopsy & $995(500-1990)$ & [44] \\
\hline Specialist consultation & $159(106-159)$ & [28] \\
\hline False-positive follow-up & $1800(900-3600)$ & [44] \\
\hline Liver resection $^{\mathrm{a}}$ & 25,917 & [36] \\
\hline $\mathrm{RFA}^{\mathrm{a}}$ & 20,260 & [36] \\
\hline TACE $^{\mathrm{a}}$ & 16,658 & [71] \\
\hline Sorafenib & $54,923(50,696-59,149)$ & [72] \\
\hline Symptomatic care ${ }^{a}$ & 5000 & [36] \\
\hline Liver transplantation (first year) & $124,204(67,420-180,988)$ & [15] \\
\hline Liver transplantation (long term) & $25,000(18,756-31,260)$ & [73] \\
\hline \multicolumn{3}{|l|}{ Utilities } \\
\hline Child-Pugh class A cirrhosis & $0.80(0.64-0.96)$ & {$[32,33]$} \\
\hline Child-Pugh classes $B$ and $C$ cirrhosis & $0.60(0.48-0.72)$ & {$[32,33]$} \\
\hline Early-stage HCC (Child-Pugh class A) & $0.72(0.58-0.86)$ & [33] \\
\hline Early-stage HCC (Child-Pugh classes B and C) & $0.57(0.46-0.68)$ & [33] \\
\hline Incurable HCC & $0.40(0.32-0.48)$ & [33] \\
\hline After liver resection & $0.70(0.40-0.90)$ & [14] \\
\hline After RFA ${ }^{a}$ & 0.76 & [36] \\
\hline After TACE & $0.65(0.52-0.77)$ & [34] \\
\hline After sorafenib & $0.76(0.60-0.80)$ & [35] \\
\hline After symptomatic care ${ }^{a}$ & 0.80 & [36] \\
\hline After liver transplantation (first year) & $0.60(0.50-0.80)$ & {$[14,37]$} \\
\hline After liver transplantation (long term) & $0.85(0.70-0.90)$ & {$[14,37]$} \\
\hline False-positive diagnosis & $-0.01(-0.03$ to 0$)$ & [51] \\
\hline
\end{tabular}

Note-US = ultrasound, RFA = radiofrequency ablation, TACE = transarterial chemoembolization, $\mathrm{HCC}=$ hepatocellular carcinoma.

aRange values $=-25 \%$ and $25 \%$.

rospective study by Simmons et al. [26]. CT and MRI technical failure rates were estimated from studies that assessed the frequency of contrast extravasation and claustrophobia, respectively. Contraindication to contrast agent due to renal dysfunction was also considered [27].

\section{Costs and Utilities}

Costs incorporated into the model were preferably derived from published literature specific to the Canadian health-care system (Table 3). Values that were not available from Canadian references were converted using a conversion rate of \$1.29 Canadian per American dollar or \$1.74 Ca- nadian dollar per British pound. Costs of imaging modalities were microcosted from the Ontario Physicians Service [28], the Manitoba Physicians Manual [29], and the Régie de l'assurance maladie du Québec [30] (Table S3, which can be viewed in the $A J R$ electronic supplement to this article, available at www.ajronline.org). The cost of abbreviated MRI was also microcosted (Table S4, which can be viewed in the AJR electronic supplement to this article, available at www.ajronline. org), assuming in the base case an acquisition time of 10 minutes $[11,12]$. In the sensitivity analyses, the acquisition time varied from 5 to 15 minutes. All costs are of 2017 and were adjusted for infla- tion to 2017 when needed using the national inflation index [31] (all monetary values given in this article are shown in Canadian dollars).

A systematic review [32] and a previous costeffectiveness study [33] provided the data for utilities associated with compensated (Child-Pugh class A) and decompensated (Child-Pugh classes B and C) cirrhosis, as well as HCC stages. Utility data for survival after each treatment option were obtained from different studies [14, 34-37]. A disutility was applied to patients with a false-positive diagnosis to simulate the stress and anxiety associated with an incorrect test result. Utility values for health states are reported in Table 3.

\section{Base-Case Analysis}

Costs, QALYs, and incremental cost-effectiveness ratios (ICERs) were calculated for each strategy. The ICER was calculated by dividing the difference in cost by the difference in QALYs compared with the previous less costly and less effective strategy. In the Canadian health care setting, there is not a willingness-to-pay (WTP) threshold per se, but rather a range from $\$ 20,000$ to $\$ 100,000$ per QALY to be considered according to the context [38]. Our study considered a WTP threshold of $\$ 50,000$ per QALY, in accordance with previous Canadian studies that assessed the cost-effectiveness of screening interventions [39, 40]. A strategy is considered dominated when it results in a higher cost and lower QALY gain in comparison with another strategy.

\section{Sensitivity Analyses}

The robustness of our results was assessed in terms of deterministic and probabilistic sensitivity analyses. A one-way deterministic sensitivity analysis was performed using a range of values taken from the published literature for the majority of parameters. For parameters without a known interval, sensitivity analysis was performed using a range of $25 \%$ around the basecase estimates, a commonly used approach in pharmacoeconomic analyses [41]. The top five parameters with the greatest effect on ICER were selected for each scenario in the deterministic sensitivity analysis. A probabilistic analysis was performed according to the methods suggested by Briggs et al. [42].

\section{Results}

Base-Case Analyses

Cost-utility analysis and cost-utility curves are shown in Table 4 and Figure S5 (see the $A J R$ electronic supplement to this article, available at www.ajronline.org). In the op- 


\section{Cost-Utility Analysis of Imaging for HCC}

TABLE 4: Cost-Utility Analysis

\begin{tabular}{|c|c|c|c|c|c|}
\hline Strategy & $\begin{array}{l}\text { Cost (Canadian } \\
\text { Dollars) }\end{array}$ & QALY & $\begin{array}{l}\text { Incremental Cost } \\
\text { (Canadian Dollars) }\end{array}$ & $\begin{array}{c}\text { Incremental } \\
\text { Effectiveness } \\
\text { (QALY) }\end{array}$ & $\begin{array}{l}\text { ICER (Canadian } \\
\text { Dollars/QALY) }\end{array}$ \\
\hline \multicolumn{6}{|l|}{$\begin{array}{l}\text { Optimal scenario ( } 100 \% \text { of patients with Child-Pugh class A disease at entry } \\
\text { and } 100 \% \text { surveillance compliance) }\end{array}$} \\
\hline A: Surveillance, US; diagnosis, CT & 18,305 & 7.269 & & & \\
\hline E: Surveillance, CT; if inadequate surveillance, MRI; diagnosis, CT & 20,268 & 7.413 & 1963 & 0.144 & 13,631 \\
\hline \multicolumn{6}{|l|}{$\begin{array}{l}\text { Conservative scenario ( } 29 \% \text { of patients with Child-Pugh class A disease at } \\
\text { entry and } 52 \% \text { surveillance compliance) }\end{array}$} \\
\hline A: Surveillance, US; diagnosis, CT & 9286 & 4.300 & & & \\
\hline C: Surveillance, US; if inadequate surveillance, CT; diagnosis, CT & 10,400 & 4.332 & 1114 & 0.032 & 35,108 \\
\hline $\begin{array}{l}\text { G: Surveillance, abbreviated MRl; if inadequate surveillance, CT; diagnosis, } \\
\text { MRI }\end{array}$ & 11,273 & 4.354 & 873 & 0.022 & 39,681 \\
\hline
\end{tabular}

Note-Incremental cost-effectiveness ratio (ICER) was calculated for each strategy by dividing the difference in cost (Canadian dollars) by the difference in qualityadjusted life years (QALYs) compared with the previous less costly and less effective strategy. Dominated strategies were not included in the table. US = ultrasound.

timal surveillance scenario $(100 \%$ patients with Child-Pugh class A disease at entry and $100 \%$ compliance), strategy A (US for surveillance and CT for diagnosis) costs $\$ 18,305$ per person with a total utility value of 7.269 QALYs over the patient's lifetime. Strategy E (surveillance and diagnosis with CT followed by complete MRI for inadequate surveillance) required $\$ 1963$ more per person but also delivered an incremental effectiveness of 0.144 QALYs. This option was found to be the most cost-effective strategy according to the WTP threshold of $\$ 50,000 / \mathrm{QALY}$, with an ICER of \$13,631/QALY.

In the conservative surveillance scenario (29\% patients with Child-Pugh class A disease at entry and 52\% surveillance compliance), strategy A costs $\$ 9286$ per person with a total utility value of 4.300 QALYs over the patient's lifetime. Strategy C (US for surveillance and CT for inadequate or positive surveillance) required $\$ 1114$ more per person but also delivered an incremental effectiveness of 0.032 QALYs, with a calculated ICER of $\$ 35,108 /$ QALY. Strategy G (surveillance with abbreviated MRI followed by CT for inadequate surveillance or complete MRI for positive surveillance) required $\$ 873$ more per person and delivered an incremental effectiveness of 0.022 QALYs when compared with strategy $\mathrm{C}$. This option was found to be the most cost-effective strategy according to the WTP threshold, with an ICER of \$39,681/QALY.

Model validity was assessed by comparing model predictions with literature values of 1- and 2-year survival for Child-Pugh class A cirrhosis, 3-year survival for surveillance-detected and non-surveillance-detected HCCs, and probability of early-stage HCC detection among patients who underwent or did not undergo surveillance (see Table S6, which can be viewed in the $A J R$ electronic supplement to this article, available at www. ajronline.org).

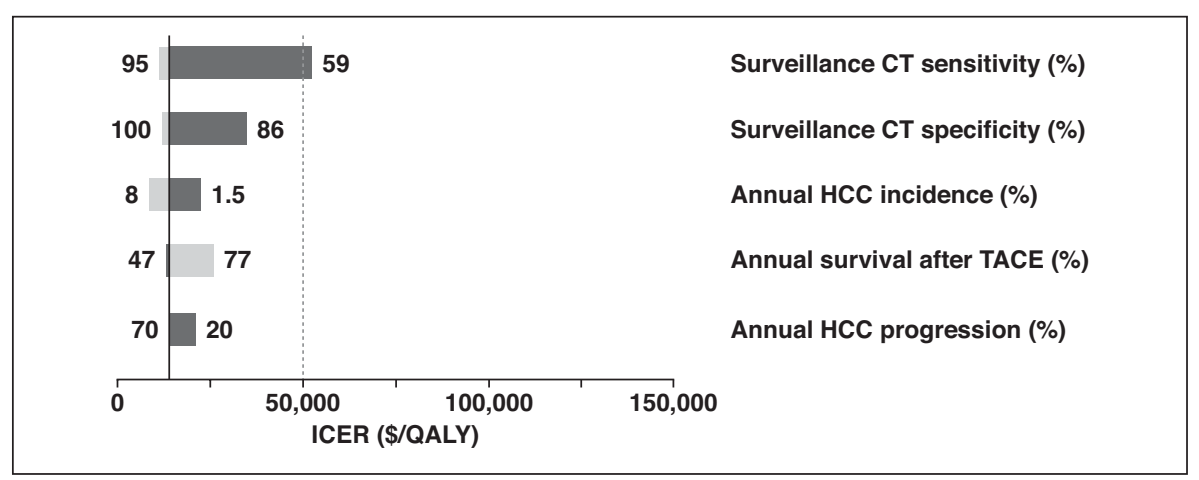

Deterministic Sensitivity Analyses

Figure 2 summarizes one-way sensitivity analyses for optimal and conservative surveillance scenarios. In the optimal scenario, only the surveillance CT sensitivity could exceed the WTP threshold. If the surveillance CT sensitivity was $95 \%$, the ICER would be $\$ 11,186 /$ QALY. At a lower limit of $59 \%$, the ICER increased to $\$ 52,321 /$ QALY.

In the conservative scenario, all the top five parameters could exceed the WTP threshold: the sensitivity, specificity, and cost for abbreviated MRI and the sensitivity and specificity for surveillance US. The sensitivity of abbreviated MRI for surveillance varied from $71 \%$ to $91 \%$, leading to ICER values ranging from $\$ 140,556 / \mathrm{QALY}$ to $\$ 30,435 / \mathrm{Q} A L Y$. The abbreviated MRI cost varied from $\$ 158$ to $\$ 368$, leading to ICER values ranging from \$9483/ QALY to $\$ 68,791 /$ QALY. This range of costs includes the values of 5-minute (\$158-293), 10-minute (\$198-331), and 15-minute (\$236-

Fig. 2-One-way sensitivity analyses. A and B, Graphs show analyses for optimal (strategy E vs strategy $A ; A$ ) and conservative (strategy $G$ vs strategy C; B) surveillance scenarios. Black lines represent expected incremental cost-effectiveness ratio (ICER) values. Dotted gray lines represent willingness-to-pay threshold. Costs are shown in Canadian dollars. HCC = hepatocellular carcinoma, $\mathrm{TACE}=$ transarterial chemoembolization, US = ultrasound, $\mathrm{OALY}=$ quality-adjusted life year.

(Fig. 2 continues on next page) 


\section{Lima et al.}

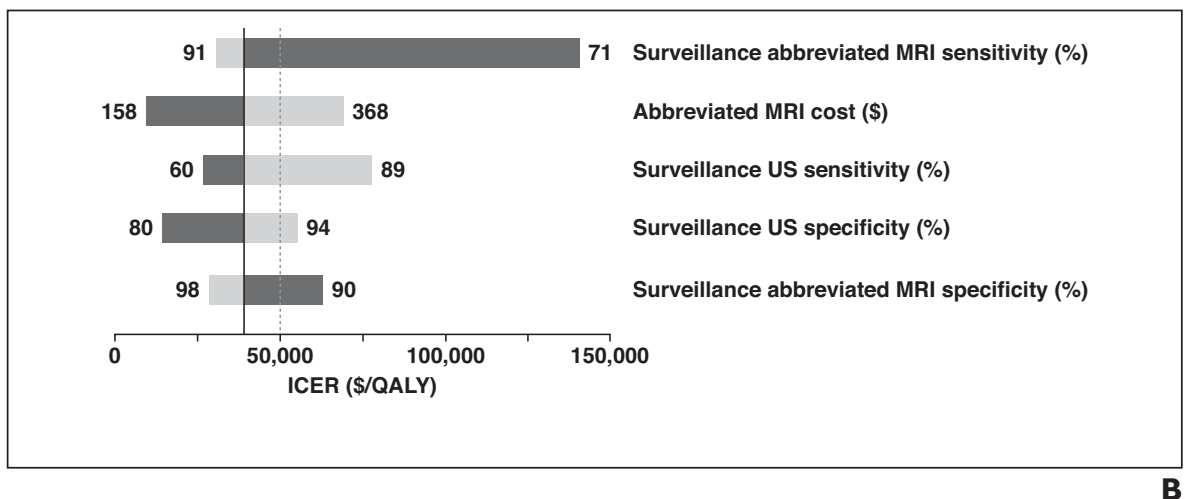

368) abbreviated MRI protocols. The surveillance US sensitivity varied from $60 \%$ to $89 \%$, leading to ICER values ranging from $\$ 26,704 / \mathrm{QALY}$ to $\$ 77,489 / \mathrm{QALY}$. The specificity of surveillance US varied from $80 \%$ to $94 \%$, leading to ICER values ranging from $\$ 14,261$ to $\$ 55,129$. The specificity of abbreviated MRI for surveillance varied from $90 \%$ to $98 \%$, leading to ICER values ranging from $\$ 62,671$ to $\$ 28,529$.

\section{Probabilistic Sensitivity Analyses}

Figure 3 summarizes the probabilistic sensitivity analyses for both optimal and conservative surveillance scenarios. This analysis evaluates the effect of uncertainty using distribution curves for each parameter instead of value ranges. In the optimal surveillance scenario, strategy $\mathrm{E}$ was the most likely cost-effective strategy, with a probability of $73 \%$ at the WTP threshold. In the conservative surveillance scenario, strategy $\mathrm{G}$ was the most likely cost-effective strategy, with a probability of $79 \%$ at the WTP threshold.

\section{Discussion}

This study complements prior cost-effectiveness studies on HCC surveillance [14, 43-45] by comparing US, CT, complete MRI, and abbreviated MRI as options for HCC surveillance and by taking into account the effect of inconclusive surveillance imaging
Fig. 2 (continued) - One-way sensitivity analyses. A and B, Graphs show analyses for optimal (strategy Evs strategy $A ; A$ ) and conservative (strategy $G$ vs strategy C; B) surveillance scenarios. Black lines represent expected incremental cost-effectiveness ratio (ICER) values. Dotted gray lines represent willingness-to-pay threshold. Costs are shown in Canadian dollars. HCC = hepatocellular carcinoma, TACE = transarterial chemoembolization, US = ultrasound, $Q A L Y=$ quality-adjusted life year.

examinations and patient compliance. Our model relied on current knowledge of hepatocarcinogenesis, clinical practice guidelines for the treatment of $\mathrm{HCC}$, and performance of imaging tests from a meta-analysis. The incidence, transition probabilities, costs, and utilities were based on a literature review. Furthermore, the validity of our model was supported by similarities between predicted values and data found in the literature.

To evaluate the full effect of surveillance, an optimal scenario was assessed, where all patients started surveillance when they had compensated cirrhosis (Child-Pugh class A) and the compliance to surveillance was $100 \%$. However, because liver fibrosis and
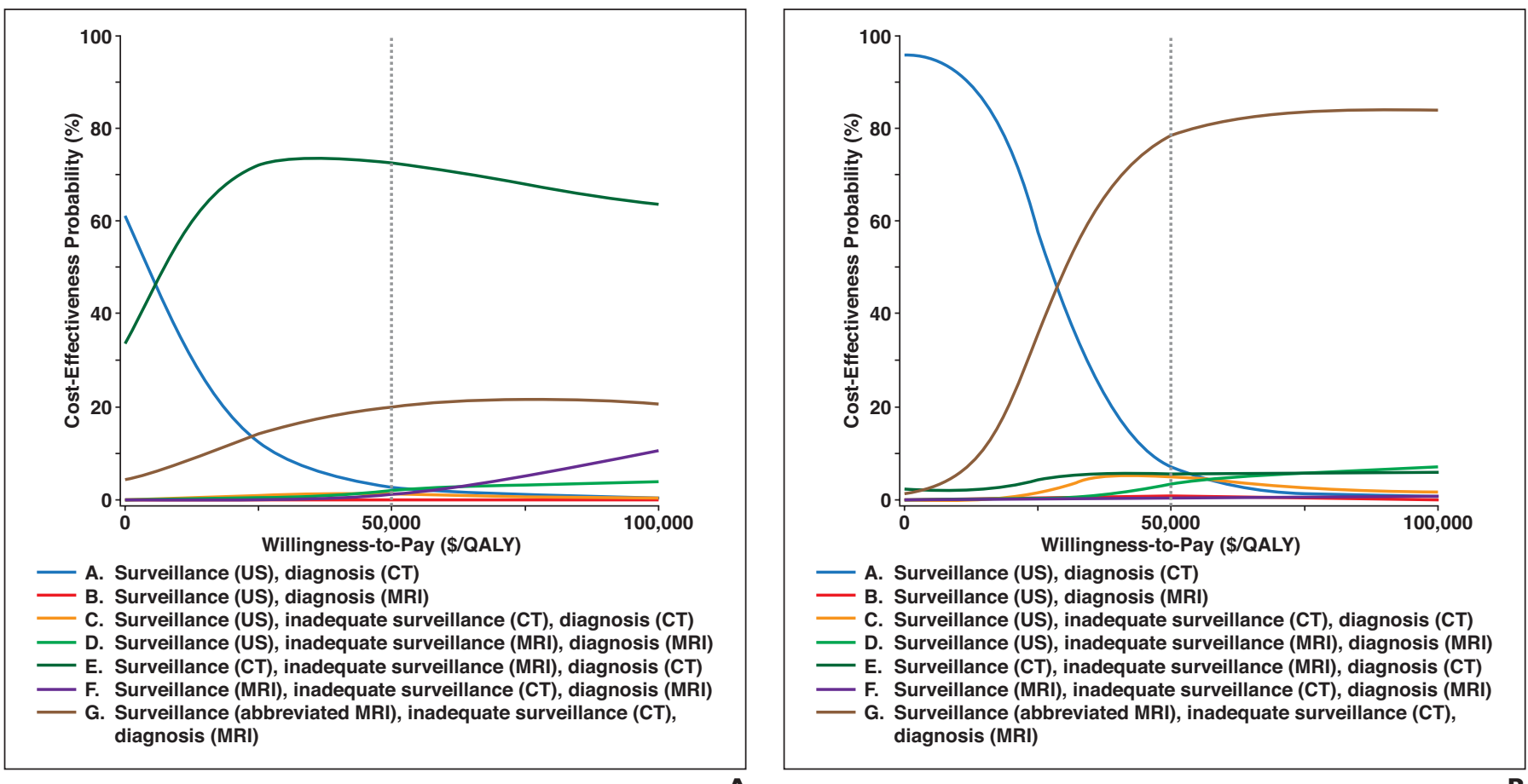

Fig. 3-Acceptability curves after 10,000 iterations.

A and B, Graphs show acceptability curves for optimal (A) and conservative (B) surveillance scenarios. Dotted gray lines represent willingness-to-pay threshold. Costs are shown in Canadian dollars. QALY = quality-adjusted life year, US = ultrasound. 


\section{Cost-Utility Analysis of Imaging for HCC}

compensated cirrhosis are asymptomatic conditions, a large number of patients may be unaware of their condition [18]. Furthermore, the HCC surveillance compliance is suboptimal, with an overall rate of only $52 \%$ [20]. Thus, a conservative scenario analysis was also modeled.

As expected, all strategies in the optimal scenario delivered more QALYs than in the conservative scenario. This finding corroborates the importance of surveillance in improving health outcomes and justifies the development of programs to increase compliance. A mailed outreach program conducted by Singal et al. [46] and a clinical reminder program implemented by Beste et al. [47], for example, had encouraging results, but further efforts are still needed.

In the optimal surveillance scenario, the most cost-effective strategy was strategy E (surveillance and diagnosis with CT followed by complete MRI for inadequate surveillance). According to deterministic sensitivity analysis, strategy E exceeded the WTP threshold only if the sensitivity of surveillance CT decreased to nearly $59 \%$. Such a low sensitivity has been reported only in the evaluation of lesions smaller than $10 \mathrm{~mm}$ [25], for which current guidelines do not recommend additional investigation or shortterm follow-up management [5]. Hence, the results of the base-case analysis were essentially confirmed by the sensitivity analyses at the WTP threshold.

Strategies relying on a single examination for both surveillance and diagnosis (such as strategy E) are prone to higher rates of falsepositive diagnoses. This is a legitimate concern, because false-positive diagnoses may expose healthy patients to psychologic stress and treatment risks and increase their health care expenditures [48, 49]. Furthermore, patients on the liver transplantation waiting list may receive additional exception points for $\mathrm{HCC}$ on the basis of a false-positive diagnosis. Hence, the choice of imaging-based surveillance and diagnostic strategies may have downstream effects on organ allocation [50].

In the conservative surveillance scenario, the most cost-effective strategy was strategy $\mathrm{G}$ (surveillance with abbreviated MRI followed by CT for inadequate surveillance or complete MRI for positive surveillance). According to deterministic sensitivity analysis, strategy G exceeded the WTP threshold depending on the sensitivity and specificity of abbreviated MRI in a surveillance setting and the cost of the abbreviated MRI. Of note, the abbreviated MRI cost is directly related to the examination duration. An abbreviated MRI protocol could reduce the current 20to 40-minute examination time to only 5-15 minutes [11-13]. According to our results, a 15-minute abbreviated MRI would not be cost-effective, whereas a 5- or 10-minute abbreviated MRI protocol had the potential to be cost-effective. Also, if the sensitivity and specificity of surveillance US were higher than the base-case estimates, strategy G may become less cost-effective than strategy $\mathrm{C}$ (US for surveillance and CT for inadequate or positive surveillance). Interestingly, the probabilistic sensitivity analysis also favored strategy G at a WTP threshold of $\$ 50,000$.

Abbreviated MRI protocols aim to offer a lower-cost alternative to complete MRI while preserving the advantages of MRI technique, such as high contrast and absence of ionizing radiation. However, to date, only retrospective simulations have assessed this emergent approach [11-13]. Further prospective or randomized studies may be required to assess the diagnostic performance of abbreviated MRI in an HCC surveillance setting before the introduction of this approach in large population-based surveillance programs.

There are limitations to our study. There is a knowledge gap in the literature concerning the costs and utilities associated with falsepositive diagnoses of HCC. The cost of follow-up for a false-positive diagnosis of HCC was based on values reported by Andersson et al. [44], whereas the disutility associated with a false-positive diagnosis was based on a cost-effectiveness study of patients undergoing evaluation for coronary artery disease [51]. Thus, our model may overestimate the cost-effectiveness of strategies that use the same imaging modality for surveillance and diagnosis (which are prone to higher rates of false-positive diagnosis). Another limitation was that abbreviated MRI sensitivity and specificity were derived from retrospective simulations. Finally, concerns regarding radiation associated with $\mathrm{CT}$ were not modeled. Although it is acceptable to perform CT for diagnostic imaging, the cumulative radiation burden associated with a surveillance program may not be justifiable.

In conclusion, in a scenario that assumes optimal patient compliance and takes into account inconclusive imaging examinations, CT for HCC surveillance and diagnosis and complete MRI for inadequate CT was most cost-effective. However, in a scenario that assumes conservative patient compliance and also takes into account inconclusive imaging examinations, abbreviated MRI may be a cost-effective alternative to the current USsurveillance practice. Before implementing a surveillance program incorporating imaging modalities other than US, future studies should address the economic burden associated with false-positive HCC diagnoses. Also, future prospective trials should assess the accuracy of abbreviated MRI examinations in a surveillance setting.

\section{References}

1. Ferenci P, Fried M, Labrecque D, et al; World Gastroenterology Organization. Hepatocellular carcinoma (HCC): a global perspective. J Clin Gastroenterol 2010; 44:239-245

2. Canadian Liver Foundation. Liver disease in Canada: a crisis in the making. Canadian Liver Foundation website. www.liver.ca/wp-content/uploads/2017/09/ CLF_LiverDiseaseInCanada_Synopsis_E.pdf. Published March 2013. Accessed August 20, 2017

3. Yuen MF, Cheng CC, Lauder IJ, Lam SK, Ooi CG, Lai CL. Early detection of hepatocellular carcinoma increases the chance of treatment: Hong Kong experience. Hepatology 2000; 31:330-335

4. Zhang BH, Yang BH, Tang ZY. Randomized controlled trial of screening for hepatocellular carcinoma. J Cancer Res Clin Oncol 2004; 130:417-422

5. Marrero JA, Kulik LM, Sirlin CB, et al. Diagnosis, staging, and management of hepatocellular carcinoma: 2018 practice guidance by the American Association for the Study of Liver Diseases. Hepatology 2018; 68:723-750

6. Sherman M, Burak K, Maroun J, et al. Multidisciplinary Canadian consensus recommendations for the management and treatment of hepatocellular carcinoma. Curr Oncol 2011; 18:228-240

7. Del Poggio P, Olmi S, Ciccarese F, et al.; Italian Liver Cancer Group. Factors that affect efficacy of ultrasound surveillance for early stage hepatocellular carcinoma in patients with cirrhosis. Clin Gastroenterol Hepatol 2014; 12:1927.e2-1933.e2

8. Uppot RN, Sahani DV, Hahn PF, Kalra MK, Saini SS, Mueller PR. Effect of obesity on image quality: fifteen-year longitudinal study for evaluation of dictated radiology reports. Radiology 2006; 240:435-439

9. Kim SY, An J, Lim YS, et al. MRI with liver-specific contrast for surveillance of patients with cirrhosis at high risk of hepatocellular carcinoma. JAMA Oncol 2017; 3:456-463

10. Sutherland T, Watts J, Ryan M, et al. Diffusionweighted MRI for hepatocellular carcinoma screening in chronic liver disease: direct comparison with ultrasound screening. J Med Imaging Radiat Oncol 2017; 61:34-39

11. Lee JY, Huo EJ, Weinstein S, et al. Evaluation of 


\section{Lima et al.}

an abbreviated screening MRI protocol for patients at risk for hepatocellular carcinoma. Abdom Radiol (NY) 2018; 43:1627-1633

12. Besa C, Lewis S, Pandharipande PV, et al. Hepatocellular carcinoma detection: diagnostic performance of a simulated abbreviated MRI protocol combining diffusion-weighted and T1-weighted imaging at the delayed phase post gadoxetic acid Abdom Radiol (NY) 2017; 42:179-190

13. Marks RM, Ryan A, Heba ER, et al. Diagnostic per-patient accuracy of an abbreviated hepatobiliary phase gadoxetic acid-enhanced MRI for hepatocellular carcinoma surveillance. AJR 2015; 204:527-535

14. Arguedas MR, Chen VK, Eloubeidi MA, Fallon MB. Screening for hepatocellular carcinoma in patients with hepatitis $\mathrm{C}$ cirrhosis: a cost-utility analysis. Am J Gastroenterol 2003; 98:679-690

15. Myers RP, Krajden M, Bilodeau M, et al. Burden of disease and cost of chronic hepatitis $\mathrm{C}$ infection in Canada. Can J Gastroenterol Hepatol 2014; 28:243-250

16. Thein HH, Isaranuwatchai W, Campitelli MA, et al. Health care costs associated with hepatocellular carcinoma: a population-based study. Hepatology 2013; 58:1375-1384

17. Canadian Agency for Drugs and Technologies in Health. Guidelines for the economic evaluation of health technologies: Canada, 4th ed. Canadian Agency for Drugs and Technologies in Health website. www.cadth.ca/about-cadth/howwe-do-it/methods-and-guidelines/guidelines-forthe-economic-evaluation-of-health-technologiescanada. Published March 2017. Accessed February 6, 2019

18. Scaglione S, Kliethermes S, Cao G, et al. The epidemiology of cirrhosis in the United States: a population-based study. J Clin Gastroenterol 2015; 49:690-696

19. Ratib S, West J, Crooks CJ, Fleming KM. Diagnosis of liver cirrhosis in England, a cohort study, 1998-2009: a comparison with cancer. Am J Gastroenterol 2014; 109:190-198

20. Zhao C, Jin M, Le RH, et al. Poor adherence to hepatocellular carcinoma surveillance: a systematic review and meta-analysis of a complex issue. Liver Int 2018; 38:503-514

21. D’Amico G, Garcia-Tsao G, Pagliaro L. Natural history and prognostic indicators of survival in cirrhosis: a systematic review of 118 studies. J Hepatol 2006; 44:217-231

22. Park JW, Chen M, Colombo M, et al. Global patterns of hepatocellular carcinoma management from diagnosis to death: the BRIDGE Study. Liver Int 2015; 35:2155-2166

23. Miller DK, Homan SM. Determining transition probabilities: confusion and suggestions. Med Decis Making 1994; 14:52-58
24. Fattovich G, Stroffolini T, Zagni I, Donato F. Hepatocellular carcinoma in cirrhosis: incidence and risk factors. Gastroenterology 2004; 127(suppl 1):S35-S50

25. Chou R, Cuevas C, Fu R, et al. Imaging techniques for the diagnosis of hepatocellular carcinoma: a systematic review and meta-analysis. Ann Intern Med 2015; 162:697-711

26. Simmons O, Fetzer DT, Yokoo T, et al. Predictors of adequate ultrasound quality for hepatocellular carcinoma surveillance in patients with cirrhosis. Aliment Pharmacol Ther 2017; 45:169-177

27. Choi YJ, Kim JH, Koo JK, et al. Prevalence of renal dysfunction in patients with cirrhosis according to ADQI-IAC working party proposal. Clin Mol Hepatol 2014; 20:185-191

28. Canadian Ministry of Health and Long Term Care. Schedule of benefits: physicians services under the Health Insurance Act. Canadian Ministry of Health and Long Term Care website. www. health.gov.on.ca/en/pro/programs/ohip/sob/physserv/ sob_master20160401.pdf. Published December 22, 2015. Accessed September 10, 2017

29. The Minister of Health, Manitoba, Canada. Manitoba physician's manual. The Minister of Health, website. www.gov.mb.ca/health/documents/physmanual. pdf. Published April 2016. Accessed September 12 2017

30. Ministry of Health and Social Services, Quebec, Canada. Régie de l'assurance maladie du Québec (RAMQ): addendum 4-radiologie diagnostique. Ministry of Health and Social Services website. www.ramq.gouv.qc.ca/SiteCollectionDocuments/ professionnels/manuels/150-facturation-specialistes/ 030_v_radio_diagnos_acte_spec.pdf. Published January 2016. Accessed September 14, 2017

31. Bank of Canada. Inflation calculator. Bank of Canada website. www.bankofcanada.ca/rates/related/ inflation-calculator. Accessed October 18, 2017

32. McLernon DJ, Dillon J, Donnan PT. Health-state utilities in liver disease: a systematic review. Med Decis Making 2008; 28:582-592

33. Cucchetti A, Trevisani F, Cescon M, et al; Italian Liver Cancer (ITA.LI.CA) Group. Cost-effectiveness of semi-annual surveillance for hepatocellular carcinoma in cirrhotic patients of the Italian Liver Cancer population. J Hepatol 2012; 56:1089-1096

34. Cucchetti A, Trevisani F, Cappelli A, et al. Cost-effectiveness of doxorubicin-eluting beads versus conventional trans-arterial chemo-embolization for hepatocellular carcinoma. Dig Liver Dis 2016; 48:798-805

35. Cammà $\mathrm{C}$, Cabibbo $\mathrm{G}$, Petta $\mathrm{S}$, et al; WEF study group; SOFIA study group. Cost-effectiveness of sorafenib treatment in field practice for patients with hepatocellular carcinoma. Hepatology 2013; 57:1046-1054

36. McKay A, Kutnikoff T, Taylor M. A cost- utility analysis of treatments for malignant liver tumours: a pilot project. HPB (Oxford) 2007; 9:42-51

37. Bennett WG, Inoue Y, Beck JR, Wong JB, Pauker SG, Davis GL. Estimates of the cost-effectiveness of a single course of interferon-alpha $2 \mathrm{~b}$ in patients with histologically mild chronic hepatitis $\mathrm{C}$. Ann Intern Med 1997; 127:855-865

38. Laupacis A, Feeny D, Detsky AS, Tugwell PX. How attractive does a new technology have to be to warrant adoption and utilization? Tentative guidelines for using clinical and economic evaluations. CMAJ 1992; 146:473-481

39. Ten Haaf K, Tammemägi MC, Bondy SJ, et al. Performance and cost-effectiveness of computed tomography lung cancer screening scenarios in a population-based setting: a microsimulation modeling analysis in Ontario, Canada. PLoS Med 2017; 14:e1002225

40. Telford JJ, Levy AR, Sambrook JC, Zou D, Enns RA. The cost-effectiveness of screening for colorectal cancer. CMAJ 2010; 182:1307-1313

41. Mittmann N, Stout NK, Lee P, et al. Total costeffectiveness of mammography screening strategies. Health Rep 2015; 26:16-25

42. Briggs AH, Claxton K, Sculpher MJ. Making decision models probabilistic. In: Briggs AH, Claxton K, Sculpher MJ, eds. Decision modelling for health economic evaluation. Oxford, UK: Oxford University Press, 2006:77-120

43. Goossens N, Singal AG, King LY, et al. Costeffectiveness of risk score-stratified hepatocellular carcinoma screening in patients with cirrhosis. Clin Transl Gastroenterol 2017; 8:e101

44. Andersson KL, Salomon JA, Goldie SJ, Chung RT. Cost effectiveness of alternative surveillance strategies for hepatocellular carcinoma in patients with cirrhosis. Clin Gastroenterol Hepatol 2008; 6:1418-1424

45. Thompson Coon J, Rogers G, Hewson P, et al. Surveillance of cirrhosis for hepatocellular carcinoma: a cost-utility analysis. $\mathrm{Br} J$ Cancer 2008; 98:1166-1175

46. Singal AG, Tiro JA, Marrero JA, et al. Mailed outreach program increases ultrasound screening of patients with cirrhosis for hepatocellular carcinoma. Gastroenterology 2017; 152:608.e4 615.e4

47. Beste LA, Ioannou GN, Yang Y, Chang MF, Ross D, Dominitz JA. Improved surveillance for hepatocellular carcinoma with a primary careoriented clinical reminder. Clin Gastroenterol Hepatol 2015; 13:172-179

48. Barratt AL. Cancer screening: benefits, harms and making an informed choice. Aust Fam Physician 2006; 35:39-42

49. Lafata JE, Simpkins J, Lamerato L, Poisson L, Divine G, Johnson CC. The economic impact of false-positive cancer screens. Cancer Epidemiol 


\section{Cost-Utility Analysis of Imaging for HCC}

Biomarkers Prev 2004; 13:2126-2132

50. Bittermann T, Goldberg DS, Bauer CM, Khungar V. Characterizing the risk of false-positive hepatocellular carcinoma in recipients transplanted with T2 MELD exceptions. Transplantation 2017; 101:1099-1105

51. Priest VL, Scuffham PA, Hachamovitch R, Marwick TH. Cost-effectiveness of coronary computed tomography and cardiac stress imaging in the emergency department: a decision analytic model comparing diagnostic strategies for chest pain in patients at low risk of acute coronary syndromes. JACC Cardiovasc Imaging 2011; 4:549-556

52. Dienstag JL, Ghany MG, Morgan TR, et al; HALT-C Trial Group. A prospective study of the rate of progression in compensated, histologically advanced chronic hepatitis C. Hepatology 2011; 54:396-405

53. Taouli B, Goh JS, Lu Y, et al. Growth rate of hepatocellular carcinoma: evaluation with serial computed tomography or magnetic resonance imaging. J Comput Assist Tomogr 2005; 29:425-429

54. Singal AG, Pillai A, Tiro J. Early detection, curative treatment, and survival rates for hepatocellular carcinoma surveillance in patients with cirrhosis: a meta-analysis. PLoS Med 2014; 11:e1001624

55. Khalaf N, Ying J, Mittal S, et al. Natural history of untreated hepatocellular carcinoma in a US cohort and the role of cancer surveillance. Clin Gastroenterol Hepatol 2017; 15:273.e1-281.e1

56. Llovet JM, Fuster J, Bruix J. Intention-to-treat analysis of surgical treatment for early hepatocellular carcinoma: resection versus transplantation. Hepatology 1999; 30:1434-1440

57. Dhir M, Lyden ER, Smith LM, Are C. Comparison of outcomes of transplantation and resection in patients with early hepatocellular car- cinoma: a meta-analysis. HPB (Oxford) 2012; 14:635-645

58. Livraghi T, Solbiati L, Meloni MF, Gazelle GS, Halpern EF, Goldberg SN. Treatment of focal liver tumors with percutaneous radio-frequency ablation: complications encountered in a multicenter study. Radiology 2003; 226:441-451

59. Mazzaferro V, Regalia E, Doci R, et al. Liver transplantation for the treatment of small hepatocellular carcinomas in patients with cirrhosis. N Engl J Med 1996; 334:693-699

60. Lencioni R, Cioni D, Crocetti L, et al. Early-stage hepatocellular carcinoma in patients with cirrhosis: long-term results of percutaneous image-guided radiofrequency ablation. Radiology 2005; 234:961-967

61. She WH, Chan ACY, Cheung TT, Lo CM, Chok KSH. Survival outcomes of liver transplantation for hepatocellular carcinoma in patients with normal, high and very high preoperative alpha-fetoprotein levels. World J Hepatol 2018; 10:308-318

62. Nakano M, Tanaka M, Kuromatsu R, et al; Kurume Liver Cancer Study Group of Japan. Sorafenib for the treatment of advanced hepatocellular carcinoma with extrahepatic metastasis: a prospective multicenter cohort study. Cancer Med 2015; 4:1836-1843

63. Wang P, Sheng L, Wang G, et al. Association of transarterial chemoembolization with survival in patients with unresectable hepatocellular carcinoma. Mol Clin Oncol 2014; 2:203-206

64. Cabibbo G, Enea M, Attanasio M, Bruix J, Craxì A, Cammà C. A meta-analysis of survival rates of untreated patients in randomized clinical trials of hepatocellular carcinoma. Hepatology 2010; 51:1274-1283

65. Wang CL, Cohan RH, Ellis JH, Adusumilli S, Dunnick NR. Frequency, management, and out- come of extravasation of nonionic iodinated contrast medium in 69,657 intravenous injections. Radiology 2007; 243:80-87

66. Federle MP, Chang PJ, Confer S, Ozgun B. Frequency and effects of extravasation of ionic and nonionic CT contrast media during rapid bolus injection. Radiology 1998; 206:637-640

67. Cohan RH, Bullard MA, Ellis JH, et al. Local reactions after injection of iodinated contrast material: detection, management, and outcome. Acad Radiol 1997; 4:711-718

68. Eshed I, Althoff CE, Hamm B, Hermann KG. Claustrophobia and premature termination of magnetic resonance imaging examinations. J Magn Reson Imaging 2007; 26:401-404

69. Sarji SA, Abdullah BJ, Kumar G, Tan AH, Narayanan P. Failed magnetic resonance imaging examinations due to claustrophobia. Australas Radiol 1998; 42:293-295

70. Forner A, Vilana R, Ayuso C, et al. Diagnosis of hepatic nodules $20 \mathrm{~mm}$ or smaller in cirrhosis: Prospective validation of the noninvasive diagnostic criteria for hepatocellular carcinoma. Hepatology 2008; 47:97-104

71. Fateen W, Khan F, O'Neill RJ, James MW, Ryder SD, Aithal GP. Healthcare costs of transarterial chemoembolization in the treatment of hepatocellular carcinoma. J Hepatocell Carcinoma 2017; 4:123-130

72. Muszbek N, Shah S, Carroll S, et al. Economic evaluation of sorafenib in the treatment of hepatocellular carcinoma in Canada. Curr Med Res Opin 2008; 24:3559-3569

73. El Saadany S, Coyle D, Giulivi A, Afzal M. Economic burden of hepatitis $\mathrm{C}$ in Canada and the potential impact of prevention. Results from a disease model. Eur J Health Econ 2005; 6:159-165

\section{FOR YOUR INFORMATION}

A data supplement for this article can be viewed in the online version of the article at: www.ajronline.org. 